\title{
Quality of life and criminal recidivism in forensic outpatients with personality disorders : a good lives approach.
}

Citation for published version (APA):

Bouman, Y. H. A. (2009). Quality of life and criminal recidivism in forensic outpatients with personality disorders : a good lives approach. [Doctoral Thesis, Maastricht University]. Gildeprint Drukkerijen. https://doi.org/10.26481/dis.20091210yb

Document status and date:

Published: 01/01/2009

DOI:

10.26481/dis.20091210yb

Document Version:

Publisher's PDF, also known as Version of record

\section{Please check the document version of this publication:}

- A submitted manuscript is the version of the article upon submission and before peer-review. There can be important differences between the submitted version and the official published version of record. People interested in the research are advised to contact the author for the final version of the publication, or visit the DOI to the publisher's website.

- The final author version and the galley proof are versions of the publication after peer review.

- The final published version features the final layout of the paper including the volume, issue and page numbers.

Link to publication

\footnotetext{
General rights rights.

- You may freely distribute the URL identifying the publication in the public portal. please follow below link for the End User Agreement:

www.umlib.nl/taverne-license

Take down policy

If you believe that this document breaches copyright please contact us at:

repository@maastrichtuniversity.nl

providing details and we will investigate your claim.
}

Copyright and moral rights for the publications made accessible in the public portal are retained by the authors and/or other copyright owners and it is a condition of accessing publications that users recognise and abide by the legal requirements associated with these

- Users may download and print one copy of any publication from the public portal for the purpose of private study or research.

- You may not further distribute the material or use it for any profit-making activity or commercial gain

If the publication is distributed under the terms of Article 25fa of the Dutch Copyright Act, indicated by the "Taverne" license above, 


\section{Quality of life and criminal recidivism in}

forensic outpatients with personality disorders

A Good Lives approach 
The publication of this thesis has been made possible with the financial support of Maastricht University and the Pompestichting. This research has been made possible by the support of the Pompestichting, Forensic Psychiatric Institution, Nijmegen, The Netherlands.

ISBN/EAN 9789490122782

Cover and illustrations by Martien Philipse

Printed by Gildeprint Drukkerijen - www.gildeprint.nl

(C) 2009, Yvonne H.A. Bouman, The Netherlands

All rights reserved. Save exceptions stated by law, no part of this publication may be reproduced, stored in a retrieval system, or transmitted in any form or by any means, electronic, mechanical, photocopy, recording or otherwise, without prior permission from the holder of the copyright. 


\section{QUALITY OF LIFE AND CRIMINAL RECIDIVISM IN FORENSIC OUTPATIENTS}

\section{WITH PERSONALITY DISORDERS}

A Good Lives approach

KWALITEIT VAN LEVEN EN CRIMINELE RECIDIVE BIJ AMBULANTE FORENSISCHE PATIËNTEN MET EEN PERSOONLIJKHEIDSSTOORNIS

Een Good Lives benadering

\section{PROEFSCHRIFT}

ter verkrijging van de graad van doctor

aan de Universiteit Maastricht,

op gezag van de Rector Magnificus,

Prof. mr. G.P.M.F. Mols

volgens het besluit van het College van Decanen,

in het openbaar te verdedigen

op donderdag 10 december 2009 om 14.00 uur

door

Yvonne Helena Alexandra Bouman

geboren 15 februari 1964, te Eindhoven 


\section{Promotores:}

Prof. dr. C. de Ruiter

Prof. dr. A.H. Schene MD, Universiteit van Amsterdam

\section{Beoordelingscommissie:}

Prof. dr. H.L.G.J. Merckelbach, voorzitter

Dr. D.P. Bernstein

Prof. dr. J.J.D.M. van Lankveld

Prof. dr. Ch. van Nieuwenhuizen, Universiteit van Tilburg

Prof. dr. H.L.I. Nijman, Radboud Universiteit Nijmegen 


\section{Contents}

CONTENTS 1

LIST OF PUBLICATIONS 2

CHAPTER 1. GENERAL INTRODUCTION 3

CHAPTER 2. QUALITY OF LIFE OF MALE OUTPATIENTS WITH PERSONALITY DISORDERS OR PSYCHOTIC DISORDERS 23

CHAPTER 3. QUALITY OF LIFE OF VIOLENT AND SEXUAL OFFENDERS 37

CHAPTER 4. RECENT LIFE EVENTS AND SUBJECTIVE WELL-BEING 57

CHAPTER 5. CHANGES IN QUALITY OF LIFE AFTER SIX MONTHS 73

CHAPTER 6. SOCIAL TIES AND SHORT-TERM SELF-REPORTED DELINQUENT

BEHAVIOUR 91

CHAPTER 7. SUBJECTIVE WELL-BEING AND RECIDIVISM 111

CHAPTER 8. GENERAL CONCLUSIONS AND DISCUSSION 131

$\begin{array}{lr}\text { SUMMARY } & 149\end{array}$

NEDERLANDSE SAMENVATTING 154

$\begin{array}{ll}\text { REFERENCES } & 160\end{array}$

$\begin{array}{ll}\text { LIST OF ABBREVIATIONS } & 178\end{array}$

$\begin{array}{ll}\text { DANKWOORD } & 180\end{array}$

CURriculum Vitae 182

$\begin{array}{lc}\text { PREVIOUS PUBLICATIONS } & 183\end{array}$ 


\section{List of publications}

This thesis is based on the following papers:

Bouman, Y.H.A., Nieuwenhuizen, Ch. van, Schene, A.H., \& Ruiter, C. de (2008). Quality of life of male outpatients with severe personality disorders or psychotic disorders: A comparison. Criminal Behaviour and Mental Health, 18, 279-291, doi: 10.1002/cbm.703.

Bouman, Y.H.A., Ruiter, C. de, \& Schene, A.H. (2008). Quality of life of violent and sexual offenders in community-based forensic psychiatric treatment. The Journal of Forensic Psychiatry \& Psychology, 19, 484-501, doi: 10.1080/14789940701877669.

Bouman, Y.H.A., Ruiter, C. de, \& Schene, A.H. (in press). Recent life events and subjective well-being of personality disordered forensic outpatients. International Journal of Law and Psychiatry, doi: 10.1016/j.ijlp.2009.09.003.

Bouman, Y.H.A., Ruiter, C. de, \& Schene, A.H. (2009). Changes in quality of life after six months in forensic psychiatric outpatients. Under review.

Bouman, Y.H.A., Ruiter, C. de, \& Schene, A.H. (in press). Social ties and short-term selfreported delinquent behaviour of forensic personality disordered outpatients. Legal and Criminological Psychology, published online 16 May 2009, URL:http://bpsoc.publisher.ingenta-connect.com/content/bpsoc/lcp/pre-prints/lcp269, doi: 10.1348/13-5532509X444528.

Bouman, Y.H.A., Schene, A.H., \& Ruiter, C. de (2008). Subjective well-being and recidivism in forensic psychiatric outpatients: Preliminary evidence for a good lives model. Under review. 


\section{Chapter 1}

\section{General introduction}

In a modified form, parts of this chapter have been used in: Bouman, Y.H.A., \& Bulten, B.H. (2009). De protectieve werking van kwaliteit van leven: Een 'good lives' benadering. [The protective function of quality of life: A 'good lives' approach]. In T.I.Oei \& M.S. Groenhuijsen (eds.), De forensische psychiatrie en haar grensgebieden - actualiteit, geschiedenis en toekomst [Forensic psychiatry and its boundaries current, history and future]. Deventer, The Netherlands: Kluwer. 
CHAPTER 1 
Quality of life is an increasingly important concept in forensic psychiatry, for two reasons. Firstly, people in general strive for the good life: as high a quality of life as possible (Diener \& Suh, 1997; King, 2001; Oliver, Huxley, Bridges, \& Mohamad, 1996) and this also applies to forensic psychiatric patients. The majority of these patients, including those in communitybased forensic treatment, suffer from mental disorders, including personality disorders (PDs; de Ruiter \& Trestman, 2007). By definition, PDs disrupt their daily lives. Most of the PD diagnostic criteria as listed in the Diagnostic and Statistical Manual of Mental Disorders (DSM-IVTR; American Psychiatric Association [APA], 2000) are related to the way people behave in human interactions. Patients with a PD tend to show poor social and work-related adjustment. Because quality of life is defined as a sense of well-being and satisfaction experienced by individuals under their current life conditions (Lehman, 1983), the poor adjustment directly influences patients' quality of life, since many social indicators of quality of life are related to societal participation.

Secondly, patients in forensic psychiatry are treated with the aim to reduce the risk of reoffending. Risk assessment and risk management are therefore at the core of forensic treatment (de Ruiter \& Hildebrand, 2007). Risk assessment is the estimation of the chance that a person will commit a crime or display criminal behaviour within a certain timeframe and in a certain context (Webster, Douglas, Eaves, \& Hart, 1997). Risk management are the strategies monitoring, treatment, supervision and victim safety planning - devised on the basis of the risk assessment and aimed at the reduction of the violence potential (Douglas, Webster, Hart, Eaves, \& Ogloff, 2001). Several aspects of daily living have been related, empirically and/or theoretically, to criminal desistance (e.g. Gendreau, Goggin, \& Gray, 2000; Monahan et al., 2001; Sampson \& Laub, 1990). However, only a limited number of these aspects, which are also objective indicators of quality of life (e.g. financial debts and previous hospitalisations), are explicitly included in currently well-established risk assessment tools (de Ruiter \& Hildebrand, 2007), such as the Historical/Clinical/Risk-20 (HCR-20; Webster et al., 1997). Patients' subjective assessment of their quality of life $(\mathrm{QoL})$ is generally neglected in these tools (except in the Structured Outcome Assessment and Community Risk Monitoring; SORM; Grann et al., 2001).

From both a patient perspective and a risk perspective, improvement of quality of life is therefore a legitimate target in forensic psychiatric treatment and therefore an important object of study in research with forensic psychiatric patients. In the current dissertation, these two 


\section{CHAPTER 1}

perspectives on quality of life in forensic psychiatric patients will be investigated. Since risk assessment and risk management are primarily guiding forensic treatment, we pay attention to these issues first in this introduction. Subsequently, we will focus on quality of life in general and of (forensic) psychiatric patients and the hypothesized relationship between QoL and (desistance from) criminal recidivism.

\section{RISK ASSESSMENT AND RISK MANAGEMENT IN FORENSIC PSYCHIATRY}

Structured risk assessment instruments are generally used in treatment of in- and outpatients in forensic psychiatry in The Netherlands (e.g. Hildebrand, Hesper, Spreen, \& Nijman, 2005; Philipse, 2006; de Ruiter \& Hildebrand, 2007; de Vogel, de Ruiter, \& Bouman, 2007). Most forensic patients pose a high risk of violent or sexual recidivism at the start of their treatment, due to their criminal and/or psychiatric background. Risk management offers clinicians a method to monitor and improve the status of a patient in order to diminish this risk.

Risk factors are divided into static and dynamic ones. A number of the factors which are associated with a higher risk of recidivism are static (or historical) in nature, such as number of previous convictions or a young age at first offence: they "change little and slowly, if at all, over time" (Douglas et al., 2001, p. 27). Dynamic factors are "causes of future violence that can change over time, especially in response to interventions" (Douglas et al., 2001, p. 27) and so these are essential in formulating risk management plans. Dynamic factors are further subdivided into acute and stable factors (see Hanson \& Harris, 2000). Acute factors, for instance negative mood and anger (Hanson \& Harris, 2000), are related to (re-)offending and can change rapidly over time. Stable factors, for instance self-management skills and substance use (Thornton, 2002), change more slowly and/or are considered as more difficult to change.

Risk factors are positively related to recidivism in empirical research (see e.g. Bonta, Law, \& Hanson, 1998; Hanson \& Bussière, 1998; Hanson \& Morton-Bourgon, 2005; Monahan et al., 2001). However, a comprehensive theoretical model to understand or explain relapse into criminal behaviour is hardly ever used in this type of research. Previously, Bonta (1997) has termed this kind of a-theoretical identification of risk factors 'dustbowl empiricism'. A comprehensive risk assessment and management model, which is based on theoretical principles, is the Risk-Need-Responsivity model (RNR; Andrews \& Bonta, 1998; Andrews, Bonta, \& Wormith, 2006; Bonta \& Andrews, 2007). In this RNR model, the risk principle 
"asserts that criminal behaviour can be reliably predicted and that treatment should focus on the higher risk offenders; [...] the need principle highlights the importance of criminogenic needs in the design and delivery of treatment; and $[\ldots]$ the responsivity principle describes how treatment should be provided" (Bonta \& Andrews, 2007, p. i).

In an elaboration on the RNR model, Ward, Melser and Yates (2007) stated that a reduction of dynamic risk is "a necessary but not sufficient condition for effective treatment" (p. 210), and that, in conjunction with risk reduction, the promotion of human goods, which "are experiences and activities that are likely to result in enhanced levels of well-being" (Ward, Mann, \& Gannon, 2007, p. 90), should be taken into account when formulating treatment plans. In line with this critique, Ward and colleagues (Ward, 2002; Ward \& Brown, 2004; Ward, Mann, \& Gannon, 2007) developed a treatment model - the Good Lives Model - which is a strength based approach and offers forensic clinicians guidelines to target human goods (valued aspects of human functioning and living; Ward \& Brown, 2004, p. 246). They proposed "that the best way to lower offending recidivism rates is to equip individuals with the tools to live more fulfilling lives rather then [sic, YB] to simply develop increasingly sophisticated risk management measures and strategies" (Ward \& Brown, 2004, p. 244).

A comprehensive model of risk assessment in forensic psychiatric patients should therefore include static, historical risk factors, which help to establish the base rate of risk for future criminal behaviour; dynamic risk factors in order to diminish risk; and strength based protective factors (Douglas et al., 2001; Farrington \& Loeber, 2000; Miller, 2006; Rogers, 2000) to decrease the risk of re-offending and to enhance engagement in treatment through increased emphasis on positive aspects of the patient's life.

\section{Protective factors}

So far, protective factors have been relatively neglected in risk assessment research (Rogers, 2000) or in risk assessment tools, with four exceptions: the Inventory of Offender Risk, Needs, and Strengths (IORNS; Miller, 2006), the Short Term Assessment of Risk and Treatability (START; Webster, Martin, Brink, Nicholls, \& Middleton, 2004), the Structured Assessment of PROtective Factors for violence risk (SAPROF; de Vogel, de Ruiter, Bouman, \& de Vries Robbé, 2007, 2009), and the Level of Service/Case Management Inventory (LS/CMI; Andrews, Bonta, \& Wormith, 2004). In the SAPROF, protective factors are defined as "Any characteristic of a person, his/her environment or situation which reduces the risk of future violent behavior" 


\section{CHAPTER 1}

(original italics; de Vogel et al., 2009, p. 25). Protective factors have been operationalised as the reverse of risk factors (Costa, Jessor, \& Turbin, 1999; Hawkins, Catalano, \& Miller, 1992; Webster et al., 2004), but they could also function (independently) either as mediator or as buffer for offending behaviour (Fitzpatrick, 1997). Objective and subjective indicators of quality of life may constitute a group of factors which could act as buffer or mediator for criminal recidivism.

\section{QUALITY OF LIFE}

The contemporary concept of QoL used in general psychiatry originates from two different sources. One started in the mid 1960s when the American president Lyndon B. Johnson declared that happiness "cannot be measured by the size of our bank balances. They can only be measured in the quality of the lives that our people lead." (cited in McCall, 1975, p. 246). By this, he shifted attention from a mere economic view to a more holistic view on people's quality of life and well-being. Societal progress was measured using the level of social wellbeing, which in turn was expressed through social indicators on a wider set of domains. Furthermore, the recognition grew that objective progress would not automatically lead to an increase of happiness or psychological well-being. From this time onwards, subjective indicators were included in the study of life's quality.

The second source is the definition of one of the indicators of well-being - health - as incorporated in the constitution of the World Health Organization (WHO): "a state of complete physical, mental and social well-being and not merely the absence of disease or infirmity" (see WHO, 2005, p. 1). With the inclusion of "handicap" in the International Classification of Impairment, Disability, and Handicap (ICIDH; WHO, 1980), the subjective experience of the person resulting from his / her impairment and / or disability was included in the assessment of a patient's health status. More recently, the ICIDH was transformed into the International Classification of Functioning, Disability and Health (ICF, WHO, 2002), which proposes an even more positive approach by focussing on health and on what people can (still) do instead of focussing on their limitations. In line with the definition of health, QoL has often been used as a subjective indicator of health status and as a subjective evaluation of the patient's psychological well-being and of his / her social and material world (Orley, Saxena, \& Herrman, 1998). 
In the emerging 'Good Lives Model' in forensic psychiatric treatment (Ward, 2002), creating fulfilling or good lives is considered important to assist offenders in refraining from further criminal behaviour. Striving for the good life is also regarded as the most important goal in life in theoretical models of QoL (e.g. Diener \& Suh, 1997; King, 2001; Oliver et al., 1996). Global QoL is related to personal characteristics, objective circumstances in various domains and subjective satisfaction with these life domains (Lehman, 1983). Following this description, the division of indicators of QoL into economic, social and subjective indicators is generally accepted (Diener \& Suh, 1997; Farquhar, 1995; Glatzer \& Mohr, 1987; Goodinson \& Singleton, 1989; McCall, 1975).

Subjective well-being, measured using subjective indicators of quality of life, refers to the individual's cognitive and affective judgement of his entire life-situation, as well as of specific life domains. Social indicators, including economic indicators, reflect a person's objective circumstances in a given cultural or geographic environment (Diener \& Suh, 1997). Examples are: employment, financial situation, social contacts or intimate relationship.

\section{Dimensions of quality of life in psychiatric patients}

The concept of QoL encompasses a holistic approach to well-being and therefore also applies to patients suffering from mental disorders. However, a global definition of QoL is not very useful for treatment evaluation and so disease-specific QoL measures ${ }^{1}$ have been developed in order to meet criteria for sensitivity to change: the ability to measure (slight) changes in the patient's condition related to the treatment and disease at hand. Mental disorders, including PDs, influence many aspects of a patient's life. The diagnostic criteria of PDs used in the DSM-IV-TR (APA, 2000) require that the illness has a limiting effect on several life domains, such as work and social relationships.

Most authors agree on the fact that a broad set of life domains should be used when studying QoL in psychiatric patients (Lehman, 1983; Oliver et al., 1996; WHOQOL Group, 1998). Most of the commonly used measures of QoL in psychiatry fulfil this criterion (see e.g. Atkinson \& Zibin, 1996; Bowling, 1995, 1997), which was confirmed by concept mapping

1 For many diseases, such a measure has been developed during the last few decades. On an internet-site that aims at listing every available patient-related outcome (PRO) or QoL instrument, a total of 641 instruments are mentioned (November 2008), of which 99 are deemed to be generic (useful for every kind of population), and 114 instruments are listed as useful in psychiatry or psychology (see http://www.proqolid.org/proqolid). 
explorations of the concept (Bech, Dunbar, \& Stoker, 1993; Boevink, Wolf, van Nieuwenhuizen, \& Schene, 1995; Lehman, 1983; WHOQOL Group, 1995). However, there is no consensus on which domains should be included, due to cultural differences (Oliver et al., 1996).

In the development of a Dutch instrument for the assessment of QoL in psychiatric patients, an initial exploration of available QoL measures (van Nieuwenhuizen, Schene, Boevink, \& Wolf, 1997) was combined with the concept-mapping procedure on QoL among chronic psychiatric patients in The Netherlands (Boevink et al., 1995). Based on both procedures, Van Nieuwenhuizen (1998) identified 10 subjective indicators of QoL which were divided into two dimensions. The internal dimension relates to personal autonomy ${ }^{2}$ and to selfefficacy $^{3}$, comprising positive and negative self-esteem, life fulfilment and framework. The external dimension consists of the subjective life domain-specific ratings on six life domains: housing, finances, safety, health, leisure time and social relationships, and family (van Nieuwenhuizen, Schene, Koeter, \& Huxley, 2001). Based on these findings, the Lancashire Quality of Life Profile (LQoLP; Oliver et al., 1996), which was developed to measure QoL in chronic psychiatric patients in the United Kingdom, was translated, adapted and extended for the Dutch culture by Van Nieuwenhuizen, Schene and Koeter (1998). Previously, the LQoLP (Oliver et al., 1996) or its predecessor: the Lehman Quality of Life Interview (QOLI; Lehman, 1988) have been used in several studies on quality of life in forensic psychiatric in- and outpatients settings (Draine \& Solomon, 1992, 1994, 2000; Gerber et al., 2003; Long, McLean, Boothby, \& Hollin, 2008; Swanson et al., 1998; Swinton, Carlisle, \& Oliver, 2001; Swinton, Oliver, \& Carlisle, 1999; Walker \& Gudjonsson, 2000).

\section{Objective and subjective quality of life}

The influence of objective life circumstances (or social indicators) on global subjective QoL has been a topic of debate (Goodinson \& Singleton, 1989; Lehman, 1983; Orley et al., 1998; Simmons, 1994). Several authors state that social indicators hardly influence global subjective

2 ""Personal autonomy" refers to a capacity for self-governance, specifically, self-governance with regard to the choice of and commitment to personal projects, relationships, and ideals." (original italics; Anderson, 2008, p. 8).

3 Perceived self-efficacy is defined as people's beliefs about their capabilities to produce designated levels of performance that exercise influence over events that affect their lives. Self-efficacy beliefs determine how people feel, think, motivate themselves and behave. Such beliefs produce these diverse effects through four major processes. They include cognitive, motivational, affective and selection processes (Bandura, 1994). 
QoL (see Bowling, 1991; Lehman, 1983), while others report that the previously found low correlations might be an artefact of the heterogeneity of the populations studied (Oliver et al., 1996; van Nieuwenhuizen, 1998). According to Fakhoury and Priebe (2002), there is currently a consensus that QoL in psychiatry should encompass both objective and subjective indicators, because of the weak correlations between objective indicators and subjective QoL (e.g. Diener \& Suh, 1997; Glatzer \& Mohr, 1987). Several models of global QoL also include both objective and subjective indicators (Holloway, 1995; Lehman, 1983; Masthoff et al., 2007; Ruggeri, Warner, Bisoffi, \& Fontecedro, 2001), supporting the view that QoL is a multidimensional concept including both objective and subjective indicators. Several other characteristics have been established as influential in the overall subjective QoL of psychiatric patients.

\section{Patient characteristics and quality of life}

In research on (change in) QoL in psychiatric patients, several demographic factors and psychiatric characteristics have been related to levels of global subjective QoL. Findings with regard to demographic characteristics are contradictory. Regarding gender, Slade and colleagues (2004) and Van Nieuwenhuizen (1998) found that female patients tended to report lower subjective QoL than male patients, while Cramer, Torgersen and Kringlen (2006, 2007) concluded that women reported higher QoL when controlling for other relevant variables, such as any PD, living with a partner or physical health, which was confirmed in a metaanalysis among psychiatric outpatients (Vatne \& Bjørkly, 2008). Male and female psychiatric patients seem to differ on their QoL, but in what way is inconclusive.

With regard to age, Cramer et al. (2007) did not find a correlation with QoL; Trompenaars, Masthoff, Van Heck, Hodiamont and De Vries (2005) found a negative relationship between age and domains of the WHO Quality of Life-abbreviated version (WHOQOL-bref) in psychiatric outpatients; and Van Nieuwenhuizen (1998) reported that younger psychiatric patients tended to be more dissatisfied than older patients. Hence, none of these studies support each other's results. Most other (socio)demographic characteristics which are related to QoL, such as employment and cohabitation (see e.g. Vatne \& Bjørkly, 2008), have been included in the concept of QoL as objective indicators.

Several mental illness characteristics have been linked to a lower QoL. Firstly, the level of psychopathology has been shown to influence QoL. Ruggeri et al. (2005) found that a higher level of psychopathology, as measured with the Brief Psychiatric Rating Scale (BPRS), 


\section{CHAPTER 1}

predicted a lower satisfaction with health, legal situation and general well-being. Self-reported psychiatric symptoms have also been found to explain a significant degree of variance in overall QoL (Hansson \& Björkman, 2007; Swanson, Swartz, Elbogen, Wagner, \& Burns, 2003), as has severity of psychopathology (Fakhoury \& Priebe, 2002).

Secondly, personality disorder (PD) diagnoses have been related to QoL. Psychiatric patients and persons from the general population with a PD reported lower QoL than persons from the general population without a PD (Cramer et al., 2006; Narud, Mykletun, \& Dahl, 2005). Findings on global QoL in PD patients compared to patients with an Axis I disorder contradict each other. Trompenaars, Masthoff, Van Heck, Hodiamont and De Vries (2006) found no differences whereas Lehman (1999) and Swinton et al. (1999) reported that PD patients had a lower global QoL than patients with an Axis I disorder; differences on domainspecific ratings indicate that PD patients are less satisfied on several specific domains (Lehman, 1999; Masthoff, Trompenaars, van Heck, Hodiamont, \& de Vries, 2006; Swinton et al. 1999). Co-morbidity of an Axis I disorder in PD patients has been related to a lower QoL in psychiatric outpatients (Draine \& Solomon, 2000; Masthoff et al., 2006).

Studies into different (clusters of) PDs also report equivocal outcomes. Outpatients with a cluster B (dramatic, emotional or erratic) PD (Chen et al., 2006) and, more specifically, persons with antisocial PD characteristics (Sareen, Stein, Cox, \& Hassard, 2004) demonstrated a lower QoL than persons without such traits or with a cluster A (odd or eccentric) or cluster C (anxious or fearful) PD. However, Saloppé and Pham (2007) reported that forensic psychiatric inpatients with a cluster B PD were more satisfied than patients without these disorders.

Finally, negative affect, which can be regarded as the equivalent of negative mood (van Nieuwenhuizen et al., 1997), was associated with a lower QoL in psychiatric patients (Fakhoury \& Priebe, 2002; Oliver et al., 1996; Skevington \& Wright, 2001). Anxiety and depression were identified as explaining a part of the variance in global QoL (range $=6 \%-30 \%$; Vatne \& Bjørkly, 2008) and as negatively related to all subjective life domains for schizophrenic outpatients (Draine \& Solomon, 2000).

To summarize, neither gender nor age are systematically related to QoL. General level of psychopathology, Axis I disorders (DSM-IV-TR), and negative affect (including anxiety and depression) are all negatively related to subjective QoL. However, the relationship between (different types of) Axis II disorders and QoL is less clear. 


\section{Change in quality of life in psychiatric patients}

If improvement or stabilisation of QoL becomes an objective of forensic treatment, the question is raised to what extend QoL can change. Are both objective and subjective indicators equally changeable, and, if specific indicators of QoL change, does overall subjective QoL also change? The LQoLP has been previously used to measure change in QoL during communitybased psychiatric treatment in several studies. In all studies, this was within a general psychiatric sample consisting mainly of patients suffering from schizophrenia or other psychotic disorders (Hansson \& Björkman, 2007; Oliver et al., 1996; Ruggeri et al., 2005). These researchers showed that most objective indicators of QoL remain stable over time, only work-related indicators and mental health indicators improved progressively (Ruggeri et al., 2005; Oliver et al., 1996). However, most domain-specific subjective indicators of QoL improved during treatment (Hansson \& Björkman, 2007; Ruggeri et al., 2005), although Oliver et al. (1996) found that only satisfaction with leisure had increased at one year follow up. Overall subjective QoL increased after community-based psychiatric treatment, regardless of follow-up time (range: 21 months - 6 years; Hansson \& Björkman, 2007; Oliver et al., 1996; Ruggeri et al., 2005).

Several studies have examined the development of QoL of general psychiatric (out)patients with PD (Karterud et al., 2003; Chen et al., 2006), but used different assessment methods. Only Karterud and colleagues used a baseline and follow-up measurement of QoL, using only a single item to assess QoL. They found that QoL improved between admission and discharge for PD patients who completed treatment. Also patients with dual diagnoses of substance use disorder, other Axis I disorders, or an additional PD reported improvement of self-esteem and satisfaction with finances at 18 months follow-up (Judd, Thomas, Schwartz, Outcalt, \& Hough, 2003). However, cluster B PD symptoms impacted (change in) global QoL negatively in elderly patients with depression in remission (Abrams, Alexopoulos, Spielman, Klausner, \& Kakuma, 2001).

Change in objective indicators of QoL is naturally more difficult to establish through treatment. These indicators tend to be stable, generally. Changing these indicators touches on the principal problems of PD patients, which is their inability to engage in and maintain stable social relationships, work or organised leisure activities. In general, the subjective quality of life of psychiatric patients seems to improve during or after treatment, but for patients with personality disorders findings are equivocal. 


\section{QUALITY OF LIFE IN FORENSIC PSYCHIATRY}

The emergence of long-term high security facilities for forensic psychiatric patients led Mason (1999) to state that the primary objective of these types of psychiatric institutes is to deliver a service which could result in as high a quality of life for these patients as possible. However, he noted that this is a sheer impossible task, due to the very nature of this type of care. For forensic inpatients, the usefulness of the LQoLP or any other existing instrument measuring QoL in psychiatric patients has been questioned (Coid, 1993; Swinton et al., 1999; van Nieuwenhuizen, Schene, \& Koeter, 2002). Coid (1993) argued that in order to deliver quality of care for detained patients, a normative standard of quality of life for these patients needs to be established. In his view, dealing with detained patients justifies a separate approach to QoL and the development of a setting-specific, as opposed to a disease-specific, quality of life measure. Swinton and colleagues (1999) argued that for detained patients different life domains, such as autonomy, could be more important than for non-detained persons. Van Nieuwenhuizen et al. (2002) stated that, although they are unsuitable for forensic inpatients, existing instruments could be useful in studying QoL in forensic outpatients.

Despite these limitations, several studies on QoL have been conducted in inpatient forensic psychiatric settings (Long et al., 2008; Saloppé \& Pham, 2007; Swinton et al., 2001; Swinton et al., 1999; Walker \& Gudjonsson, 2000). Different groups were compared: either patients with high subjective QoL to patients with low subjective QoL, in general and on each of the life domains; patients with PD to patients without PD; patients with schizophrenia to patients with PDs; patients from a setting in the United Kingdom to patients from a Dutch setting; forensic inpatients to general psychiatric outpatients. They all agree that for a clinical forensic population a different concept of QoL is needed, due to the secure setting these patients reside in and the bearing this has on QoL for these patients.

Very few studies have been published on the subject of QoL in forensic outpatients. In an evaluation of a community-based forensic psychiatric treatment program performed in 1988 by Wilson, Tien and Eaves (1995), improvement in QoL was explored. Since this study, five new studies have appeared in the literature. Four of these involved outpatients under mandatory treatment (Chung, Cumella, Wensley, \& Easthope, 1998; Gerber et al., 2003; Swanson et al., 2003; Williams, 2003), and one study compared patients with and without a criminal history (Draine \& Solomon, 1992; for a more detailed description of four of these 
studies, see Chapter 3). With regard to overall QoL, forensic outpatients scored higher after 12 month follow-up if the duration of mandatory treatment had been longer (Swanson et al., 2003). Comparatively, forensic outpatients were more satisfied with their global QoL than general psychiatric outpatients (Gerber et al., 2003). Sex offenders participating in sex offender treatment in a community correctional setting or "halfway house" were neither satisfied nor dissatisfied with their total QoL (Williams, 2003).

On domain-specific subjective well-being, the results of the different studies were inconsistent. For instance, Draine and Solomon (1992) found that patients with a prior arrest history were more dissatisfied with feelings of personal safety than patients without such a history, whereas Gerber et al. (2003) reported that forensic outpatients were more satisfied on the legal and safety domain compared with general psychiatric outpatients. With regard to the objective indicators of QoL, a similar picture emerged. Gerber and colleagues (2003) did not find a difference between forensic and general psychiatric outpatients; Draine and Solomon (1992) and Chung et al. (1998), on the other hand, concluded that forensic patients were in a less favourable situation than general psychiatric patients without a criminal background or than a general population urban sample.

In summary, quality of life has been scarcely studied in forensic psychiatric patients. The conceptualisation of QoL in clinical forensic settings warrants attention, due to the difference between detained and non-detained patients with regard to QoL. This makes comparisons between forensic inpatients and outpatients problematic. Studies on QoL in forensic populations have only involved men, and patients were hardly ever divided into subgroups according to psychiatric disorder, except in studies among inpatients. Previous research has shown that forensic outpatients seem satisfied with their life in general, their satisfaction on specific domains varies between the domains, and their objective life circumstances tend to be less favourable than the circumstances of psychiatric outpatients without a criminal background.

\section{QUALITY OF LIFE IN RELATION TO REDUCTION OF RECIDIVISM RISK}

An improved QoL might contribute to the primary target in community-based forensic psychiatric treatment: reduction of the risk of criminal offending. The empirical relationship between objective indicators of quality of life, such as work, church attendance, financial 
status, and criminal behaviour and recidivism has been demonstrated in several empirical studies and meta-analyses (Ellis \& Peterson, 1996; Gendreau et al., 2000; Monahan et al., 2001; Pettersson, 1991; Sampson \& Laub, 1990). There are indications from research in juvenile offenders that structured leisure activities with others can prevent re-offending (DuRant, Knight, \& Goodman, 1997; Hoge, Andrews, \& Leschied, 1996; Reddon, Pope, Friel, \& Sinha, 1996). Furthermore, previous research has provided evidence for a protective role of social relationships (e.g. having a spouse, a stable and pro-social intimate and extended social network) in criminal behaviour both within a general criminal population and a population of psychiatric patients (Estroff \& Zimmer, 1994; Goggin, Gendreau, \& Gray, 1998; Hilterman, 2000; Klassen \& O'Connor, 1989; Miller, 2006; Oddone-Paolucci, Violato, \& Schofield, 2000; Sampson \& Laub, 2005; Wright \& Wright, 1992).

On the other hand, the relationship between subjective QoL and criminal recidivism has rarely been explored. One study focussed on the relationship between subjective quality of life as measured with Lehman's Quality of Life Interview (Lehman, 1988) and return to jail, due to violation of probation or parole conditions (Draine \& Solomon, 1994). The sample consisted predominantly of male patients with schizophrenia (84.6\%). Patients who had to return to jail within six months (27.7\%) were less satisfied with their living circumstances and with their lives in general than those who did not violate parole conditions.

Hence, the protective function of several objective indicators of QoL has been established in a number of studies, whereas evidence for a relationship between subjective indicators of QoL and desistance from re-offending is lacking. Such a relationship can, however, be hypothesized based on several existing criminological theories.

\section{Towards a theoretical model on the relationship between quality of life and recidivism}

Several criminological theories suggest mechanisms for criminal desistance. In the present thesis, General Strain Theory of Agnew (1992) and Social Control Theory of Sampson and Laub $(1990,2005)$ were chosen as the basis for a model on the relationship between QoL and desistance (see Figure 1.1). A third theory, which is used in this thesis, is the Good Lives Model of offender rehabilitation as it has been developed by Ward and colleagues (see e.g. Ward, 2002; Ward, Mann, \& Gannon, 2007). All theories incorporate elements of quality of life and relate these elements to (desistance from) criminal behaviour. 
Figure 1.1. Theoretical model based on Social Control Theory (Sampson \& Laub, 2005), General Strain Theory (Agnew, 1992) and the Good Lives Model (Ward, 2002).

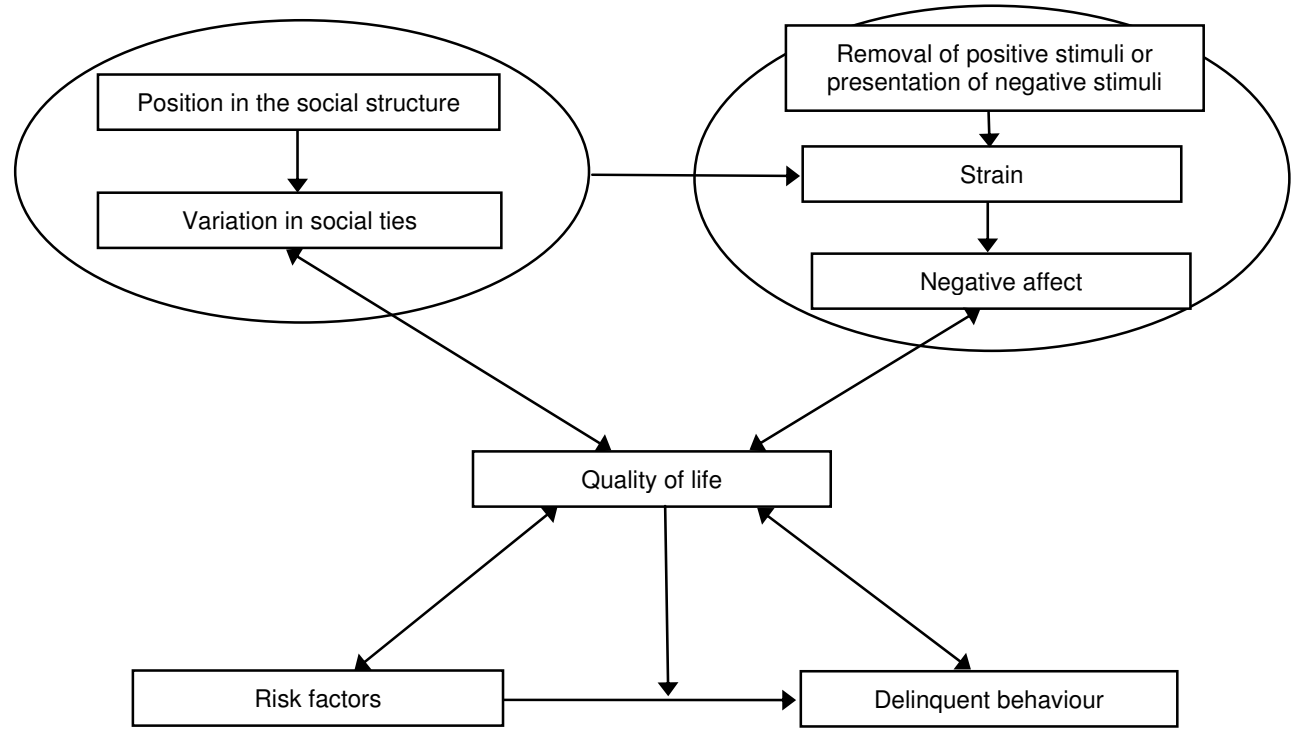

\section{General Strain Theory}

Agnew (1992) identifies three sources of strain: (1) failure to achieve positively valued goals; (2) removal of positively valued stimuli (actual or anticipated); and (3) presentation of negative stimuli. The latter two sources of strain are considered the most important in relation to delinquent behaviour, although the distinction between the two is small. Strain leads to negative affect, such as disappointment, depression, despair, fear, and anger. Negative emotions may fuel aggression or delinquency. In the General Strain Theory, Agnew considers anger the most important type of negative emotion in relation to aggression or delinquent behaviour. Strain has several dimensions: magnitude, recency, duration, and clustering of straining events. Treatment could aim at the prevention of the sources of strain and at employing more effective coping strategies in handling strain, which might result in a more positive emotional state (Agnew, 1997). Following General Strain Theory, life events (LE), especially negative events, can be a source of strain and therefore have a negative influence on QoL (Fakhoury \& Priebe, 2002). 


\section{CHAPTER 1}

\section{Social Control Theory}

This theory states that persons act delinquently when their interpersonal bonds as well as their bond to society in general are weak or broken (Hirschi, 1969). Four types of bonds are distinguished: (1) attachment to parents, peers, and school; (2) commitment to conventional lines of action; (3) involvement in conventional activities; and (4) belief in a common value system. Sampson and Laub (1990, 2005) incorporated Hirschi's Control theory into their lifecourse theory of crime. They hypothesized links between social ties and criminal acts, and empirically explored the role of social bonds in desistance from crime in adults. They contend that social ties in adulthood - to work, family, and community - explain changes in criminality over the life span, in spite of the fact that continuity in deviant behaviour also exists (Sampson \& Laub, 1990). Social interaction within these social institutions, which can exert informal social control, has important reducing effects on criminal behaviour. They studied the influence of job stability, commitment, and attachment to spouse on criminal and deviant behaviour in young adults, and demonstrated that all three sources of informal social control were negatively correlated with adult antisocial behaviour.

\section{Good Lives Model}

As noted, the GLM has been developed to expand on the RNR-model of risk assessment and risk management. The central assumption underlying the GLM is that "an individual is hypothesized to commit criminal offences because he lacks the capabilities to realize valued outcomes in personally fulfilling and socially acceptable ways" (Ward, Mann, \& Gannon, 2007, p. 90). Every human being, and as such also forensic psychiatric patients, is goal directed and his goal is to achieve psychological well-being by obtaining and keeping primary goods. These goods are "states of affairs, states of mind, personal characteristics, activities, or experiences sought for their own sake" (p. 90) which are likely to increase psychological well-being. Besides these primary goods, instrumental or secondary goods (e.g. work or relationships) exist which offer individuals ways to secure the primary goods. A fulfilling and good life as used in the GLM is closely related to the concept of QoL, and the GLM therefore offers a framework to relate QoL to (desistance from) criminal behaviour.

The integration of the three theoretical approaches (Good Lives Model, Social Control Theory and General Strain Theory) resulted in a model (see Figure 1.1) designed by us to stimulate research on the role of quality of life in risk assessment and management in forensic 
psychiatric patients. Quality of life can be influenced by both objective (social) and subjective indicators. These indicators are closely related to the human and instrumental goods as mentioned in the GLM. Social Control Theory proposes that social ties, which are part of the social indicators used in QoL research, can lead to criminal desistance. A strong bond to society can reduce the chance of re-offending, due to the exertion of formal and informal control and to the fulfilment of (human) needs. Most of these objective protective indicators of quality of life have previously been empirically related to criminal desistance in the general or juvenile criminal population and in psychiatric patients (DuRant et al., 1997; Ellis \& Peterson, 1996; Estroff \& Zimmer, 1994; Gendreau et al., 2000; Goggin et al., 1998; Hilterman, 2000; Hoge et al., 1996; Klassen \& O'Connor, 1989; Miller, 2006; Monahan et al., 2001; Oddone-Paolucci et al., 2000; Pettersson, 1991; Reddon et al., 1996; Sampson \& Laub, 1990; Sampson \& Laub, 2005; Wright \& Wright, 1992).

Subjective QoL is related to negative affect, which can occur as a result of strain invoked by negative life events. General Strain Theory relates negative affect to delinquent behaviour. Subjective QoL might mediate this relationship. Risk factors have been statistically related to criminal behaviour. The position a person occupies in the social structure determines the presence of and access to social ties and relationships. Limited presence of these sources of (social) control are expected to increase the risk of criminal behaviour. The multidimensional variable QoL could therefore be a protective factor, which either mediates or buffers the relationship between risk factors and criminal recidivism (see Figure 1.1).

\section{AIMS OF THE CURRENT THESIS}

Forensic psychiatric patients who are treated in a community-based setting reside in the community and have the opportunity to seek employment of their own choice and to engage in social relationships. Studying this group of patients offers the opportunity to relate life circumstances, both objective and subjective, to criminal behaviour. The majority of forensic psychiatric patients in The Netherlands are men who suffer from personality disorders (Derks, Hildebrand, \& Mulder, 1998; Hildebrand \& de Ruiter, 2004; Plemper, 2001). In this dissertation, adult male forensic outpatients with a PD or with PD traits will be examined. Firstly, the QoL of these patients will be studied. Secondly, the relationship of QoL with criminal behaviour will be explored, using hypotheses derived from the theoretical framework. 


\section{CHAPTER 1}

The aims of the present thesis are:

- To explore quality of life in male forensic psychiatric outpatients with a personality disorder or trait(s) from personality disorders, by comparing these patients with outpatients with schizophrenia (Chapter 2); and by comparing non-sexually violent and sexually violent forensic outpatients (Chapter 3).

- To investigate the influence of strain in the form of stressful life events on the quality of life of forensic psychiatric outpatients with a personality disorder (Chapter 4).

- To study the changeability of subjective and objective indicators of quality of life during six months of community-based forensic psychiatric treatment (Chapter 5).

- To examine the relationship between objective and subjective indicators of quality of life and criminal recidivism (Chapters 6 and 7 ).

\section{SETTING}

Patients who participated in this study were recruited from four different community-based forensic treatment centres throughout The Netherlands. The four participating outpatient facilities, all part of larger forensic psychiatric centres, were: De Waag (part of the Van der Hoevenstichting), Kairos (part of the Pompestichting), De Tender (part of FPC Oldenkotte) and Het Dok (part of FPC De Kijvelanden). During this study, De Waag had treatment centres in five major cities in The Netherlands: Utrecht, Almere, Amsterdam, The Hague, and Haarlem. De Tender had one location in the eastern part of The Netherlands (Deventer), whereas Het Dok was located in Rotterdam. At the beginning of the study, Kairos had four facilities: in Nijmegen, Arnhem, Tiel and 's-Hertogenbosch, from which patients were recruited.

The first forensic psychiatric outpatient facilities in The Netherlands originated in the early 90's to fill a void in the care-system for clinical forensic patients in their resocialisation phase. Once outpatient forensic care for this initial target group was established, two additional target groups became apparent: psychiatric patients who came into contact with the law but whose behaviour was not severe enough to require clinical forensic treatment and patients with a personality or psychiatric disorder at risk of criminal behaviour. Compared to a clinical forensic population, patients treated at an outpatient facility have committed fewer or less severe offences. Most convicted outpatients have a conditional sentence with mandatory 
treatment. Treatment in forensic outpatient facilities can be mandated by court or voluntary. Referrals generally come from probation offices, but patients are also referred to these highly specialised forensic institutions by general practitioners and psychiatric care facilities. 



\title{
Chapter 2
}

\section{Quality of life of male outpatients with personality disorders}

\author{
or psychotic disorders
}

In a slightly revised version, this chapter has previously been published as: Bouman, Y.H.A., Nieuwenhuizen, Ch. van, Schene, A.H., \& Ruiter, C. de (2008). Quality of life of male outpatients with severe personality disorders or psychotic disorders: A comparison. Criminal Behaviour and Mental Health, 18, 279-291, doi: 10.1002/cbm.703, (C (2008), John Wiley \& Sons, Ltd. 


\section{CHAPTER 2}

\section{Abstract}

Quality of life (QoL) has become increasingly important as an outcome-measure in communitybased psychiatry. QoL refers to an individual's sense of well-being and satisfaction with his current life conditions. It is measured both through objective social indicators and life domainspecific subjective indicators. People with a personality disorder (PD) or a major mental disorder (MMD) tend to show poor social adjustment, but their relative subjective QoL is not known. The aim of this study is to compare the QoL of male outpatients in treatment for PD or MMD, overall and by means of specific social and subjective indicators. A sample of 135 men under treatment for PD in Dutch forensic outpatient facilities were compared with 79 men with major mental illness (MMD) using the extended Dutch version of the Lancashire Quality of Life Profile (LQoLP). Almost all of the objective indicators of QoL were significantly poorer among men with MMD than those with PD, but the groups did not differ on domain-specific subjective ratings of QoL. Indeed, global subjective QoL was lower in the PD than in the MMD patient group. PD outpatients seemed to have a more complex concept of QoL than the MMD outpatients for whom almost half of the variance in subjective QoL rating was related to their everyday activities and their objective sense of safety. Further study of QoL among PD patients would be warranted to test the extent to which subjective dissatisfaction is intrinsic to PD and to explore the possibility of improving it with targeted treatments. 


\section{INTRODUCTION}

Since the mid-nineteenth century, psychiatric services have had a responsibility to help patients with severe mental illnesses who show problem behaviour in the community (Link, Phelan, Bresnahan, Stueve, \& Pescosolido, 1999; Oosterhuis, 2004). Two main groups of people use these services: those suffering from chronic and severe mental illnesses, mostly psychotic disorder, and those with personality disorders (PDs). In the last decade, it has become important to consider not only symptomatic aspects of these disorders, but also the general adaptive functioning and quality of life (QoL) of these patients (Coid, 1993; Mason, 1999; van Nieuwenhuizen, Schene, \& Koeter, 2002; Wilson, Tien, \& Eaves, 1995). The focus of this Chapter is on the latter.

Personality and psychotic disorders are both characterised by a chronic course and thus may be expected to have an impact on patients' QoL. Chronic psychotic disorder is often characterised by negative symptoms affecting both personal functioning and social integration. Patients with PDs may also be characterised by failures of social integration as a result of an inability to maintain social relationships. Hence, at first sight, the disabling effect of psychotic and PDs disorders on objective and subjective life circumstances might be similar.

Quality of life refers to a sense of well-being and satisfaction experienced by people under their current life conditions (Lehman, 1983). The division of QoL into three categories of indicators - economic, social and subjective - is generally accepted (Farquhar, 1995; Glatzer \& Mohr, 1987; Goodinson \& Singleton, 1989; McCall, 1975). Recently, economic indicators were incorporated into the social indicators, leaving two main categories. Diener and Suh (1997) stated that QoL is best approached using the strengths of both perspectives, because "neither set of indicators is exhaustive, and the fact that each captures a different aspect of societal well-being." (p. 207-8). Subjective well-being refers to the individual's cognitive and affective reaction to his or her whole life, as well as to specific life domains. Social indicators are measures that reflect people's objective circumstances in a given cultural or geographic unit (Diener \& Suh, 1997). In studies on QoL in (general) psychiatry, most authors agree on the fact that a broad set of life domains should be used when studying QoL (e.g. housing, finances, work and family; Lehman, 1983; Oliver, Huxley, Bridges, \& Mohamad, 1996; WHOQOL Group, 1998). 


\section{CHAPTER 2}

The study of the quality of life of patients with major mental disorder (MMD) has increased over the past decade, but there are few studies on QoL of PD patients. Co-morbidity of an Axis I disorder in PD patients has been found to be related to a lower QoL in outpatients (Draine \& Solomon, 2000; Masthoff, Trompenaars, van Heck, Hodiamont, \& de Vries, 2006), whereas patients with PD alone did not differ from patients with an Axis I disorder on global QoL (Trompenaars, Masthoff, Van Heck, Hodiamont, \& De Vries, 2006). The same PD patients were, however, less satisfied with their environment, which includes, among other things, their financial situation, leisure activities and home environment (Masthoff, Trompenaars, van Heck, Hodiamont, \& de Vries, 2006). Narud, Mykletun and Dahl (2005) found that, compared with adults in the general population, PD outpatients gained lower scores on all dimensions of the Short Form-36 (SF36; Ware \& Sherbourne, 1992), a generic QoL questionnaire. In two studies with inpatients, PD patients displayed a lower subjective QoL than MMD patients, both in general and on several of the domains (Lehman, 1999; Swinton, Oliver, \& Carlisle, 1999). In all these studies, except for Swinton et al. (1999), over half of the samples consisted of women, which might have skewed the results since men have been found to report a higher QoL than women (Slade et al., 2004; van Nieuwenhuizen, 1998). Patients in the studies just described were most likely to be suffering from cluster A (odd or eccentric) or cluster C (anxious or fearful) PD, although cluster B PD was sometimes represented with borderline PD. None of the patients had antisocial PD.

\section{Research aims}

Our aim was to compare male outpatients with PD with male outpatients suffering from schizophrenia or other psychotic disorder, on social indicators of quality of life and on domain-specific and global subjective indicators of quality of life. We also tested which indicators associated with global subjective QoL in these groups.

\section{METHOD}

\section{Participants}

Patients under treatment for PD were randomly selected from four forensic outpatient facilities in The Netherlands. The inclusion criteria were: male gender; 18 years or older; intelligence quotient higher than 70; and a primary diagnosis of PD or markedly abnormal PD 
traits (the Diagnostic and Statistical Manual of Mental Disorders [DSM-IV-TR]; American Psychiatric Association [APA], 2000). Exclusion criteria were having a co-morbid Axis I disorder of mood, anxiety or psychosis. The patients had to have been in contact with the forensic treatment centre at least once a month.

A total of 214 patients were contacted by their therapist or the first author and handed a leaflet containing basic information about the study; 79 of them did not want to participate (36.9\%) and 135 agreed to participate. If a patient agreed to participate, an appointment was made for a first interview, when written informed consent was taken. Patients who did not participate did not differ from patients who consented with regard to age, substance abuse or paraphilic disorders (DSM-IV-TR diagnoses), or on most criminal history variables (ever convicted, ever incarcerated, violent or sexual offence). Patients who did not participate were more likely to have had a co-morbid Axis I disorder (41.6\% vs. $\left.21.5 \% ; \chi^{2}[1]=9.64 ; p=.002\right)$, and less likely to have been arrested before age $16\left(6.9 \%\right.$ vs. $\left.28.5 \% ; \chi^{2}[1]=13.03 ; p<.001\right)$ than patients who participated.

Thirty percent of the patients in treatment for PD did not meet the DSM-IV criteria for PD, but had one or more abnormal PD traits, mainly from cluster B (61\%). Of the patients with PD, the largest group was classified as 'PD not otherwise specified' (37.8\%). cluster B disorders (antisocial, borderline and narcissistic PD) were present in $23 \%$ of the patients. Most PD patients $(83 \%)$ had one or more co-morbid Axis I disorders, which were substance-use disorders, sexual disorders or impulse control disorders.

Patients were selected for the comparison group from a large database used to develop the Dutch version of the Lancashire Quality of Life Profile (LQoLP; van Nieuwenhuizen, 1998; see also van Nieuwenhuizen, Schene, Koeter, \& Huxley, 2001). Inclusion criteria for this group were one or more years of contact with psychiatric services and a diagnosis of a severe and persistent mental illness. Exclusion criteria were: florid psychotic symptoms or evidence of organic brain dysfunction (van Nieuwenhuizen, 1998, p. 75). Patients, who were selected for this study, were adult men suffering from schizophrenia or another psychotic disorder without a co-morbid personality disorder (referred to in this Chapter as MMD patients). These outpatients were treated at several community psychiatric services throughout The Netherlands, most participating treatment programmes for psychosis. In summary, 79 male outpatients with psychotic disorders were compared with 135 outpatients with PD or abnormal personality traits. 


\section{Instruments}

\section{Quality of life}

The Dutch version of the LQoLP (van Nieuwenhuizen, 1998; van Nieuwenhuizen, Schene, \& Koeter, 1998) was used to measure objective and subjective QoL in both samples. This structured interview assesses QoL across seven domains: leisure and social participation (15 objective and 7 subjective items), religion (two objective items), finances (eight objective and two subjective items), living arrangements (four subjective and four objective items), legal status and safety (six objective and two subjective items), family relations (five objective and three subjective items), and health (nine objective and seven subjective items; see also van Nieuwenhuizen et al., 2001). No data on satisfaction with religion were used in this study because of the great number of missing values for most people in the MMD sample. The internal consistency of the Dutch version of the LQoLP was adequate to good (Cronbach's alpha range $=0.62-0.84$ ). The two-week test-retest reliability was $0.67-0.90$ (van Nieuwenhuizen, 1998; van Nieuwenhuizen, Schene, Boevink, \& Wolf, 1998).

At the end of the interview, the patient is asked to rate his overall life quality at that time, by indicating on a $100 \mathrm{~mm}$ ladder how he perceives his life on a continuum ranging from life at its worst to life at its best. This is called Cantril's ladder (Cantril, 1965, discussed in: van Nieuwenhuizen, Schene, Boevink, \& Wolf, 1998). The Life Satisfaction Scale (LSS) is used throughout the interview for rating satisfaction on the 25 subjective items of the six domains, ranging from one (cannot be worse) to seven (cannot be better). For each domain, a mean domain score was calculated by adding the scores of domain-specific subjective indicators and dividing the total by the number of items used.

\section{Demographic background}

Demographic variables are incorporated in the LQoLP. Additional information on the forensic outpatients with regard to psychiatric diagnosis and background was taken from patient files or gathered during an interview used to score the Level of Service Inventory revised (Andrews \& Bonta, 1995), which is not part of the current study. Axis I and II diagnoses were determined by clinicians trained in DSM-IV assessment. 


\section{Statistical analyses}

Independent sample $t$-tests were used to examine differences between MMD and PD outpatients on ordinal or interval variables. Chi Square-tests were used to study groupdifferences on nominal variables. Significance levels were set at $\alpha \leq .05$. A Bonferroni correction was employed in the comparison of the PD outpatients with the MMD outpatients. For each category of variables, the significance of a result was assessed by dividing $\alpha=.05$ by the number of items analysed, which were eight general characteristics $(\alpha \leq .006) ; 11$ objective social indicators $(\alpha \leq .005)$; and six subjective indicators $(\alpha \leq .008)$. A forward multiple linear regression was performed for PD and MMD patients, separately, to explore determinants of global quality of life entering the 11 objective (see Tables 2.1 and 2.2) and six subjective domain-specific indicators of QoL and Cantril's ladder as dependent variable. One social (objective) indicator was chosen for analysis from each of the domains of the original LQoLP (see Oliver et al., 1996; Ruggeri, Warner, Bisoffi, \& Fontecedro, 2001; Ruggeri et al., 2005; van Nieuwenhuizen, Schene, Boevink, \& Wolf, 1998): having work; number of leisure activities; having a helping friend; being religious; living alone; having debts; frequency of family contact; psychiatric hospitalisation in the previous year; and having been a victim of violence. The indicator 'having an intimate relationship' was added because of correlations found previously with subjective QoL (see Ruggeri et al., 2001; Ruggeri et al., 2005). We also added whether or not the patient had children. For PD patients, the number of Axis I disorders was added in a second analysis (see Trompenaars et al., 2006).

\section{RESULTS}

\section{General characteristics}

The groups did not differ on average age (Table 2.1). About one-third of both groups finished primary school, which starts at the age of six, but MMD patients spent an average of two more years in formal education than PD patients.

\section{Psychiatric background}

The age at first admission to a psychiatric hospital did not differ between the groups. Most PD patients $(65.8 \%)$ had been treated in a psychiatric facility before the current episode, mainly as outpatients (44.4\%). MMD patients had a more extensive psychiatric history than PD patients. 
More MMD than PD patients had previously been hospitalised at all, and more frequently; $30 \%$ of the MMD group had been inpatients the year before the interview. Most of the MMD patients used medication (Table 2.1 and Table 2.2).

Table 2.1. Demographic characteristics and indicators of quality of life of personality disordered and psychotic outpatients.

\begin{tabular}{|c|c|c|c|c|}
\hline \multirow[b]{2}{*}{ General characteristics } & \multicolumn{2}{|c|}{$\begin{array}{l}\text { Personality disordered } \\
\text { outpatients }(\mathrm{N}=135)\end{array}$} & \multicolumn{2}{|c|}{$\begin{array}{l}\text { Psychotic outpatients } \\
\qquad(\mathrm{N}=79)\end{array}$} \\
\hline & M & $(\mathrm{SD})$ & M & $(\mathrm{SD})$ \\
\hline Average age & 37.5 & $(10.4)$ & 40.2 & $(9.9)$ \\
\hline Average age formal education $* * *$ & 17.5 & (2.8) & 19.5 & $(5.1)$ \\
\hline Frequency of psychiatric hospital admissions $* * *$ & $1.5 \mathrm{a}$ & $(0.8)$ & $2.8 \mathrm{~b}$ & $(1.1)$ \\
\hline Average age at first admission & $27.5 \mathrm{a}$ & $(11.4)$ & $25.7 \mathrm{c}$ & $(8.3)$ \\
\hline \multicolumn{5}{|l|}{ Subjective indicators } \\
\hline Living circumstances LSS & 5.0 & $(1.18)$ & 5.0 & $(1.14)$ \\
\hline Social participation and leisure LSS & 4.8 & $(0.87)$ & 4.7 & $(0.89)$ \\
\hline Health LSS * & 4.5 & $(0.98)$ & 4.5 & $(0.92)$ \\
\hline Finances LSS $\ddagger$ & 3.8 & $(1.40)$ & 4.0 & $(1.31)$ \\
\hline Family relationships LSS * & 4.5 & (1.38) & 4.9 & $(1.40)$ \\
\hline Safety LSS ${ }^{*}$ & 5.2 & $(1.10)$ & 5.1 & (1.03) \\
\hline Cantril's ladder $* * *$ & 47.6 & (22.8) & $59.9 \mathrm{~d}$ & (23.3) \\
\hline
\end{tabular}

Note. $\mathrm{M}=$ mean; LSS = life satisfaction scale, range 1 (life at its worst) -7 (life at its best). $\ddagger$ Variables used in linear regression.

${ }^{\mathrm{a}} \mathrm{n}=33 .{ }^{\mathrm{b}} \mathrm{n}=72 .{ }^{\mathrm{c}} \mathrm{n}=71 .{ }^{\mathrm{d}} \mathrm{n}=78$.

$* * * p \leq .001$.

\section{Social and subjective quality of life}

Objective social indicators of QoL are shown in Table 2.2; subjective indicators are presented in Table 2.1.

Social indicators of quality of life

Several differences between PD and MMD outpatients were found in terms of objective social indicators of QoL (Table 2.2). More PD patients had an intimate relationship and/or had 
children. MMD patients were more likely to be living alone (62\% vs. $35 \%)$ and they rarely had a job (6\% vs. 34\%). With regard to general social contacts, MMD patients assessed their contacts with friends as less helpful than PD patients did (52\% vs. $73 \%)$. Almost a quarter of the patients in both samples had been a victim of some form of aggression in the previous year. PD and MMD patients were similar in reports of having a religious belief (53 - 60\%).

Table 2.2. Personality disordered and psychotic outpatients: general characteristics and social indicators of quality of life.

\begin{tabular}{|c|c|c|c|c|}
\hline \multirow[b]{2}{*}{ General characteristics } & \multicolumn{2}{|c|}{$\begin{array}{l}\text { Personality disordered } \\
\text { outpatients }(\mathrm{N}=135)\end{array}$} & \multicolumn{2}{|c|}{$\begin{array}{c}\text { Psychotic outpatients }(\mathrm{N} \\
=79)\end{array}$} \\
\hline & $\%$ & (n) & $\%$ & (n) \\
\hline Education: none or primary school & 35.6 & (48) & 27.8 & (22) \\
\hline Been accused of crime in previous year & $37.3_{a}$ & (50) & $12.7 * * *$ & (10) \\
\hline Visited a doctor for physical problems & 74.1 & $(100)$ & $54.4 * *$ & (43) \\
\hline Uses medication for mental problems & 46.7 & (63) & 91.1 *** & (72) \\
\hline \multicolumn{5}{|l|}{ Social indicators } \\
\hline Work: yes $\ddagger$ & 34.1 & (46) & $6.3 * * *$ & (5) \\
\hline Daily or weekly family contact $¥$ & 80.0 & (108) & 65.8 & (52) \\
\hline Relationship: yes * & 48.9 & (66) & $11.4^{* * *}$ & (9) \\
\hline Has a friend who will help when needed $\ddagger$ & 73.3 & (99) & $51.9^{* * *}$ & (41) \\
\hline Living situation: alone $\ddagger$ & 34.8 & $(47)$ & $62.0^{* * *}$ & $(49)$ \\
\hline Children: yes $\ddagger$ & 49.6 & (67) & $16.5 * * *$ & (13) \\
\hline Debts: yes $\ddagger$ & 58.5 & (79) & $37.2_{\mathrm{b}} * *$ & (29) \\
\hline Been victim of violence in previous year ${ }^{*}$ & 26.7 & (36) & 20.3 & (16) \\
\hline Religious: yes $\ddagger$ & 52.6 & (71) & 59.5 & (47) \\
\hline $\begin{array}{l}\text { Hospitalised in psychiatric hospital the previous } \\
\text { year }{ }^{*}\end{array}$ & 5.9 & (8) & $30.4^{* * *}$ & (24) \\
\hline
\end{tabular}

Note. Cells represent proportions of the samples with the characteristic. $¥$ Variables used in regression analyses.

${ }^{\mathrm{a}} \mathrm{N}=134 .{ }^{\mathrm{b}} \mathrm{N}=78$.

$* * * p \leq .001 . * * p \leq .01$. 
MMD patients engaged in fewer leisure activities than PD patients $\left(\mathrm{M}_{\mathrm{PD}}=3.1 ; \mathrm{SD}=0.8\right.$; $\left.\mathrm{M}_{\mathrm{MMD}}=2.7 ; \mathrm{SD}=0.8 ; p<.001\right)$.

\section{Domain-specific subjective indicators of quality of life}

PD and MMD outpatients did not differ on domain-specific subjective indicators of quality of life (Table 2.1). On average, PD and MMD patients were satisfied with their leisure and social participation; with their family; with their living circumstances; with regard to safety and legal matters; and with their health in general. In contrast, the PD and MMD patients were, on average, neither satisfied nor dissatisfied with their financial situation.

\section{Global quality of life}

MMD outpatients were more satisfied with their current life than PD patients as measured with Cantril's ladder (Table 2.1).

Table 2.3. Prediction of global quality of life by social and subjective indicators for personality disordered outpatients and psychotic outpatients.

\begin{tabular}{|c|c|c|c|c|c|c|}
\hline \multirow[b]{2}{*}{ Predictor } & \multicolumn{3}{|c|}{$\begin{array}{l}\text { Personality disordered } \\
\text { outpatients }(\mathrm{N}=135)\end{array}$} & \multicolumn{3}{|c|}{$\begin{array}{c}\text { Psychotic outpatients }(\mathrm{N}= \\
78)\end{array}$} \\
\hline & $\mathrm{B}$ & SE B & $\beta$ & $\mathrm{B}$ & SE B & $\beta$ \\
\hline Victim of violence & & & & -11.6 & 5.05 & $-.20^{*}$ \\
\hline Religiosity & -10.3 & 3.18 & $-.23^{* * *}$ & & & \\
\hline Social participation and leisure LSS & 6.6 & 2.10 & $.25^{* *}$ & 16.2 & 2.32 & $.61^{* * *}$ \\
\hline Health LSS & 5.8 & 1.91 & $.25^{* *}$ & & & \\
\hline Finances LSS & 3.2 & 1.21 & $.20 * *$ & & & \\
\hline
\end{tabular}

Note: Only indicators emerging in the models are presented. See Tables 2.1 and 2.2 for entered indicators, 'number of leisure activities' was also entered. LSS $=$ life satisfaction scale. Model forensic psychiatric outpatients: $\mathrm{R}=.62 ; \mathrm{R}^{2}=.38 ;$ Adj. $\mathrm{R}^{2}=.36 ; \mathrm{F}(4,128)=19.9 ; p$ $\leq .001$. Model general psychiatric outpatients: $\mathrm{R}=.65 ; \mathrm{R}^{2}=.43 ;$ Adj. $\mathrm{R}^{2}=.41 ; \mathrm{F}(2,74)=27.7 ; p \leq .001$.

$* * * p \leq .001 . * * p \leq .01{ }^{*} p \leq .05$.

\section{Multivariate analyses}

Performing forward multiple regression analyses, we found a different equation for MMD patients compared with PD patients (Table 2.3). For MMD patients, satisfaction with leisure 
and social participation and having been a victim of crime significantly predicted global subjective QoL; the amount of variance explained was 41\%. For PD patients, however, satisfaction with health, with leisure and social participation and with finances and whether or not a patient considered himself religious explained 36\% of the variance in Cantril's ladder.

The presence of an Axis I disorder was then added to the analysis for PD patients. This resulted in a non-significant increase of the explained variance $(0.9 \%)$.

\section{Discussion}

In this study with male outpatients with severe personality disorders or schizophrenia (or another psychotic disorder), we found that the groups differed on most social indicators of quality of life; overall MMD patients displayed a lower objective QoL than PD patients, but the PD patients gave a lower subjective global QoL rating. The groups, however, did not differ with regard to domain-specific subjective QoL. Satisfaction with leisure and social participation predicted subjective global QoL for both groups, but otherwise the qualities accounting for their subjective states differed.

Our findings differed from those of Swinton et al. (1999), who found no differences between forensic PD and forensic MMD patients except for having a job (within the hospital) $(\mathrm{PD}>\mathrm{MMD})$ and social benefit refusal: (MMD > PD), but they were comparing inpatients, albeit, like us, all men. The difference in settings may have determined the level of freedom patients had to shape their lives, and might therefore explain the differences in outcomes between the two studies. High security hospital inpatients live in a very structured environment with limited choices with regard to how and with whom they spend their time, whereas outpatients have more choices and are responsible for their course of action.

For PD patients, satisfaction with their health and with their leisure and social participation contributed the most to their general level of subjective QoL. For MMD patients, satisfaction with leisure and social participation was most important. Global QoL seems to be a predominantly subjective matter for PD patients whereas for MMD patients global subjective QoL was related to one social and one subjective indicator. The relationship between victimisation and QoL, which surfaced for MMD patients, has previously been demonstrated by Lehman (1983) and Holloway (1995). The negative relationship between adhering to a religion and global subjective QoL for PD patients is counterintuitive. It might be that 


\section{CHAPTER 2}

belonging to a religion, with its strong set of values, makes PD patients, specifically, more aware of the harm they cause other people, and might therefore negatively influence their subjective well-being.

A possible explanation for the discrepancy between objective and subjective ratings of QoL among MMD patients may be that they may have adapted to their situation better than PD patients. Blenkiron and Hammill (2003), for example, reported that the duration of a disorder positively correlates with life satisfaction. Besides a lower QoL as measured by social indicators, MMD patients had a more extensive psychiatric history than PD patients. The objective life circumstances of MMD patients may have reflected adjustment to this long and severe period of disabling illness. People tend to adapt their expectations to new, less favourable circumstances and shift their life goals to more attainable ones (see e.g. Goodinson \& Singleton, 1989). This shift may contribute to higher levels of life satisfaction despite lower levels of objective QoL. Inability to make such adjustments may be a fundamental component of men with PD; they are often regarded as finding it difficult to learn from experience. By definition, the men with PD would have been struggling with the disorder for longer than those with psychosis, even if their use of services was less.

In a more general theory of response shift (see Schwartz \& Sprangers, 2000), three explanations for this shift are offered: reconceptualization, reprioritization and recalibration. The first explanation refers to a change in the concept of QoL over time. The second, reprioritisation, explains the shift from a rebalance in the concept, by which the same predictors are used but with different values. According to the third explanation, patients can also change their point of reference and adopt a different benchmark. The difference between PD and MMD patients could not be explored by using response shift theory, because the present research-design was not longitudinal.

This study has several limitations, which should be considered when interpreting the results. First, the patients participating in this research were adult male outpatients who were either suffering from a PD or MMD. No distinction was made between different PDs, although previous research has indicated that studying the quality of life of subgroups of PDs seems useful (Chen et al., 2006; Sareen, Stein, Cox, \& Hassard, 2004). Subcategories were not employed because the level of apparent co-morbidity between PDs or traits from multiple categories of PD was high. This made a clear distinction between subgroups impossible. Second, non-response could confound the results by selection bias. Non-responders differed 
on 2 of the 11 characteristics on which they were compared: they were more likely to have a co-morbid Axis I disorder and fewer had been arrested before age 16.

The two main goals of psychiatric treatment are reduction in the primary effect of the mental disorder and of harm to self and/or others. The correlation between objective life circumstances, defined as social indicators of QoL, and recidivism or criminal behaviour has been established in several studies (e.g. Gendreau, Goggin, \& Gray, 2000; Goggin, Gendreau, \& Gray, 1998; Monahan et al., 2001; Oddone-Paolucci, Violato, \& Schofield, 2000). We could find no studies exploring the relationship between subjective indicators of QoL and recidivism or criminal behaviour except for a study using return to jail as an outcome measure (Draine \& Solomon, 1994). So far, the influence of subjective well-being on crime desistance has not been established empirically, although one could expect a protective role of subjective QoL against criminal recidivism. The effects of treatment on subjective QoL and, in turn, on criminal recidivism await empirical evaluation. 



\section{Chapter 3}

\section{Quality of life of violent and sexual offenders}

In a slightly revised version, this chapter has previously been published as: Bouman, Y.H.A., Ruiter, C. de, \& Schene, A.H. (2008). Quality of life of violent and sexual offenders in community-based forensic psychiatric treatment. The Journal of Forensic Psychiatry \& Psychology, 19, 484-501, doi: 10.1080/ 14789940701877669, (C) 2008 Taylor \& Francis. 


\section{CHAPTER 3}

\section{ABstract}

Subjective well-being is a common outcome measure in the evaluation of treatment in general psychiatry, but not yet in forensic psychiatry. The impact of quality of life, defined in terms of objective indicators and subjective well-being, on criminal recidivism is unknown. Several criminological theories, such as Ward's Good Lives Model, point at a possible relationship. In a study of male forensic psychiatric outpatients suffering from personality disorders, the quality of life of sexual and violent offenders was compared, using the Dutch version of the Lancashire Quality of Life Profile. The results indicated that although sexual offenders and violent offenders hardly differed on objective indicators of quality of life, their judgment of their subjective wellbeing differed significantly. Sexual offenders were more satisfied in general and in particular with their family relationships, safety, and health. For both groups, different objective and subjective indicators correlated with global well-being. Assessment of domain-specific objective and subjective issues and global well-being, at the beginning of treatment, may improve the effectiveness of treatment and the quality of life of the forensic patient. 


\section{INTRODUCTION}

Following the Good Lives Model (GLM; Ward, 2002), it can be hypothesized that reductions in criminal offending can be established by creating more fulfilling and meaningful lives for offender populations, including those with mental disorders. In theories of quality of life (QoL), striving for the good life is regarded as the most important goal in life (e.g. Diener \& Suh, 1997; King, 2001; Oliver, Huxley, Bridges, \& Mohamad, 1996). Although several criminological theories emphasise aspects of this good lives notion (e.g. Agnew, 1992; Rovers, 1998), it is far from clear what empirical relationship exists between criminal behaviour and subjective well-being. In the GLM, offenders are seen as active agents striving for the highest level of well-being through achieving human goods (Ward \& Brown, 2004). However, their criminogenic needs are considered obstacles in the achievement of these primary goods. According to the GLM model, rehabilitation should focus both on reduction of risk factors and on promoting the attainment of human goods. This theory has not yet received a lot of empirical support due to a lack of research, besides two unpublished studies mentioned by Ward, Mann and Gannon (2007) and one experiment evaluating different treatment approaches based on the GLM (Mann, Webster, Schofield, \& Marshall, 2004). There is also little empirical knowledge on the subject of well-being of offenders (Ogloff \& Davis, 2004), nor has there been much attention for QoL in forensic psychiatry (Van Nieuwenhuizen, Schene, \& Koeter, 2002). The current study is an attempt to fill a part of this gap.

\section{The concept of quality of life}

Diener and Suh (1997) mention three philosophical approaches to the good life resulting in three different groups of indicators, namely economic, social and subjective indicators of the good life. This division into three categories of indicators of QoL is generally accepted (Farquhar, 1995; Glatzer \& Mohr, 1987; Goodinson \& Singleton, 1989; McCall, 1975). A broad definition using indicators in a wide range of life domains is also generally accepted in psychiatry (Lehman, 1983; Oliver et al., 1996; WHOQOL Group, 1998). There is a debate regarding whether to solely focus on subjective indicators or to include both objective and subjective indicators in the study of QoL; this has not been resolved (Goodinson \& Singleton, 1989; Lehman, 1983; Orley, Saxena, \& Herrman, 1998; Simmons, 1994). In the current research, both types of indicators were used to measure global QoL. This choice was made 


\section{CHAPTER 3}

because a combination of these indicators best reflects treatment goals in community-based forensic psychiatry.

\section{Quality of life in forensic outpatients}

Four studies have examined the QoL of forensic psychiatric outpatients, and one studied sexual offenders in a correctional community centre or 'halfway house'.

Draine and Solomon (1992) studied clients with or without an arrest history, mainly suffering from schizophrenia $(85 \%)$, attending a community mental health centre. The patients with an arrest history were more dissatisfied with their current living arrangements, with how they spent their time, and with their personal safety. These patients more often lived in nonindependent housing and had smaller social networks than patients without an arrest history.

In another study on QoL, Draine and Solomon (2000) explored the role of anxiety, depression, and continued involvement with the criminal justice system in psychiatric patients suffering from depression, mania or schizophrenia, on probation or parole. They concluded that the 'quality of community life for persons with a mental illness can have a significant impact on affective symptom course' (p. 44), and could therefore have an impact on criminal recidivism.

Gerber et al. (2003) explored objective and subjective QoL in forensic patients $(n=15)$, mainly diagnosed with schizoaffective disorder and on Disposition Order specifying conditional discharge, and general psychiatric outpatients $(n=48)$. They reported that the forensic outpatients were more satisfied with their family relationships, with work/school, in the legal and safety domain, and with their global QoL. They seemed less satisfied in the financial domain.

Chung, Cumella, Wensley and Easthope (1998) compared the subjective QoL of mentally disordered offenders in a court diversion scheme with normative data of a general population. A small proportion (4.6\%) of the outpatients suffered from a personality disorder. Six months after entering the program, half of the offenders lived at home, whereas the others lived in hostels $(20 \%)$, prison $(22 \%)$, or in a psychiatric hospital $(9 \%)$. The mentally disordered offenders scored lower on all domains than the general population. This difference could be explained by living arrangements, because patients living at home or in hostels tended to have similar scores to the general population. 
Williams (2003) quantitatively and qualitatively explored the QoL of 23 male sex offenders participating in sex offender treatment in a community correctional setting, or 'halfway house', as part of their parole or probation agreements. There was no control group. No data on offenders' psychiatric diagnoses were reported. Results from the quantitative part of the study indicated that the participants were neither satisfied nor dissatisfied with their living situation, total QoL, leisure, social relationships, and access to medical care. They were dissatisfied with their finances and satisfied with their family relationships and health. Combining the quantitative and qualitative parts of the study, the author concluded that QoL for sex offenders may be primarily related to degree of freedom, interpersonal relationships (especially with family), and positive emotions.

The vast majority of patients treated in forensic outpatient facilities in The Netherlands are male and suffer from a personality disorder (Hildebrand \& de Ruiter, 2004; Plemper, 2001). Patients with personality disorders (PD) have generally been found to have lower global subjective well-being than patients with psychotic disorders (Lehman, 1999; Swinton, Oliver, \& Carlisle, 1999) or the general population (Narud, Mykletun, \& Dahl, 2005). Co-morbidity of a PD with a major mental disorder also seems to lead to a lower subjective QoL (Draine \& Solomon, 2000; Masthoff, Trompenaars, van Heck, Hodiamont, \& de Vries, 2006). However, in most of these studies (Draine \& Solomon, 2000; Lehman, 1999; Masthoff et al., 2006; Narud et al., 2005), a large percentage of the samples consisted of women. Previous studies have demonstrated significant differences in subjective well-being between male and female psychiatric patients (Slade et al., 2004; van Nieuwenhuizen, 1998), with men reporting a higher QoL. Furthermore, the difference between forensic psychiatric patients and other groups could be influenced by living circumstances (see Draine \& Solomon, 1992; Williams, 2003): patients living in non-independent housing displayed lower levels of subjective well-being than patients living in independent circumstances (Chung et al., 1998).

\section{Quality of life of different types of offenders}

It is unknown whether forensic patients with non-sexually aggressive behaviour and those patients who have committed a sexual offence perceive their lives differently, and consider different life domains important. Ward, Mann and Gannon (2007) reported that the absence of three types of human goods - agency, inner peace, and relatedness - was strongly associated with sexual offending. Swinton, Carlisle and Oliver (2001) noted that sexual offenders, 


\section{CHAPTER 3}

especially child molesters, might define a good QoL differently from violent offenders, due to different life goals and (unmet) needs.

Due to these presumed differences between male and female patients, between patients with a psychotic disorder and patients with a PD, and between patients living in nonindependent and patients living in independent housing, we compared two groups of adult male personality-disordered forensic outpatients who differed only in terms of type of offence. The two groups comprise sexual and violent offenders. The results of this study could provide information for treatment planning by identifying those aspects of a patient's life which can be considered problematic, using objective social indicators and subjective assessments by the patient. Following the Risk-Need-Responsivity principles (see Ogloff \& Davis, 2004), the results may aid clinicians in establishing a treatment relationship with the patient, which can form a starting point for addressing criminogenic needs.

\section{METHOD}

\section{Setting}

Patients were recruited from four forensic psychiatric outpatient treatment centres throughout The Netherlands. In total, the four outpatient facilities have 11 locations in larger (population app. 500,000) and midsize (population app. 100,000) cities, each with a regional service function. Most of the patients have a court order which requires them to participate in treatment to reduce the risk of re-offending. Treatment generally consists of psychotherapy, psychiatric consultation, pharmacotherapy, and social assistance by a psychiatric nurse or social worker. In some cases, art therapy or social skills training is offered. These forms of therapy can be given either individually, in groups, or in a couple format.

\section{Participants}

The inclusion criteria were: male gender; 18 years or older; IQ higher than 70; and suffering from a PD or PD traits (the Diagnostic and Statistical Manual of Mental Disorders [DSM-IV-TR]; American Psychiatric Association [APA], 2000) without a predominant Axis I disorder. Comorbidity with an Axis I disorder was allowed as long as the Axis I disorder was not primarily a mood, anxiety or psychotic disorder. Patients had to have contact at least once a month with a clinician from the forensic treatment centre. 
A sample of 214 patients were contacted by their therapist or the first author and handed a leaflet containing basic information about the present study: 79 did not want to participate (36.9\%), and 135 agreed to participate. All gave informed consent. On average, these patients had been in treatment for almost two years (644 days; SD = 636), ranging from a patient just entering treatment to a patient who had been in treatment for over eight years. Patients who did not participate did not differ from patients who consented with regard to age, substance abuse, the presence of paraphilic disorders (DSM-IV-TR diagnoses), or on most criminal history variables (ever convicted, ever incarcerated, violent or sexual offence). Patients who did not participate had co-morbid Axis I disorders more often (41.6\% vs. $21.5 \% ; \chi^{2}[1]=9.64 ; p=$ $.002)$, and had less often been arrested before the age of $16\left(6.9 \%\right.$ vs. $28.5 \% ; \chi^{2}[1]=13.03 ; p$ $\leq .001)$ than patients who participated. For five patients, it was impossible to make a second appointment; file information was used to score the Level of Service Inventory-Revised (Andrews \& Bonta, 1995). More than half of the patients (57.8\%) displayed violent behaviour for which treatment was recommended; $28 \%$ were in treatment because of sexually violent behaviour; $13 \%$ had committed a property offence and $6 \%$ had committed arson; two patients showed both aggressive and sexually violent behaviour. Of the sexual offenders, $66 \%$ had molested children. Patients who had committed arson or a property offence were excluded, unless they had also exhibited aggressive or sexually violent behaviour. The patients with both aggressive and sexually violent behaviour were also excluded from the study, which led to a final sample of 76 patients with violent behaviour and 36 patients with sexually violent behaviour.

\section{Instruments}

Quality of life

We used the extended Dutch version of the Lancashire Quality of Life Profile (LQoLP; van Nieuwenhuizen, Schene, \& Koeter, 1998) to measure objective and subjective QoL. This structured interview assesses seven life domains: leisure and social participation (26 items), religion ( 2 items), finances ( 9 items), living arrangements (8 items), legal status and safety (8 items), family relations (8 items), and health (16 items). No data on the subjective rating of religion were gathered in the present study. The internal consistency of the Dutch version of the LQoLP was adequate to good (Cronbach's alpha range $=.62-.84)$. The two-week testretest reliability ranges from .67 to .90 (van Nieuwenhuizen, 1998). 


\section{CHAPTER 3}

At the end of the interview, each patient was asked to rate his overall life quality at the moment, by indicating on a $100 \mathrm{~mm}$ ladder how he perceives his life on a continuum ranging from 'life at its worst' to 'life at its best'. This is called Cantril's ladder. A score of $\leq 50 \mathrm{~mm}$ was regarded as dissatisfaction, and $\geq 51 \mathrm{~mm}$ as satisfaction.

The Life Satisfaction Scale (LSS) was also used in the interview: patients were asked to state their satisfaction with 32 subjective items from the six domains, using a scoring system ranging from 1 ('cannot be worse') to 7 ('can not be better'). A mean domain score of $<4$ was regarded as dissatisfied, and $\geq 4$ as satisfied.

\section{Criminal history}

Here we used a section of the Level of Service Inventory-Revised (LSI-R; Andrews \& Bonta, 1995, 2000). The LSI-R is a measure of risk and need assessment. It was developed to determine offenders' needs for assistance when reintegrating into society. The interrater reliability of the English version of the LSI-R ranges from moderate (interrater agreement $=71 \%$ in Austin, Coleman, Peyton, \& Johnson, 2003) to good (.80 to .96 in Andrews \& Bonta, 1995; interrater agreement $=88 \%$ in Austin et al., 2003) depending, according to the latter authors, on the degree of training of raters. The interrater reliability of the Dutch version of the LSI-R is good (ICC $=.87$; De Rooy, 2004). The LSI-R in the present study was scored using file and interview data. The interviews were conducted by the first author or by master's-level psychology students as part of their clinical internship. They all were trained in administering the instruments used.

\section{Demographic background}

Demographic variables are assessed by the LQoLP. Additional information with regard to psychiatric diagnosis and background was taken from patient files or gathered during the LSI$\mathrm{R}$ interview. Psychiatric classification was determined by clinicians who were treating the patients, which resulted in Axis I and/or II diagnoses. These clinicians indicated whether the primary diagnosis related to treatment in the forensic facility was the Axis I or the Axis II disorder. Patients were included if they were diagnosed with PD traits or with a PD. PD traits was defined as sub-clinical PD, which means the patients show a number of traits of one or more PDs, but do not meet the required number to reach the clinical threshold. Patients with a current mood, anxiety or psychotic disorder were excluded, as were patients with a lifetime 
psychotic disorder. Clinicians who performed the assessment were all trained in using the DSM standard as part of their professional education.

Table 3.1. Demographic characteristics

\begin{tabular}{|c|c|c|c|c|}
\hline & \multicolumn{2}{|c|}{$\begin{array}{l}\text { Violent } \\
(n=76)\end{array}$} & \multicolumn{2}{|c|}{$\begin{array}{l}\text { Sexual } \\
(n=36)\end{array}$} \\
\hline & $\mathrm{P}$ or $\mathrm{M}$ & $S D$ & $\mathrm{P}$ or $\mathrm{M}$ & $S D$ \\
\hline Education: none or primary school & 39.5 & & 33.3 & \\
\hline Social benefit & 63.2 & & 47.2 & \\
\hline Average debts, if any: & $15,778^{a}$ & 18,668 & $16,944^{b}$ & 20,867 \\
\hline Income per month, average in euros & 1026 & 594 & $1101^{c}$ & 443 \\
\hline Children, If yes: how many & $2.3^{d}$ & 1.3 & $1.9^{\mathrm{e}}$ & 1.6 \\
\hline Age, average & 37.5 & 9.1 & 41.1 & 12.3 \\
\hline
\end{tabular}

Note: $\mathrm{P}=$ Percentage of group; $\mathrm{M}=$ Mean per group

${ }^{\mathrm{a}} n=49 ; \mathrm{b} n=16 ;{ }^{\mathrm{c}} n=34 ; \mathrm{d}^{\mathrm{d}}=45 ;{ }^{\mathrm{c}} n=14$.

No significant differences between groups.

\section{Statistical analyses}

Student's $t$ tests were used to examine differences between sexual and violent offenders on ordinal or interval variables. Pearson $\chi^{2}$ was used to examine group differences on nominal variables. Furthermore, Pearson's R's were calculated to indicate correlations between scale variables. Significance levels were set at $\alpha \leq$.05. If applicable, a Bonferroni correction was employed.

\section{RESULTS}

\section{Demographic background}

Violent offenders and sexual offenders did not differ significantly with regard to age, educational level, IQ, or income (see Table 3.1). 
Table 3.2. Clinical characteristics and criminal background

\begin{tabular}{|c|c|c|c|c|}
\hline & \multicolumn{2}{|c|}{$\begin{array}{l}\text { Violent } \\
(n=76)\end{array}$} & \multicolumn{2}{|c|}{$\begin{array}{l}\text { Sexual } \\
(n=36)\end{array}$} \\
\hline & $\mathrm{P}$ or $\mathrm{M}$ & $S D$ & P or $\mathrm{M}$ & $S D$ \\
\hline Reason treatment: offence * & 65.8 & & 86.1 & \\
\hline Framework treatment: mandatory $* *$ & 31.6 & & 61.1 & \\
\hline Prior psychiatric treatment & 72.4 & & 58.4 & \\
\hline Personality disorder & 71.1 & & 66.7 & \\
\hline Cluster B PD * & 28.9 & & 8.3 & \\
\hline Cluster C PD & 3.9 & & 13.9 & \\
\hline $\begin{array}{l}\text { Used medication for mental health problems in } \\
\text { previous year }\end{array}$ & 52.6 & & 36.1 & \\
\hline Offence history: ever convicted & $75.3^{\mathrm{a}}$ & & $71.4^{\mathrm{b}}$ & \\
\hline Average number of convictions & $3.61^{\mathrm{c}}$ & 5.23 & $1.97^{\mathrm{d}}$ & 4.33 \\
\hline Incarceration: yes & $46.6^{\mathrm{a}}$ & & $45.7^{\mathrm{b}}$ & \\
\hline Been accused of crime in previous year $* *$ & 50.0 & & 22.2 & \\
\hline Judicial charge for violence $* * *$ & $90.4^{\mathrm{a}}$ & & $31.4^{\mathrm{b}}$ & \\
\hline Arrested before age $16 *$ & $34.2^{\mathrm{a}}$ & & $11.4^{\mathrm{b}}$ & \\
\hline Same delinquent behaviour before admission * & $75.7^{\mathrm{e}}$ & & $54.3^{\mathrm{b}}$ & \\
\hline Criminal family member $*$ & $49.3^{a}$ & & $24.2^{\mathrm{b}}$ & \\
\hline Criminal acquaintances & $75.3^{a}$ & & $67.6^{\mathrm{b}}$ & \\
\hline Criminal friends & $44.4^{a}$ & & $27.3^{\mathrm{b}}$ & \\
\hline
\end{tabular}

Note: $\mathrm{P}=$ Percentage of group; $\mathrm{M}=$ Mean per group

${ }^{\mathrm{a}} n=73 ; \mathrm{b}_{n}=35 ; \mathrm{c} n=69 ; \mathrm{d} n=32 ;{ }^{\mathrm{c}} n=70$.

$* p \leq .05 ; * * p \leq .01 ; * * * p \leq .001$

\section{Psychiatric background}

Violent and sexual offenders did not differ in terms of prevalence of PD (Table 3.2). However, the two offender groups had different types of PDs. Over three times more violent offenders 
were diagnosed with a cluster B PD (borderline, antisocial, or narcissistic PD) than sexual offenders. Moreover, sexual offenders tended $(p=.06)$ to have a cluster C PD (dependent, avoidant, or obsessive-compulsive PD) more often than violent offenders. No significant differences were found between the two groups with regard to prior psychiatric hospitalisations, mental health treatment, or use of medication.

Table 3.3. Social indicators of quality of life

\begin{tabular}{|c|c|c|c|c|}
\hline & \multicolumn{2}{|c|}{$\begin{array}{l}\text { Violent } \\
(n=76)\end{array}$} & \multicolumn{2}{|c|}{$\begin{array}{l}\text { Sexual } \\
(n=36)\end{array}$} \\
\hline & $\mathrm{P}$ or $\mathrm{M}$ & $S D$ & P or $\mathrm{M}$ & $S D$ \\
\hline Work: yes & 30.3 & & 47.2 & \\
\hline Out to watch or participate in sports the past 2 weeks & 46.1 & & 33.3 & \\
\hline Average of leisure activities $(\max =4)$ & 3.1 & 0.9 & 3.1 & 0.6 \\
\hline Relationship: yes & 53.9 & & 36.1 & \\
\hline Children: yes * & 59.2 & & 38.9 & \\
\hline Has a friend who will help when needed & 69.7 & & 72.2 & \\
\hline Daily or weekly family contact $* *$ & 72.4 & & 94.4 & \\
\hline Debts: yes $*$ & 67.1 & & 44.4 & \\
\hline Living situation: alone & 32.9 & & 44.4 & \\
\hline Been victim of violence in previous year & 25.0 & & 33.3 & \\
\hline Hospitalised in psychiatric hospital the previous year & 6.6 & & 5.6 & \\
\hline Religious: yes $* *$ & 60.5 & & 30.6 & \\
\hline Average number of positive social indicators $\dagger$ & 6.6 & 1.7 & 6.3 & 1.9 \\
\hline
\end{tabular}

Note: $\mathrm{P}=$ Percentage of group; $\mathrm{M}=$ Mean per group; $\dagger$ range $=0-11$ (av. leisure activities not included)

$* p \leq .05 ; * * p \leq .01 ; * * * p \leq .001$.

\section{Criminal history}

Most patients treated at the outpatient facilities had a criminal history (Table 3.2). About threequarters had previous convictions. Although the same number of violent and sexually offenders had previous convictions, four times more violent offenders than sexual offenders 


\section{CHAPTER 3}

had been convicted three times or more $(\mathrm{F}[1]=11.98 ; p \leq .001)$, with a maximum of 35 convictions. Over a quarter of the patients had been arrested before 16 years of age, including three times more violent offenders than sexual offenders. Nearly half $(46 \%)$ of the patients had been incarcerated after a conviction as an adult. Twice as many violent offenders as sexual offenders had been accused of a crime during the year prior to the interview. For $41.1 \%$ of the patients, the background for the current treatment was a conditional sentence in combination with mandatory treatment. The sexual offenders' treatment was mandatory twice as often as that of violent offenders. More violent offenders than sexual offenders had a family member with a criminal record. Overall, violent offenders had a more severe criminal history than sexual offenders.

\section{Social indicators of quality of life}

Violent and sexual offenders did not differ on objective QoL as indicated by the average number of positive social indicators (see Table 3.3). However, the two groups differed in terms of several underlying circumstances. More violent offenders had children, more of them had debts, and more of them were religious, compared with sexual offenders. Sexual offenders more frequently had contact with their family than violent offenders.

\section{Domain-specific subjective quality of life}

Overall, sexual offenders were satisfied in more domains than violent offenders (see Figure 3.1; $\mathrm{M}$ sexual offenders $=5.2, \mathrm{M}$ violent offenders $=4.2 ; F=14.63 ; p \leq 001)$. Significantly more sexual offenders than violent offenders were satisfied with their family, safety, and health. In the other life domains, the differences were not significant.

In terms of domain-specific indicators, patients were satisfied with most aspects of their leisure time and social activities, except with their sexual activities. Violent patients were neither satisfied nor dissatisfied with their daily structure whereas sexually violent patients were significantly more satisfied in this respect. On most of the variables of the family domain, the groups did not differ significantly, except for family support: violent patients were on average neither satisfied nor dissatisfied whereas patients who committed a sexual crime were satisfied. Violent patients were significantly less satisfied with the amount of money they had, their income, and how much money they could spend on leisure activities. Violent offenders evaluated the quality of their housing similarly to sex offenders. On average, both patient 
groups felt satisfied about their safety. Subjectively, patients who had committed a sexual offence were significantly more satisfied with every aspect of their health, except for the perceived attitude of their doctor towards their mental health problems, compared to violent patients. Violent offenders tended to be neither positive nor negative with regard to their health, while sexual offenders were satisfied with every aspect of their mental and general health.

Figure 3.1. Proportion of satisfied violent and sexual patients per domain and in general

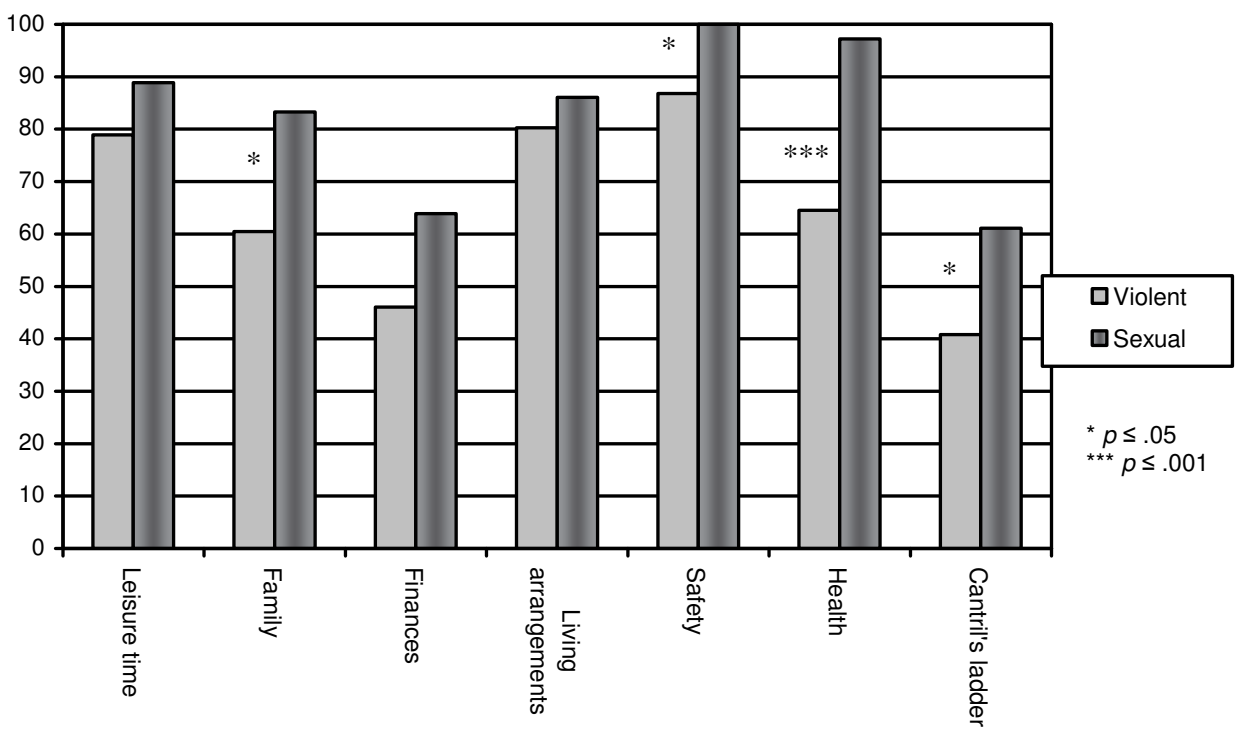

\section{Global subjective quality of life}

Violent offenders were less satisfied with their current life, as measured by Cantril's Ladder, than patients who had committed a sexual offence (see Figure $3.1 ; \chi^{2}[1]=4.05 ; p=.044$ ). Prior to the examination of the relationship between objective and subjective indicators and global subjective well-being, bivariate correlations among the social indicators and among the domain-specific subjective indicators were calculated in order to check for possible multicollinearity. No correlations of .5 or higher were found between social indicators for the total group, for the group of violent offenders, or for the group of sexual offenders. Subjective wellbeing with regard to health and with regard to leisure and social participation correlated 


\section{CHAPTER 3}

significantly at .51 for the total group. No correlations higher than the threshold were found among domain-specific subjective indicators for the group of violent offenders. For the group of sexual offenders, the correlations between satisfaction with health and satisfaction with leisure and social participation, and between satisfaction with health and satisfaction with living arrangements were .74 and .56 respectively. When calculating the correlations between the objective and subjective indicators and global subjective well-being, we therefore applied a Bonferroni correction for these three subjective indicators.

The relationships between objective and domain-specific subjective QoL scores on the one hand, and a global measure of QoL (i.e. Cantril's ladder) on the other, revealed different pictures for violent offenders and for sexual offenders (see Table 3.4). For violent offenders, having paid work and not having financial debts correlated with high scores on Cantril's ladder. For sexual offenders, having a religious faith correlated with lower scores on Cantril's ladder. For violent offenders, the total number of positive objective indicators correlated with Cantril's ladder, indicating that more positive circumstances correlated with higher global subjective well-being.

Of the domain-specific subjective ratings, satisfaction with leisure time and social participation, finances, and health all correlated with Cantril's ladder for both groups of offenders. For violent offenders, satisfaction with safety also correlated with Cantril's ladder; however, this was not the case for sexual offenders. Satisfaction with family was not correlated with Cantril's ladder score for either groups. The total number of domains with which patients were dissatisfied correlated negatively with Cantril's ladder for both groups.

\section{Discussion}

This study aimed to compare sexual and violent male forensic outpatients in terms of quality of life and its determinants. Sexual and violent offenders displayed the same objective QoL. Subjectively, sexual offenders were more satisfied with their life in general and with their health, safety, and family relationships, compared to violent offenders. For violent and sexual offenders different indicators were associated with global well-being. 
QUALITY OF LIFE OF VIOLENT AND SEXUAL OFFENDERS

Table 3.4. Bivariate correlations of objective and subjective quality of life measures and Cantril's ladder

\begin{tabular}{|c|c|c|c|c|}
\hline \multirow[b]{2}{*}{ Social Indicators \# } & \multicolumn{2}{|c|}{$\begin{array}{l}\text { Violent } \\
(n=76)\end{array}$} & \multicolumn{2}{|c|}{$\begin{array}{l}\text { Sexual } \\
(n=36)\end{array}$} \\
\hline & $r$ & $p$ & $r$ & $p$ \\
\hline Relationship & .08 & & .00 & \\
\hline Work & .29 & .012 & .23 & \\
\hline Debts & .29 & .012 & .20 & \\
\hline Been victim of violence in previous year & .15 & & .14 & \\
\hline Children & -.02 & & -.12 & \\
\hline Religious & -.08 & & -.41 & .014 \\
\hline Been out to participate in or watch sports the past 2 weeks & .14 & & -.15 & \\
\hline Average of leisure activities $(\max =4) \ddagger$ & .22 & & .06 & \\
\hline Daily or weekly family contact & .01 & & -.22 & \\
\hline Has a friend who will help when needed & .10 & & -.02 & \\
\hline Living situation & .07 & & -.09 & \\
\hline Hospitalised in psychiatric hospital the previous year & .08 & & .05 & \\
\hline Number of positive Social Indicators & .29 & .010 & -.06 & \\
\hline \multicolumn{5}{|l|}{ Average Life satisfaction on domains } \\
\hline Leisure time and social participation & .37 & .001 & .59 & .000 \\
\hline Family & .08 & & .05 & \\
\hline Finances & .42 & .000 & .41 & .014 \\
\hline Living arrangements & .05 & & .20 & \\
\hline Safety & .32 & .005 & .16 & \\
\hline Health & .42 & .000 & .52 & .001 \\
\hline Number of domains dissatisfied & -.39 & .001 & -.54 & .001 \\
\hline
\end{tabular}

\# Lower scores on social indicators imply negative circumstances; $¥$ Not used for sum positive social indicators. 


\section{CHAPTER 3}

Although violent offenders and sexual offenders did not differ with regard to their total score on objective indicators, they did differ from sexual offenders on four of the social indicators. Violent offenders had more debts, were more often religious, more often had children, had less contact with family members, tended to be unemployed more often, and tended to be in an intimate relationship more often. Other studies (Hanson, Scott, \& Steffy, 1995; Lievore, 2004) have also reported that rapists and child molesters tend more often to be single than other types of offenders. However, Craig, Brown, Beech, and Stringer (2006) found that violent offenders were more often single compared to sexual and other offenders. In line with our findings, Craig et al. (2006) demonstrated that violent offenders more often had a history of school and employment problems compared to sexual and other offenders. The results of our study with regard to having children are comparable to other studies (see Lievore, 2004). Overall, forensic outpatients in the current sample seemed to have an unfavourable socio-economic position. Compared to the Dutch male adult population (Centraal Bureau voor de Statistiek, n.d.), our offender samples more often had little education, were unemployed, had financial problems, and did not have an intimate relationship. Only $6.8 \%$ of the adult male Dutch workforce has either an unknown level of education or only primary school. Furthermore, $5 \%$ of the Dutch households have serious financial problems, and $14.5 \%$ of the male Dutch population is single.

In general, the majority of the sexual offenders were satisfied, while most violent offenders were dissatisfied. Most violent and sexual offenders were satisfied with their leisure time and social participation, living circumstances, and safety. Both groups were neither satisfied nor dissatisfied with their financial situation. Violent patients were neither satisfied nor dissatisfied with their family relationships and their health, while sexual offenders were satisfied. Sexual offenders were also more satisfied with a number of other domains, such as general and mental health. Compared to the findings of Williams (2003), the sexual offenders in our study were more satisfied with their living arrangements, leisure time, social relationships, and finances. The sexual offenders in Williams' study resided in a halfway house, and might therefore have been more limited in their autonomy with regard to leisure time and social relationships, and thus be less satisfied with their living arrangements.

Comparing the objective social indicators with the domain-specific subjective well-being, the patients in our sample seemed to be relatively satisfied with their circumstances, despite their relatively unfavourable social position. This might reflect a different set point or 
benchmark for satisfaction. Patients seem to adapt to less positive circumstances by redefining their situation, and altering their ideals towards more realistic goals (also called response shift; Schwartz \& Sprangers, 2000).

When we explored the relationship between the objective and subjective indicators of QoL and global well-being, different pictures emerged for violent offenders and sexual offenders. For sexual offenders, having a religious belief correlated negatively with global subjective well-being. For violent offenders, financial situation and employment status correlated significantly with Cantril's ladder, as did their overall objective situation. The two groups did not differ significantly on many domain-specific subjective indicators. However, among violent offenders, subjective assessment of safety correlated significantly with Cantril's ladder, which was not the case for sexual offenders. Living arrangements and family do not seem to play an important role in these offenders' current lives; the objective and subjective indicators in these areas did not correlate with overall well-being. The relationship between religion and global well-being for sexual offenders is somewhat counter-intuitive. However, the strong values regarding sexual behaviour generally advocated by religion may prompt sexual offenders to feel bad about their lives because they have broken the rules set by their religion.

Sexual offenders were more satisfied with their lives in general than violent offenders. What could account for this difference? Do sexual offenders have different belief systems; are their expectations different from those of violent offenders? Violent offenders were diagnosed with cluster B PD more frequently than sexual offenders. Patients with a cluster B PD report lower QoL (Chen et al., 2006) and, more specifically, patients with antisocial PD characteristics have been found to be more dissatisfied than patients without such traits (Sareen, Stein, Cox, \& Hassard, 2004). Furthermore, violent offenders tend to have a more chaotic life-style than sexual and general offenders (Craig et al., 2006). In combination with the fact that violent offenders more often were diagnosed as suffering from a cluster B PD, violent offenders could be more prone to strain as a result of interpersonal conflict and a chaotic lifestyle than sexual offenders. According to Agnew (1992), strain leads to negative affect and negative affect has been found to influence subjective QoL negatively (Baker \& Intagliata, 1982; Diener \& Suh, 1997).

The Good Lives Model (GLM; Ward 2002; Ward, Mann, \& Gannon, 2007) offers a framework for constructing treatment for sexual offenders, based on positive psychology. Clinicians can try to motivate offenders to pursue more socially acceptable goals as personally 


\section{CHAPTER 3}

meaningful and valuable through insight into the value of alternative ways of living (Ward \& Brown, 2004). Several cautionary remarks should be made here. First, a treatment approach solely focussing on positive psychology can lead to inattention to criminogenic needs, which caused the original criminal behaviour. Second, sexual offenders demonstrate higher subjective well-being than seems plausible, based on their objective circumstances. Sexual offenders are known frequently to deny and minimise their offences (Ward, Hudson, \& Marshall, 1995). This tendency may also be present in their subjective QoL assessment. Third, the set of goods used in the GLM may reflect a set of values based on a particular subset of the general population. Patients seem to come from lower SES groups, whereas the goods used in the GLM may be applicable to a middle class population and may not be as relevant to individuals from other socioeconomic or cultural groups.

One of the weaknesses of this study is that only a small group of sexual offenders participated. In order to explore more fundamentally the concept of QoL in this group, it would be useful to study a larger sample of sexual offenders, preferably differentiating between child molesters and rapists. The objective of this study was to explore QoL of a sample homogeneous with regard to mental disorder. Diagnostic procedures can influence the reliability and validity of psychiatric diagnoses; however, although the clinicians who diagnosed patients did not use standardised interviews, all had been trained in diagnostic interviewing during their formal education.

When a patient enters treatment, one of the primary objectives is to create a situation where treatment can have a positive effect on the patient's life. For forensic patients, this often means creating order in the chaos. Violent patients seem to be more aware of the problem areas in their lives than sexual offenders. After assessing the objective problem domains, these can be addressed in treatment. According to Slade et al. (2004), the QoL of psychiatric outpatients can be influenced by assessing unmet needs formulated by patients. For violent patients, forensic treatment programs tend to focus on impulse control and anger management, which are legitimate and logical treatment targets. However, our study shows that by administering a more general QoL measure at intake assessment, other problem domains, which also require attention, may surface. For instance, finances seems to be problematic for a large proportion of violent offenders.

Forensic treatment should target specific life domains which have been found to correlate with the risk of recidivism. Several dynamic factors, such as having an intimate 


\section{QUALITY OF LIFE OF VIOLENT AND SEXUAL OFFENDERS}

relationship (Oddone-Paolucci, Violato, \& Schofield, 2000), work, a stable financial situation (Gendreau, Goggin, \& Gray, 2000), and structured leisure activities (for adolescents; Hoge, Andrews, \& Leschied, 1996), can protect against future criminal behaviour. Treatment can not change a criminal history, but it can try to provide a favourable starting point by helping forensic patients to change their objective circumstances and aim towards a better life. 



\section{Chapter 4}

\section{Recent life events and subjective well-being}

In a slightly revised version, this chapter will be published as: Bouman, Y.H.A., Ruiter, C. de, \& Schene, A.H. (in press). Recent life events and subjective well-being of personality disordered forensic outpatients. International Journal of Law and Psychiatry, doi:10.1016/j.jilp.2009.09.003. 


\section{CHAPTER 4}

\section{Abstract}

The majority of patients treated at forensic psychiatric outpatient facilities suffer from personality disorders, especially cluster B disorders. Life events have been shown to influence subjective well-being, severity of psychopathology and delinquent behaviour of patients with different personality disorders. However, the influence of life events on subjective well-being of patients suffering from cluster B personality disorders has rarely been studied. Following General Strain Theory and the dynamic equilibrium model, we hypothesised that negative life events would negatively influence subjective well-being, and that subjective well-being would change when instability of life events occurs. Fifty-six adult male forensic psychiatric outpatients were interviewed on their subjective well-being and filled out a self-report life event questionnaire, at three time-points, with an interval of three months. Life events were categorized along two dimensions: positive/negative and controllable/uncontrollable. Patients had a stable pattern of positive, negative controllable and uncontrollable life events. Positive controllable events did not have a stable pattern. Results indicated that only negative controllable events correlated negatively with subjective well-being. Furthermore, positive and positive controllable events correlated with a positive change in subjective well-being and uncontrollable events correlated negatively with this change. Forensic psychiatric outpatients seem to experience a relatively stable 'load' of stressful life events, that does not influence change in subjective well-being. We did not find unequivocal support for General Strain Theory. In line with the dynamic equilibrium model, forensic outpatients seemed less used to positive controllable life events, which influenced positive change in subjective well-being. In outpatient forensic treatment, attempts to limit negative life events together with enhancing behaviour which results in positive events should be targeted. This might result in better lives for patients and in reduced criminal behaviour. 


\section{INTRODUCTION}

It is well known that stressful life events influence the subjective well-being of people in general (Lu, 1999; Lucas, Clark, Georgellis, \& Diener, 2004; Lucas, Georgellis, Clark, \& Diener, 2003; Suh, Diener, \& Fujita, 1996; Zautra \& Majo, 1981), and of patients suffering from mental disorders such as schizophrenia (Chan, Ungvari, Shek, \& Leung, 2003), bipolar disorder (Chand, Mattoo, \& Sharan, 2004) and depression (Roy, 1996), in particular. Besides subjective well-being, life events (LE) also influence the severity of psychopathology. For instance, positive and negative LE correlated with depression in college students (Dixon \& Reid, 2000) and in patients with personality disorders (PD; Perry, Lavori, Pagano, Hoke, \& O'Connell, 1992), and negative LE are related to an increased symptom count in cluster B PD patients (Taylor, 2005).

The majority of individuals treated at forensic outpatient facilities in The Netherlands suffer from a personality disorder, especially cluster B PD, that is, antisocial, narcissistic, borderline and histrionic PD (American Psychiatric Association [APA], 2000; Hildebrand \& de Ruiter, 2004). In this field of psychiatry, preventing criminal recidivism is the main treatment goal, and several studies have indicated that life events in general (Steadman \& Ribner, 1982; Vaux \& Ruggiero, 1983) and specific life events in particular (such as witnessing violence, receiving traumatic news, marriage; Ouimet \& Le Blanc, 1996; Eitle \& Turner, 2002) influence delinquent behaviour and criminal recidivism. In this study, we examined life events and subjective well-being in a group of 56 male forensic psychiatric outpatients.

\section{Life events in patients with a personality disorder}

Previous research has demonstrated that PD patients experienced more LE than patients without PD (Leaf, Alington, Mass, DiGiuseppe, \& Ellis, 1991; Samuels, Nestadt, Romanoski, Folstein, \& McHugh, 1994; Heikkinen et al., 1997). In particular, PD patients encountered more positive LE (Leaf et al., 1991), and more dependent LE (i.e. controllable by the individual; Heikkinen et al., 1997). In studies relating LE to categories of PD, patients with a borderline PD seemed to experience different LE compared to patients with other PDs (Leaf et al., 1991; Jovev \& Jackson, 2006; Pagano et al., 2004). Borderline patients reported more LE in total (Jovev \& Jackson, 2006), more negative LE, fewer positive LE (Pagano et al., 2004) and more health-related and social stressors (Jovev \& Jackson, 2006; Pagano et al., 2004) than 


\section{CHAPTER 4}

patients with other PDs. Furthermore, Jovev and Jackson (2006) found that patients with borderline PD experienced more LE in the criminal and financial domains than patients with an Axis I disorder or with another PD.

Heikkinen and colleagues (1997) compared patients with cluster B and cluster C (avoidant, dependent, obsessive-compulsive) PDs, and reported that cluster B patients displayed more negative financial life events. The LE mentioned by all PD patients were mainly difficulties in interpersonal relationships (such as involvement in fights, conflict with neighbours, family arguments, and extramarital affairs) and with maladaptive behaviours (such as alcohol- and drugs-related problems, criminal activities, divorce; Samuels et al., 1994).

Several studies targeted the relationship between LE and global subjective well-being of PD patients. Pagano and colleagues (2004) studied the influence of LE on psychosocial functioning and overall life satisfaction in patients who suffered from one of four categories of PD, namely schizotypal (cluster A), borderline (cluster B), and avoidant and obsessivecompulsive (cluster C). They concluded that PD diagnosis had only a small effect on the relationship between recent LE and psychosocial functioning. However, another study (Jovev \& Jackson, 2006) showed that total LE did not influence global subjective well-being of patients with a borderline PD, whereas the influence of LE in patients with an Axis I disorder or with another PD (mainly avoidant and obsessive-compulsive PD) was negative.

Forensic psychiatric patients suffer mainly from a cluster B personality disorder, especially antisocial, narcissistic and borderline (Hildebrand \& de Ruiter, 2004). Studies on the relationship between life events and subjective well-being have rarely focussed on cluster B disorders or traits, with the exception of borderline PD.

\section{Possible mechanisms relating life events to subjective well-being}

For forensic patients, negative life events could serve as important risk factors for criminal offending according to general theories of crime such as General Strain Theory (Agnew, 1992, 1997). Following this theory, strain may lead to aggressive or criminal behaviour as a consequence of an increase in negative affect. Several kinds of negative affect have been identified, such as disappointment, depression, despair, fear, and anger. Anger is the most important type of negative affect in relation to aggression and delinquent behaviour. Agnew (1992) identifies three sources of strain, also labelled negative or adverse relations: failure to achieve positively valued goals; removal of positively valued stimuli (actual or anticipated); and 
presentation of negative stimuli. The latter two sources of strain involve life events, but the difference between the two is small: the removal of a positive stimulus, generally, results in the presentation of a negative stimulus. Strain has different dimensions: magnitude, recency, duration, and clustering of stressful events. Besides strain and the appraisal of strain as expressed in negative affect, General Strain Theory focuses on coping strategies which the individual employs in dealing with strain. Cognitive and contextual factors codetermine whether the chosen strategy is criminal behaviour or not. In forensic psychiatry, the prevention of strain and learning to employ different coping strategies in handling strain, are important treatment goals (Agnew, 1997).

Following General Strain Theory, LE, especially negative events, can be a source of strain and therefore negatively influence subjective well-being, because of the strong relationship between negative affect and subjective well-being (Fakhoury \& Priebe, 2002). The relationship between life events and subjective well-being is studied here.

In clinical forensic psychiatry, General Strain Theory has been used to study recidivism during leave by forensic inpatients (Hilterman, 2000). He confirmed several hypotheses derived from this theory, and deemed the model useful in Dutch forensic psychiatry. In other studies aiming at different samples, assumptions from General Strain Theory have been tested. In a sample of persons selected from family practices, positive life events did not correlate with strain, but negative life events, that is, undesirable, uncontrollable, and unanticipated events, did (Streiner, Norman, McFarlane, \& Roy, 1981). For (ex-) psychiatric patients, high life stress was associated with more frequent verbal, minor physical, major physical, and weapon disputes, during the same year the life events occurred (Steadman \& Ribner, 1982). In this group, the total number of life events, and the undesirable and controllable events predicted the total number of disputes.

Whereas the General Strain Theory postulates that negative LE have a negative influence on subjective well-being (SWB), the dynamic equilibrium model (Headey \& Wearing, 1989) of SWB is built around the assumption that people have a normal pattern of LE and a normal level of SWB, and both are predictable on the basis of stable personality characteristics. Only deviations from the normal pattern of LE change the normal level of SWB. According to the dynamic equilibrium model, the same life events keep happening to the same persons. Some are exogenous, and some are internally driven (endogenous), resulting from stable characteristics of the person. 


\section{AIMS OF THE STUDY}

Assumptions based on both the General Strain Theory and the dynamic equilibrium model were studied. Firstly, stability of LE categories was examined, since change in LE should lead to change in SWB. Secondly, we studied the relationship of negative (categories of) LE with SWB, and of the total number of LE with SWB, since the General Strain Theory assumes a negative relation between strain or negative life events and SWB. Thirdly, we studied the influence of LE on change in SWB. Following the General Strain Theory, negative LE would result in a negative change in SWB. From the dynamic equilibrium model, on the other hand, it follows that LE would only lead to a change in SWB if the category of LE was unstable, that is, has changed. We explored the role of both negative and other categories of LE, and used a median split in (categories of) LE (for use of median split in LE research see e.g. Steadman \& Ribner, 1982; Burns, Carroll, Ring, Harrison, \& Drayson, 2002; Klein \& Boals, 2001; Zalsman et al., 2006; and for discussion on median split, see Maxwell \& Delaney, 1993) by which our sample is divided into patients with a low level of LE and patients with a high level of LE, per category of LE. Furthermore, we examined whether severity of psychopathology (operationalised as having either a PD or PD traits) and whether type of disorder (having a borderline PD or BPD traits or not) had an effect on the relationship between LE and change in global SWB.

\section{Methods}

\section{Procedure}

The inclusion criteria were: male, 18 years or older, IQ $>70$, predominant PD or PD traits. Excluded were patients predominantly suffering from schizophrenia or related disorders, (severe) anxiety disorder or mood disorder. Psychiatric classifications were made by clinicians, resulting in Axis I and/or II diagnoses and an indication whether the primary diagnosis related to forensic treatment was the Axis I or the Axis II disorder.

Participants were randomly sampled from four forensic outpatient facilities in The Netherlands. In these facilities, both patients with and without a judicial measure are treated. All patients have displayed delinquent behaviour or are at risk for (relapse into) delinquent behaviour. In total, 214 patients were contacted by their therapist or the first author. They received a leaflet containing basic information about the present study. 
We used a longitudinal design with three assessment points: baseline $\left(\mathrm{T}_{0}\right)$, three months $\left(\mathrm{T}_{1}\right)$ and six months $\left(\mathrm{T}_{2}\right)$.

\section{Participants}

One hundred thirty-five patients agreed to participate and gave written informed consent. Seventy-nine patients declined participation. Of the 135 patients participating at $\mathrm{T}_{0}, 65(48.1 \%)$ filled out the self-report questionnaire on life events at $T_{1}$. Of these 65 responders, 9 did not participate in the second round of interviews at $\mathrm{T}_{2}$. Therefore, 56 of the 135 patients $(41.5 \%)$ were interviewed at $T_{0}$ and $T_{2}$ and returned the self-report questionnaire on life events at $T_{1}$ and $\mathrm{T}_{2}$. The 56 patients who participated in all three data collection rounds did not differ from the 79 drop-outs concerning criminal background, global subjective well-being at $\mathrm{T}_{0}$, score on categories of LE at $\mathrm{T}_{0}$, and psychiatric history.

\section{Measures}

Subjective Well-Being: to measure global SWB, we used Cantril's ladder which is part of the extended Dutch version of the Lancashire Quality of Life Profile (LQoLP), a patient interview (van Nieuwenhuizen, Schene, \& Koeter, 1998). In Cantril's ladder, a patient is asked to rate his life on a continuum ranging from life at its worst (0) to life at its best (100) by indicating it on a 100 $\mathrm{mm}$ long ladder. This rating was made at $\mathrm{T}_{0}$ and $\mathrm{T}_{2}$.

Socio-demographic and clinical data: the LQoLP (van Nieuwenhuizen, Schene, \& Koeter, 1998) also gathers information on life circumstances and demographic characteristics. A separate form containing questions regarding psychiatric and criminal background and additional demographic characteristics was designed by the first author. The form was filled out using file information and information collected during a patient interview at $\mathrm{T}_{0}$.

Life events: to assess life events, we used the Questionnaire of Recently Experienced Events (QREE; van der Willige, Schreurs, Tellegen, \& Zwart, 1985), a self-report measure. It is based on the Recent Life Change Questionnaire (RLCQ) of Rahe (1975) and consists of 59 LE divided into 115 items. At the end of the questionnaire, a subject can name up to two events not mentioned in the list. Patients were asked to indicate which events had occurred during the three months prior to the administration of the QREE. This was done at $T_{0}, T_{1}$ and $T_{2}$. At $T_{1}$, patients were either given an envelope containing the LE questionnaire and a postage paid envelope by their therapist or it was sent to their home address if a patient either no longer had 


\section{CHAPTER 4}

contact with the institute or if the frequency of therapy was low. At $\mathrm{T}_{0}$ and $\mathrm{T}_{2}$, patients filled out the LE questionnaire after the LQoLP interview and handed it to the interviewer.

Two dimensions of LE were distinguished: positive-negative LE and controllableuncontrollable LE. Along the positive-negative dimension, events are divided according to their perceived affective connotation. With regard to the controllable-uncontrollable dimension, controllable means a person has influence over the (occurrence) of the event, and uncontrollable means the person has no influence; the terms dependent or independent are also used to denote this difference (e.g. Heikkinen et al., 1997). Distinction of these two dimensions resulted in a total of eight (sub)categories of LE, which were used in this study. These distinctions have proven useful in previous research because different categories of events do not occur to the same extent in different populations (Leaf et al., 1991), and have different relationships with outcome measures such as subjective well-being (Pagano et al., 2004; Zautra \& Reich, 1980) and delinquent behaviour (Steadman \& Ribner, 1982; Vaux \& Ruggiero, 1983).

To categorise the events in the QREE along the two dimensions, the list of $115 \mathrm{LE}$ was presented to eleven independent individuals (unaware of the purpose of this study), with the request to rate each LE on two dimensions: positive-negative $(\mathrm{P} / \mathrm{N})$ and controllable uncontrollable $(\mathrm{C} / \mathrm{U})$. For both dimensions, there was also a 'neutral' category. The raters were employees of one of the participating facilities. For $84 \mathrm{LE}$, the rating resulted in a clear consensus on the two dimensions. For $31 \mathrm{LE}$, the outcome was equivocal (13 on the $\mathrm{P} / \mathrm{N}$ dimension and 18 on the $\mathrm{C} / \mathrm{U}$ dimension). These $\mathrm{LE}$ were reviewed by the first and second author, who arrived at a consensus agreement. Of the possible LE, 27 were labelled positive, and 49 negative. Fifty-four events were considered controllable and 48 uncontrollable. Of the positive events, 22 were considered controllable and four were rated as uncontrollable LE. Thirty of the negative events were labelled uncontrollable, and fifteen negative events were rated as controllable. Besides categories of LE, the weighing procedure (Life Change Units, LCU) used by Miller and Rahe (1997) was employed. In the RLCQ, a score is given to each LE depending on the estimated impact of the event, resulting in a LCU score. In accordance with Miller and Rahe's advice (1997, p. 290), a cut-off score of 300 was used to differentiate high LE stress scorers (> $300 \mathrm{LCU})$ and low LE stress scorers $(\leq 300 \mathrm{LCU})$.

A one-week test-retest reliability study of the QREE among 27 adult male forensic psychiatric outpatients was conducted. The test-retest reliability was significant for all types of 
LE and ranged from .46 for negative uncontrollable LE to .68 for positive uncontrollable LE (test-retest correlation for LE total $=.62$ ).

LE were counted for the entire $\mathrm{T}_{0}-\mathrm{T}_{2}$ period of six months. To study the stability of LE, the LE during the $\mathrm{T}_{0}-\mathrm{T}_{1}$ period and the $\mathrm{T}_{1}-\mathrm{T}_{2}$ period were compared.

\section{Data analysis}

Changes in scores on (categories of) LE between two measurements and changes in SWB were analyzed using paired sample T-tests. Stability of (categories of) LE was studied using Pearson's product moment correlations, as was the relationship between (categories of) LE and SWB. The differences in SWB between patients with a low level of LE and patients with a high level of LE per category were examined using Student's T-tests. Repeated Measures ANOVAs were performed to explore the relationship between different categories of LE and change in global subjective well-being, using dichotomized categories of life events (median-split). Partial eta $^{2}$ values for within-subject contrasts are shown; an effect size of .01 was considered small, .06 medium, and .14 large (Cohen, 1988). The influence of a diagnosis of any PD and of borderline PD or traits was examined using a repeated measures ANOVA between the categories of LE and change on Cantril's ladder, with any PD and borderline PD and traits as covariates. The two-sided significance levels were set at $\alpha \leq 0.05$.

\section{RESULTS}

\section{Patient characteristics}

Patients $(\mathrm{N}=56)$ were adult male forensic outpatients with an average age of 38 years $(\mathrm{SD}=$ 8.8). A third of them lived alone, while $12.5 \%$ still lived with their parents. Almost half of the patients had children (48.2\%). Most patients had daily or weekly contact with a family member $(87.5 \%)$. Only one third had paid employment. Patients often had financial debts (excluding mortgages; $58.9 \%$ ), this was 21,000 euros on average. More than 50 percent of the patients lived on social welfare.

Twenty-nine percent of the patients did not meet the required number of traits of one or more PDs to reach the clinical threshold for a PD diagnosis according to the Diagnostic and Statistical Manual of Mental Disorders (DSM-IV-TR; APA, 2000), but had one or more PD traits. Most patients were classified as having a PD not otherwise specified (35.7\%), and $21.4 \%$ had a 


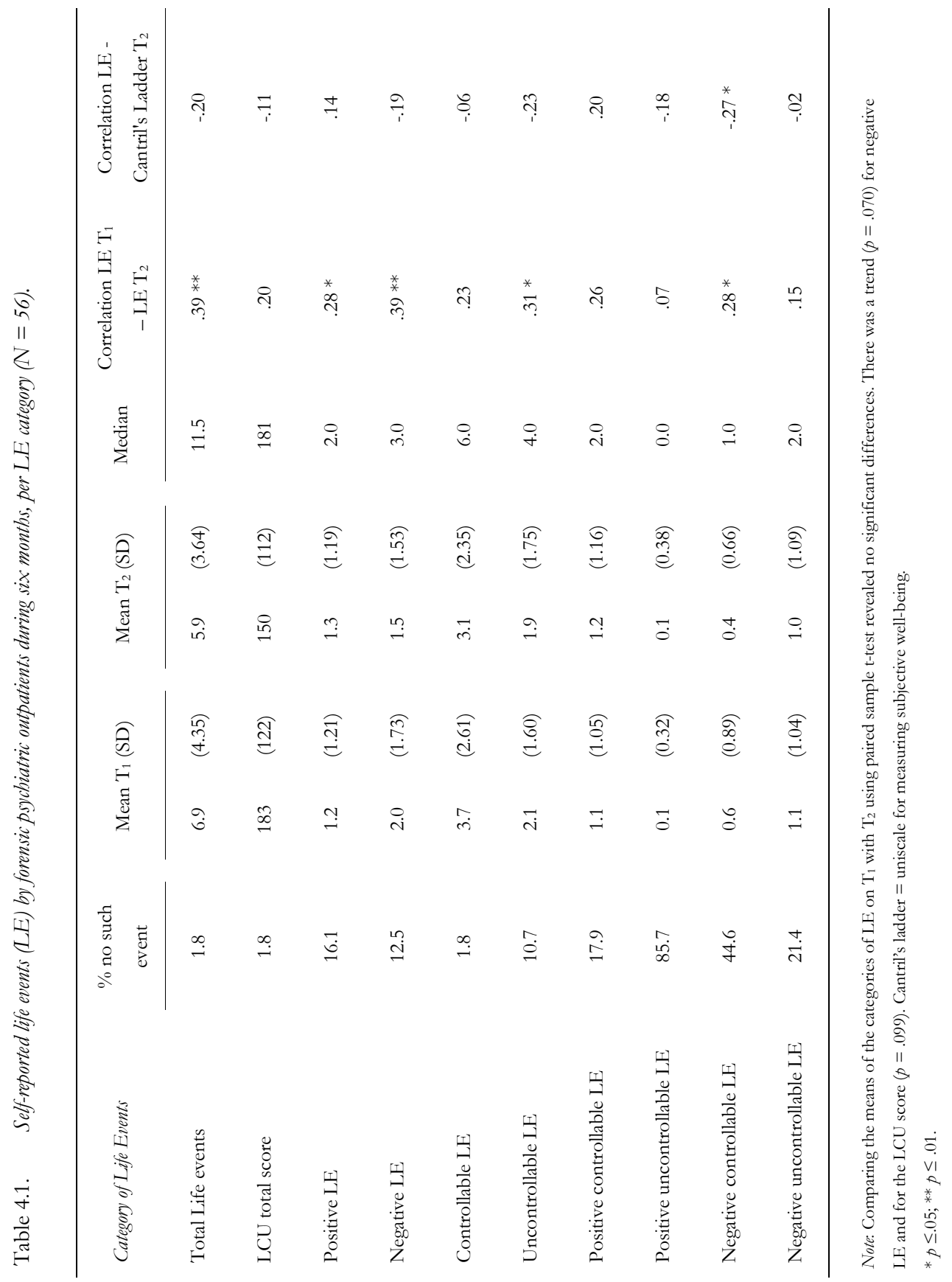




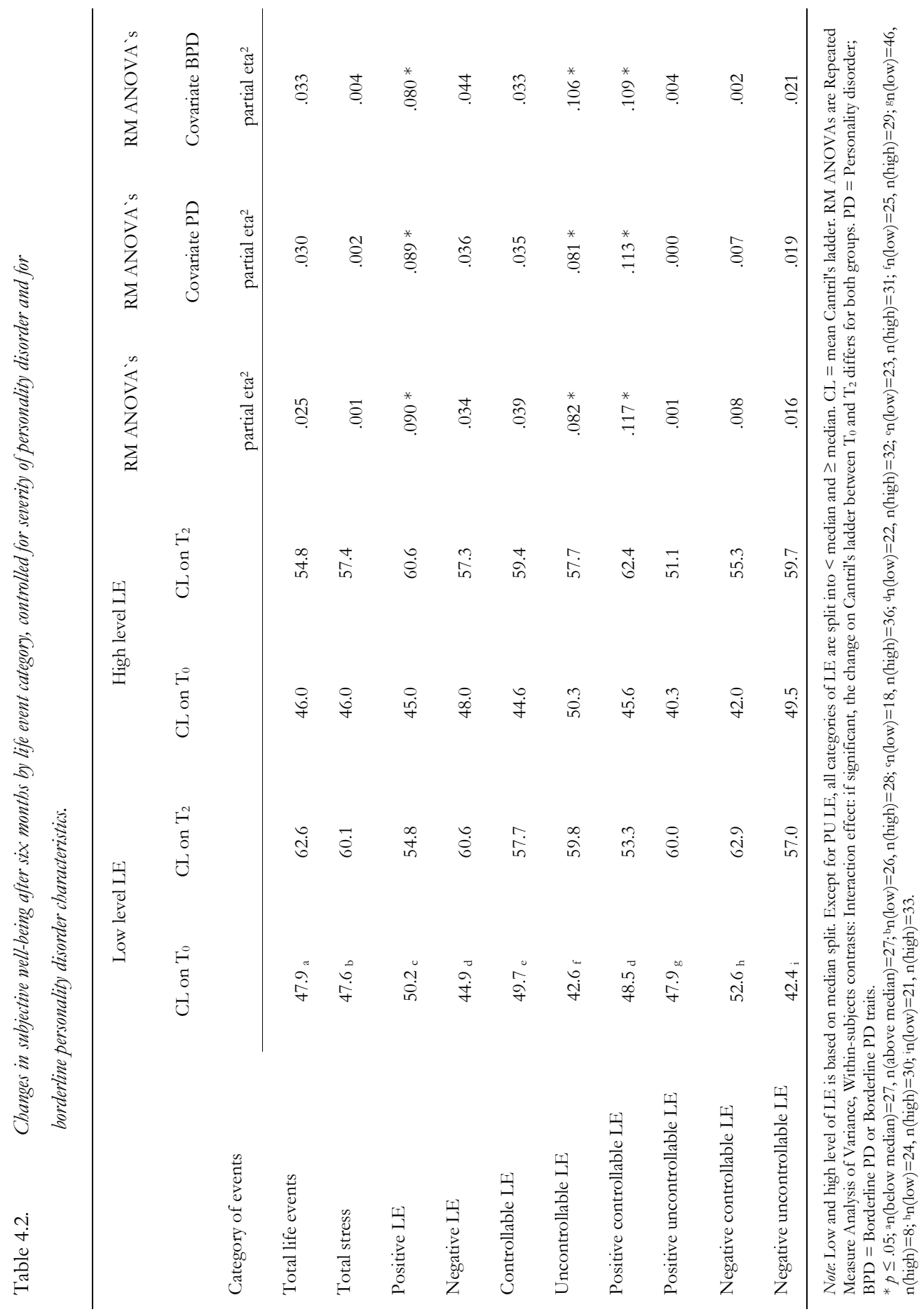




\section{CHAPTER 4}

cluster B PD (antisocial, borderline or narcissistic PD). None of the patients was diagnosed with a cluster A PD, and $10.7 \%$ had a cluster C PD. Less than a third of the patients had never been treated in a mental health facility before; $19.6 \%$ had been previously hospitalised in a psychiatric institution.

\section{Life events over the six month period $\left(T_{0}-T_{2}\right)$}

The 56 patients reported 715 life events during the six months between $\mathrm{T}_{0}$ and $\mathrm{T}_{2}$. On average, patients mentioned 12.8 life events $(\mathrm{SD}=6.67)$, with a minimum of 0 and a maximum of 31 events. No outliers were found (mean $\pm 3 *$ SD). Using the LCU, 48.1\% of the patients displayed a low level of stressful life events. Patients mentioned about the same number of LE for the $T_{0}-T_{1}$ period and the $T_{1}-T_{2}$ period.

Nine patients $(16.1 \%)$ did not report any positive event, and $12.5 \%$ did not mention any negative event during the six months. Only one patient did not register any controllable LE, whereas $10.7 \%$ of the patients did not mention any uncontrollable LE. Four positive uncontrollable events were included per three month period; $14.3 \%$ of the patients named such an event. A majority of the patients (82.1\%) listed one or more positive controllable LE and just over half mentioned one or more negative controllable LE (55.4\%). Twenty-one percent of the patients did not experience any negative uncontrollable LE during the six months.

Besides a similar number of LE in general, patients also mentioned similar numbers of LE per category during the $T_{0}-T_{1}$ period and the $T_{1}-T_{2}$ period. Furthermore, the number of LE mentioned by the patients at both assessment points correlated significantly for five categories of LE (between $r=.28$ for positive LE and $r=.39$ for negative LE), but not for LCU scores, nor for positive or negative uncontrollable LE, positive controllable LE or controllable LE (see Table 4.1).

\section{Change in global subjective well-being}

On average, patients were more satisfied at $\mathrm{T}_{2}$ than at $\mathrm{T}_{0}$, as measured with Cantril's ladder $\left(\mathrm{M}_{\mathrm{T} 0}=46.9 ; \mathrm{M}_{\mathrm{T} 2}=59.0 ; \mathrm{t}=-4.24 ; \mathrm{df}=55 ; p \leq 001\right)$. The average change in global SWB was $12.1 \mathrm{~mm}(\mathrm{SD}=21.3)$. The differences ranged from $-51 \mathrm{~mm}$ to $+83 \mathrm{~mm}$. Both extreme scores were outliers and were not used in subsequent analyses. 


\section{Relationship of categories of life events with change in global subjective well-being}

No significant differences on global SWB at $\mathrm{T}_{0}$ or at $\mathrm{T}_{2}$ were found between patients with a low level of LE and patients with a high level of LE of either category (P/N or C/U) during the six months between $\mathrm{T}_{0}$ and $\mathrm{T}_{2}$ nor between patients with a high stressful LE score (in terms of LCU) and patients with a low stressful LE score $(\mathrm{n}=54)$. Only negative controllable LE during the $\mathrm{T}_{0}-\mathrm{T}_{2}$ period correlated significantly with Cantril's ladder at $\mathrm{T}_{2}(\mathrm{r}=-.27 ; p=$ .045; Table 4.1).

Positive LE, positive controllable LE and uncontrollable LE were related to a significant difference in change on SWB between the group with a low level of LE and the group with a high level of LE on each of these three categories $\left(\mathrm{F}_{\mathrm{PLE}}[1,52]=5.161 ; p=.027\right.$; $\mathrm{F}_{\mathrm{PCLE}}[1,52]=$ 6.905; $p=.011 ; \mathrm{F}_{\mathrm{ULE}}[1,52]=4.655 ; p=.036$; Table 4.2). Both positive and positive controllable LE were related to a larger increase in SWB. A low level of uncontrollable LE correlated with a larger increase in SWB than a high level of uncontrollable LE. All three differences had medium effect sizes; partial eta ${ }^{2}$ was .082, .090, and .117 for uncontrollable, positive and positive controllable LE, respectively. The significant relationships between positive and positive controllable LE and the change in SWB did not change when controlling for any PD or borderline PD or traits: the values of $\operatorname{eta}^{2}$ remained approximately the same (Table 4.2). The relationship between uncontrollable LE and change in SWB increased when controlled for borderline traits; the test of the within-subjects contrast of the covariate was, however, not significant $(p=.08)$.

\section{DISCUSSION}

Forensic psychiatric outpatients with a personality disorder seem to have a stable, chronic pattern of LE in general, of positive and negative LE, of negative controllable LE and of uncontrollable LE. The patterns for the other (sub-) categories were not stable. Although it could not be empirically tested, the current forensic psychiatric patient sample seems to encounter more LE in total than the PD patients examined by Pagano and colleagues (2004); the last group reported on average nine LE during three years, whereas our patients reported on average thirteen LE during six months. Our patients more often reported negative than positive life events. However, the difference was not as large as reported in another study (Pagano et al., 2004), in which a ratio of 2.3 negative to 1 positive LE was reported, whereas 


\section{CHAPTER 4}

we found a ratio of 1.4 to 1 . Most patients reported more controllable events whereas fewer patients stated to have experienced uncontrollable events.

General Strain Theory (Agnew, 1992) links negative LE with SWB. We found one significant correlation, namely between negative controllable LE and SWB. Despite indications to the contrary from other studies (see e.g. Heikkinen et al., 1997; Rahe, 1975), none of the other categories of LE displayed a relationship with SWB in this sample. A high level of positive controllable LE was related to a larger positive change in SWB in our sample compared to a low level, which was also reported in a group of college students (Zautra \& Reich, 1980). A high level of positive LE was also related to a larger positive change in SWB, which was not found in another study (Streiner et al., 1981). A high level of uncontrollable LE was related to a smaller change in SWB, compared to patients with a low level of uncontrollable LE. This was also discovered in a study among the general population (Streiner et al., 1981). These relationships were not modified by suffering from a PD or PD-traits nor by borderline PD characteristics.

There are several limitations to the present study. Firstly, the main limitation is that only 56 of the total sample of 135 patients participated in all phases of the study. Although the participating patients hardly differed from drop-outs, biases can have occurred due to the limited response rate. Secondly, we assumed that global subjective well-being can be measured by a single item, in this case Cantril's ladder. Subjective well-being or quality of life have been studied for a long time, but thus far no consensus on their operationalization exists. By using a single measure, we surpassed the possibility that subjective well-being is not a single entity, but has different faces, depending on, for instance, the life-domain studied or the disease specific background of patients. However, Cantril's ladder is positioned at the end of the LQoLP interview, thus, after all life domains have been discussed with the patient. A patient will therefore be likely to take several aspects of his life into account when evaluating his overall quality of life at that moment (see Chapter 2), than when it had been asked at the beginning of the interview or outside the interview context.

Several remarks can be made concerning the measurement of LE based on this study. Firstly, the total number of life events, either simply counted or weighed as by Miller and Rahe (1997), has been assumed to negatively influence life satisfaction. This general idea should be subjected to closer scrutiny (see also Streiner et al., 1981). Several categories of life events showed a relationship with positive change in SWB in this study. Thus, total number of LE 
seems less useful in relation to SWB. It is advisable to differentiate between positive, negative, controllable and uncontrollable LE, and combinations of these categories. Secondly, the number of events differs greatly between LE measures used, for instance, the RLCQ (Rahe, 1975) lists 76 events; the QREE (Van der Willige et al., 1985) uses 115 items to measure 59 events; Heikkinen and colleagues (1997) used 32 questions to ask about life events; and Pagano et al. (2004) used a list containing 82 LE. No golden standard seems to exist in LE research, thus limiting the possibilities of comparative research. Thirdly, the procedures by which LE are categorised on dimensions are often unclear in the research literature. Most authors simply state that the events were grouped (see e.g. Pagano et al., 2004; Taylor, 2005). LE can also be rated by the subject and subsequently categorised in terms of their perceived impact, desirability and controllability (Jovev \& Jackson, 2006; Streiner et al., 1981). Self-rated pleasantness and unpleasantness of an event can also replace more objective categorization of LE into positive and negative LE. These differences in the operationalization of categories of life events may partly account for differences in findings between studies.

Although negative LE have previously been found to correlate negatively with the level of subsequent SWB, negative LE had no influence on the change in SWB of patients with PD in this study. Using a dynamic equilibrium model, Headey and Wearing (1989) hypothesized that each person has a normal pattern of LE and a normal level of SWB, both predictable on the basis of stable personality characteristics. Only deviations from the normal pattern of LE lead to changes in the normal level of SWB (see also Suh et al., 1996). In the current study, no correlations were found between the number of (positive) controllable LE at both measurements, between the number of positive uncontrollable LE at both measurements, and also not between the number of negative uncontrollable LE at both measurements.

Although the average number of (positive) controllable LE did not change, the absence of a correlation may indicate that patients with PD do not have a stable pattern of (positive) controllable LE, as opposed to the stable pattern of negative LE, uncontrollable LE and total LE. Patients with PD may be used to negative LE. This may result in (relative) immunity to the impact of such events on subjective well-being. People tend to adapt to their circumstances, and these patients may have adapted to a life in which negative LE are commonplace. According to Pagano and colleagues (2004), patients with PD tend to behave in a way in which they are more likely to encounter adverse events. We also found that subjective well-being in this forensic psychiatric sample increased over time. In general, individuals tend to adapt their 


\section{CHAPTER 4}

expectations to less favourable circumstances and shift their life goals to more attainable ones (see e.g. Goodinson \& Singleton, 1989). This shift may contribute to higher levels of life satisfaction despite the occurrence of negative controllable or uncontrollable LE. The general mechanism of response shift, as described by Schwartz and Sprangers (2000), may provide an explanation for the change in overall SWB. They offered three explanations for response shift: reconceptualisation, reprioritisation and recalibration. The first explanation refers to a change in the concept of QoL over time. The second, reprioritisation, explains the shift from a rebalance in the concept, by which the same predictors are used but with different values. Following the third explanation, persons can change their point of reference and adopt a different benchmark. The mechanisms or events leading to the increase in SWB demonstrated in the present study merit further exploration, keeping in mind the role of positive controllable events. The function of social relationships and social support in the occurrence and consequences of strain in this patient population is of interest. For instance, Cullen and Wright (1997) argued that social support is a major intervening variable that insulates strained individuals from coping by criminal means. Social support can also have a buffering effect on stress/strain, because support involves the transfer of resources, especially in reciprocal relationships. However, several of the diagnostic criteria for PDs, especially PDs from cluster B, (APA, 2000) are related to the inability to engage in or maintain social relationships or to participate responsibly in social institutions. This possible discrepancy is worthwhile studying, since research finding could help determine whether clinicians need to focus either on strengthening pro-social relationships (which could assist patients in choosing non-criminal coping strategies) or on limiting relationships in order to limit sources of strain. The possible role of psychiatric treatment in the increase in SWB should also be considered, because some of the patients in this study were undergoing treatment during the assessment period. The positive controllable events most mentioned were: holidays, having made an important decision about one's future, entering a new intimate relationship, an important buy and return to work. These are events which a person can influence. In forensic outpatient treatment, such events can be targeted and patients can be encouraged to engage in behaviour resulting in these events. In line with the Good Lives Model of Ward (2002), their subjective well-being may improve as a result of an increase in positive events, which could in turn reduce the patient's risk of re-offending. 


\section{Chapter 5}

\section{Changes in quality of life after six months}




\section{CHAPTER 5}

\section{ABstract}

Over the last few decades, quality of life (QoL) has become an important outcome measure for treatment success in general psychiatry. So far, this is not the case in forensic psychiatry, although several (treatment) models include factors related to QoL, such as the Good Lives Model. In this study, we investigated change in QoL over a six-month treatment period in 102 forensic outpatients with personality disorders (PDs) or traits of PDs. To this end, the extended Dutch version of the Lancashire Quality of Life Profile was used.

Objective indicators of QoL did not change during these six months, with one exception: significantly more patients reported to have a helping friend at the second time point. Eight of 10 subjective indicators of QoL changed differentially for patients with different baseline levels of QoL. Those with low scores showed significant improvement on nine indicators whereas those with high scores reported a lower QoL after six months on five indicators. Treatment intensity, mood and severity of PD did not mediate these changes. Subjective QoL deserves consideration as an important theoretical construct in forensic treatment and the Lancashire QoL Profile is sensitive to change during such treatment. 


\section{INTRODUCTION}

Quality of life (QoL) has become an important outcome measure for treatment in general psychiatry over the last few decades, in particular for patients with chronic diseases (Fakhoury $\&$ Priebe, 2002). So far, this is not the case in forensic psychiatry (van Nieuwenhuizen, Schene, $\&$ Koeter, 2002). In this Chapter, we explore how QoL changes in a forensic outpatient sample during the course of a six-month treatment period.

In forensic psychiatry, the primary treatment goal is the reduction of risk of future offending. Several objective life circumstances, such as adequate financial management, church attendance and work, have been identified as showing a preventive effect on re-offending (Ellis \& Peterson, 1996; Gendreau, Goggin, \& Gray, 2000; Goggin, Gendreau, \& Gray, 1998; Monahan et al., 2001). Positive subjective well-being has also been found to be related to a reduced chance of re-offending (Draine \& Solomon, 1994).

Besides these empirical indications of a relationship between objective and subjective indicators of QoL and the risk of recidivism, several theoretical (treatment) models in forensic psychiatry have included predictors related to the QoL concept. For instance, the Good Lives Model (Ward, 2002) stipulates that every patient strives for a good and fulfilling life and that such a life diminishes the chance of re-offending in forensic psychiatric patients (Ward \& Brown, 2004). In the Risk-Need-Responsivity model of forensic treatment and risk-assessment (Andrews, Bonta, \& Wormith, 2006), well-being is included as a factor related to responsivity and several objective indicators are considered as risk or need factors.

\section{Quality of life}

According to Lehman (1983), QoL refers to a sense of well-being and satisfaction experienced by people under their current life conditions. To cover life as a whole, definitions of QoL employed in psychiatric research mostly use indicators in a range of life domains (Lehman, 1983; Oliver, Huxley, Bridges, \& Mohamad, 1996; WHOQOL Group, 1998). Diener and Suh (1997) mentioned three philosophical approaches to the 'good life' resulting in three different categories of indicators; subjective, economic and social indicators. Subsequently, economic and social indicators were combined, leaving these indicators and subjective good life evaluations as the two main categories, which are now generally accepted (Farquhar, 1995; Glatzer \& Mohr, 1987; Goodinson \& Singleton, 1989). 


\section{CHAPTER 5}

Within the subjective domain, internal and external dimensions have been distinguished (van Nieuwenhuizen, 1998). The internal dimension measures domains related to personal autonomy (see Boevink, Wolf, van Nieuwenhuizen, \& Schene, 1995), comprising positive and negative self-esteem, life fulfilment and life framework. The external dimension consists of life domain-specific subjective ratings, for instance the domains living arrangements and health.

\section{Quality of life in outpatients with personality disorders}

Several studies have compared the quality of life of patients with personality disorders (PD; American Psychiatric Association [APA], 2000) in community-based treatment with other outpatient populations. PD outpatients were less satisfied with their lives than outpatients with schizophrenia (see Chapter 2). Compared with outpatients with any Axis I disorder, PD outpatients did not differ on global QoL (Trompenaars, Masthoff, van Heck, Hodiamont, \& de Vries, 2006), but they were less satisfied with their life circumstances, including their financial situation, leisure activities and home environment (Masthoff, Trompenaars, van Heck, Hodiamont, \& de Vries, 2006). Also, compared with the general population, PD outpatients were less satisfied with their lives in general (Narud, Mykletun, \& Dahl, 2005). Co-morbidity of a PD with an Axis I disorder (APA, 2000) was associated with a lower subjective QoL compared to outpatients with either a PD or an Axis I disorder (Masthoff et al., 2006). Furthermore, patients with a cluster B PD demonstrated a lower QoL than patients with other PDs (Chen et al., 2006). More specifically, patients with antisocial PD characteristics have been found to be more dissatisfied than patients without such traits (Sareen, Stein, Cox, \& Hassard, 2004). In general, patients with PD, especially cluster B PDs, tend to be less satisfied than patients without this type of disorder.

\section{Change in quality of life in (forensic) outpatients}

Changes in QoL in forensic (out)patients during treatment have not been studied previously, as far as we could determine. One study examined change of QoL in general psychiatric (out)patients with PD or without a PD and used a baseline and follow-up measurement of QoL (Karterud et al., 2003). They found that QoL improved between admission and discharge for these patients and this improvement was equally large for those without a PD. Only a quarter $(28 \%)$ of this sample was male. The largest subgroup in the Karterud et al. sample 
consisted of patients with a borderline PD (22.1\%). Very few patients had one of the other cluster B PDs (i.e. antisocial, narcissistic or histrionic).

Several factors have been identified as important mediators with regard to (change in) QoL in psychiatric patients. Severity of Axis I psychopathology, especially mood symptoms or negative affect (Ruggeri et al., 2005), has been found to influence QoL negatively (Fakhoury \& Priebe, 2002). Although Karterud et al. (2003) did not find a relationship between treatment intensity and change in QoL, we believe it is an important factor to consider in relation to treatment outcome in forensic patients, because treatment intensity predicted significantly lower violent recidivism rates in psychiatric patients in the MacArthur study on risk assessment of whom the majority had received both verbal therapy and medication (Monahan et al., 2001).

\section{Research questions}

Over a six month period of community-based treatment in male forensic psychiatric outpatients:

(1) What are the changes in objective and subjective quality of life (both general and domainspecific)?

(2) Do objective and subjective indicators of QoL improve differently in patients with a full PD than in patients with PD traits?

(3) If demonstrated, is the change in QoL related to treatment intensity?

\section{METHOD}

\section{Design}

In a multi-site study, we assessed 135 patients in community-based forensic psychiatric treatment on quality of life at two time-points $\left(T_{0}\right.$ and $\left.T_{2}\right)$ with a six months interval. The sample consisted of adult male patients diagnosed with a PD or with PD traits (APA, 2000).

\section{Subjects}

The average age of the 135 male patients was 37.5 years $(S D=10.4)$. About one third had not finished formal education or only finished primary school. For a third of the patients, the treatment in the forensic outpatient facility was their first contact with mental health services, while two thirds had either been previously hospitalised in a psychiatric institution or had been 


\section{CHAPTER 5}

treated in a community-based psychiatric facility before. Clinicians who were trained in using the Diagnostic and Statistical Manual of Mental disorders (DSM-IV-TR; APA, 2000) diagnosed $69.6 \%$ of the patients as suffering from a PD while $30.4 \%$ of the patients did not reach the threshold for a PD, but had traits of one or more PDs. Of those with a PD, 54\% obtained a diagnosis of PD Not Otherwise Specified and 33\% a diagnosis of a cluster B PD (antisocial, borderline or narcissistic PD).

All $135 \mathrm{~T}_{0}$ patients were again approached by the research staff six months later $\left(\mathrm{T}_{2}\right)$, at which time 102 patients $(75.6 \%)$ participated. Those participating and those not participating ( $\mathrm{n}=33$ ) were compared on demographic, criminal and treatment background variables and on QoL indicators at $\mathrm{T}_{0}$. Although just as many responders as drop-outs had ever been convicted, responders had fewer previous convictions (2.6 vs. $4.9 ; \mathrm{F}=4.805 ; p=.030)$ and the drop-outs less often had a co-morbid Axis I disorder (10.3\% vs. $\left.28.3 \% ; \chi^{2}[1]=3.98 ; p=.046\right)$. No differences were found between responders and drop-outs with regard to age, years of education, IQ, framework of treatment (court-ordered or not), subjective indicators of QoL, objective indicators of QoL and overall subjective QoL at $\mathrm{T}_{0}$.

\section{Measures}

Quality of life

Quality of life was assessed by means of the extended Dutch version of the Lancashire Quality of Life Profile (LQoLP; van Nieuwenhuizen, Schene, \& Koeter, 1998), a structured interview which covers seven life domains: leisure and social participation (15 objective and 7 subjective items), religion ( 2 objective items), finances (8 objective and 2 subjective items), living arrangements (4 subjective and 4 objective items), legal status and safety (6 objective and 2 subjective items), family relations (5 objective and 3 subjective items), and health ( 9 objective and 7 subjective items).

Besides information on domain-specific QoL, the LQoLP includes an internal dimension of subjective QoL (van Nieuwenhuizen, 1998). This dimension comprises the subscales positive and negative self-esteem of the Self-Esteem Scale (Rosenberg, 1965; in van Nieuwenhuizen, 1998; and in Oliver et al., 1996). Five positively labelled items were used to indicate positive self-esteem, for instance "You feel you have a number of good qualities" and five negatively phrased items were used to indicate negative self-esteem, for instance "You feel you do not have much to be proud of" (see Oliver et al., 1996, p. 255). For the analyses, the 
scores on the negative self-esteem subscale were reversed: a high score was therefore positive and a low score was negative.

The two subscales of the Life Regard Index (Dutch adaptation by Debats, van der Lubbe, \& Wezeman, 1993) were also part of the internal dimension: the Framework scale, which assesses "the degree to which individuals can envision their lives within some meaningful perspective or have derived a set of life-goals or philosophy of life from these" (Debats, 1996a, p. 14) and the Fulfilment scale, which "measures the degree to which people see themselves as having fulfilled or as being in the process of fulfilling their framework of lifegoals" (Debats, 1996a, p. 14).

At the end of the interview, the patient is asked to rate his overall life quality at that time, by indicating on a $100 \mathrm{~mm}$ ladder how he perceives his life on a continuum ranging from life at its worst to life at its best. This is called Cantril's ladder (Cantril, 1965, in: van Nieuwenhuizen, Schene, Boevink, \& Wolf, 1998).

The Life Satisfaction Scale is used throughout the interview. The patient is asked to rate his satisfaction on the 25 subjective items of the six domains, ranging from one (cannot be worse) to seven (cannot be better). For each domain, a mean score is calculated by adding the scores per domain and dividing the total by the number of items used. Next, scores on the six subjective domains, the four internal indicators and on Cantril's ladder were divided into a low score group ( $\leq 25 \%$ ), a medium score group (between $25 \%$ and $75 \%$ ), and a high score category $(\geq$ $75 \%$, in order to explore changes in QoL ratings for these different subgroups.

Eleven objective indicators of QoL were used: one objective indicator was chosen from each of the domains of the original LQoLP (see Oliver et al., 1996; Ruggeri, Warner, Bisoffi, \& Fontecedro, 2001; Ruggeri et al., 2005; van Nieuwenhuizen, Schene, Boevink, \& Wolf, 1998): having work; number of leisure activities; having a helping friend; being religious; living alone; having debts; frequency of family contact; psychiatric hospitalisation in the previous year; and having been a victim of violence. The indicator 'having an intimate relationship' was added because of previously found correlations with subjective QoL (see Ruggeri et al., 2001; Ruggeri et al., 2005). We also added whether or not the patient had children.

The internal consistency of the Dutch version of the LQoLP was adequate to good (Cronbach's alpha ranges between 0.62 - 0.84). The two-week test-retest reliability ranged from 0.67 to 0.90 (van Nieuwenhuizen, 1998; van Nieuwenhuizen, Schene, Boevink, \& Wolf, 1998). 


\section{CHAPTER 5}

The Affect Balance scale (Bradburn, 1969; in van Nieuwenhuizen, 1998; Oliver et al., 1996) is included in the LQoLP. This scale was used to assess negative affect (NA), which can be used as an indicator of mood. Sixty-three patients (61.9\%) scored high on NA and $38.2 \%$ of the patients had low NA.

In several studies, the LQoLP has been used to measure change in QoL in psychiatric outpatients suffering from schizophrenia or other psychotic disorders, and it proved to be sensitive to change, especially the subjective indicators of QoL (Hansson \& Björkman, 2007; Oliver et al., 1996; Ruggeri et al., 2005).

\section{Treatment intensity}

We used the number of treatment contacts registered for the period between $T_{0}$ and $T_{2}$ as an indicator of treatment intensity. Not every treatment facility offered the same types of treatment. However, the professional background of clinicians (i.e. clinical psychologists and psychiatrists) was comparable. Treatment of these forensic outpatients generally consists of psychotherapy, psychiatric consultation, pharmacotherapy, and social assistance by a psychiatric nurse or social worker. A relapse prevention model often guides treatment and cognitive behavioural therapy is generally applied. The forms of therapy can be given either individually, in groups, or in a couple format. We distinguished between high and low treatment intensity, based on dichotomising the number of treatment contacts between $T_{0}$ and $\mathrm{T}_{2}$ using a median split (median $=21$ contacts). Fifty patients had fewer than 21 treatment sessions during the six month period (= low treatment intensity) and 52 patients had 21 or more sessions (= high treatment intensity).

\section{Statistical analyses}

Changes in objective quality of life were analysed using non-parametric McNemar tests. McNemar's test is a method used on nominal data to determine whether the row and column marginal frequencies $(\mathrm{b}=-/+$; $\mathrm{c}=+/-)$ are equal. It is applied to $2 \times 2$ contingency tables. The formula is:

$$
\chi^{2}=\frac{(|b-c|-1)^{2}}{(b+c)}
$$


(Dawson-Saunders \& Trapp, 1994, p. 155). These tests were repeated in order to study change in objective indicators of QoL, while controlling for treatment intensity, PD or PD traits and for NA.

The within-subject contrasts of repeated measures ANOVAs were used as indicators of differences in change of subjective indicators of QoL and of global QoL between patients who initially (at $\mathrm{T}_{0}$ ) rated their lives as low, medium or high on each of the indicators and on global QoL. This analysis measures an interaction effect: if significant, the change in subjective QoL between $T_{0}$ and $T_{2}$ differs for the three groups (see Bijleveld \& van der Kamp, 1998). Partial eta $^{2}$ values for within-subject contrasts are reported; an effect size of .01 is considered small, .06 medium, and .14 large (Cohen, 1988). Paired sample $t$-tests were used to explore changes in each of the subjective domains and in global QoL in general and per category.

The relationship of treatment intensity, the presence of a PD or PD traits and of NA with change in indicators of QoL was studied using repeated measures ANOVA for subjective indicators of QoL and for global QoL, with the three covariates. Within-subject contrasts were calculated to study the influence these variables had on change in each of the indicators. A Bonferroni correction was applied in these analyses. The threshold for significance in these analyses was set at $\alpha \leq .017$.

\section{RESULTS}

\section{Change in objective indicators of quality of life}

At $\mathrm{T}_{0}$, half of the patients had an intimate relationship and half of them had children (see Table 5.1). Most patients had daily or weekly contact with family members and about three-quarters of the patients had a friend who would help them if needed. Just over half of the patients lived together with others, either the partner, parents or other persons. About a third of the patients had a job, and almost $60 \%$ of the patients had financial debts (mortgages not included). Very few patients had been hospitalised because of psychiatric problems the year prior to the interview. More than half of the sample considered themselves religious. The number of leisure activities patients engaged in was on average three $\left(\mathrm{M}_{0}=3.2 ; \mathrm{SD}_{0}=0.70 ; \mathrm{M}_{1}=3.1 ; \mathrm{SD}_{1}\right.$ $=0.78$; ns).

Of the objective indicators of quality of life, 'having a helping friend' changed significantly in a positive direction from $\mathrm{T}_{0}$ to $\mathrm{T}_{1}$ (McNemar: $\left.p=.008\right)$. Patients with a high 


\section{CHAPTER 5}

level of NA stated to have gained a helping friend more often than that they had lost one (McNemar: $p=.003)$; this was not the case for patients with a low level of negative affect at $\mathrm{T}_{0}$.

Table 5.1. Change in objective indicators of quality of life between $T_{0}$ and $T_{2}(\mathrm{n}=102)$.

\begin{tabular}{|c|c|c|c|c|}
\hline \multirow[b]{2}{*}{ Objective indicators of $Q_{0} \mathrm{~L}$} & \multicolumn{2}{|c|}{$\mathrm{T}_{0}$} & \multicolumn{2}{|c|}{$\mathrm{T}_{2}$} \\
\hline & $P_{Y E S}$ & (n) & $P_{\mathrm{YES}}$ & (n) \\
\hline Intimate relationship & 52.0 & (53) & 52.0 & (53) \\
\hline Daily or weekly family contact & 79.4 & (81) & 76.5 & (78) \\
\hline Having children & 48.0 & $(49)$ & 50.0 & (51) \\
\hline Having a helping friend $* *$ & 72.5 & (74) & 84.3 & (86) \\
\hline Living with others & 56.9 & (58) & 54.9 & (56) \\
\hline Work & 36.3 & $(37)$ & 40.2 & (41) \\
\hline Having financial debts & 57.8 & (59) & 59.8 & (61) \\
\hline Being religious & 54.9 & (56) & 52.0 & (53) \\
\hline Psychiatric hospitalisation previous year & 5.9 & (6) & 2.9 & (3) \\
\hline Been a victim of violence previous year & 26.5 & (27) & 24.5 & (25) \\
\hline
\end{tabular}

Note. Cells represent percentages of patients who scored positively on the indicator. QoL = quality of life. $\mathrm{P}=$ percentage. The indicators are dichotomous variables for which Ps and the $\mathrm{n}$ are listed.

$* * p \leq .01$.

\section{Change in subjective quality of life}

At $T_{0}$ and at $T_{2}$, patients were satisfied with Leisure time and social participation, with Living arrangements and Safety (see Table 5.2). With Finances, Health and Family, patients were neither satisfied nor dissatisfied. Patients scored very high on Positive self-esteem and on Life Framework, and they assessed their Life Fulfilment and Negative self-esteem positively. Overall, patients rated their life satisfaction positively. The subjective domain-specific QoL and patients' Positive self-esteem did not change significantly between $\mathrm{T}_{0}$ and $\mathrm{T}_{2}$, whereas patients' Negative self-esteem, Life fulfilment, Life framework and overall subjective QoL all improved over the six-months course. 
Table 5.2. $\quad$ Subjective quality of life indicators at $T_{0}$ and $T_{2}(n=102)$.

\begin{tabular}{|c|c|c|c|c|}
\hline & \multicolumn{2}{|c|}{$\mathrm{T}_{0}$} & \multicolumn{2}{|c|}{$\mathrm{T}_{2}$} \\
\hline Subjective QoL indicators & mean & $(\mathrm{SD})$ & mean & $(\mathrm{SD})$ \\
\hline Leisure time and social participation & 4.8 & $(0.89)$ & 4.9 & $(0.83)$ \\
\hline Family & 4.4 & $(1.40)$ & 4.5 & $(1.49)$ \\
\hline Finances & 3.9 & $(1.42)$ & 3.8 & $(1.49)$ \\
\hline Living arrangements & 5.1 & $(1.12)$ & 5.3 & $(1.10)$ \\
\hline Safety & 5.3 & $(0.92)$ & 5.4 & $(1.02)$ \\
\hline Health & 4.5 & $(1.01)$ & 4.6 & $(0.89)$ \\
\hline Positive self-esteem & 5.8 & $(1.33)$ & 6.0 & $(1.32)$ \\
\hline Negative self-esteem ${ }_{\mathrm{a}} * *$ & 4.9 & $(1.57)$ & 5.3 & $(1.55)$ \\
\hline Life framework $* *$ & 5.7 & $(1.13)$ & 6.0 & $(1.02)$ \\
\hline Life fulfilment $* * *$ & 4.8 & $(1.28)$ & 5.1 & $(1.28)$ \\
\hline Cantril's Ladder *** & 49.3 & (23.1) & 58.0 & (19.4) \\
\hline
\end{tabular}

Note. QoL = quality of life; significant differences have been calculated using Paired sample t-tests; except for Cantril's ladder, all scores were transformed into a 1-7 scale, with 1 indicating low QoL and 7 indicating high QoL.

${ }^{\mathrm{a}} \mathrm{n}=101$.

$* p \leq .05 ; * * p \leq .01 ; * * * p \leq .001$.

Patients with a low score on Cantril's ladder at $\mathrm{T}_{0}$ improved more than patients falling in the medium category. Patients with an initially high global QoL score rated their global QoL lower at $\mathrm{T}_{2}$. The difference in slope for the three groups - high, medium and low QoL at $\mathrm{T}_{0}-$ was significant and large in terms of effect size (see Figure 5.1; within-subject contrast: $F[1,99]$ $=21.51 ; p \leq .001 ;$ eta $\left.^{2}=.30\right)$. Patients in the lower quartile improved between $\mathrm{T}_{0}$ and $\mathrm{T}_{2}$ on Cantril's ladder $\left(\mathrm{M}_{0}=20.3 ; \mathrm{SD}_{0}=7.4 ; \mathrm{M}_{2}=43.9 ; \mathrm{SD}_{2}=20.1 ; t[26]=-5.623 ; p \leq .001\right)$ as did patients in the medium category $\left(\mathrm{M}_{0}=49.3 ; \mathrm{SD}_{0}=10.7 ; \mathrm{M}_{2}=58.6 ; \mathrm{SD}_{2}=17.2 ; t[47]=-4.176\right.$; $p \leq .001)$. As can be seen in Figure 5.1, patients in the highest quartile reported a significantly lower overall $\mathrm{QoL}$ at $\mathrm{T}_{2}$ than at $\mathrm{T}_{0}\left(\mathrm{M}_{0}=78.2 ; \mathrm{SD}_{0}=8.8 ; \mathrm{M}_{2}=71.0 ; \mathrm{SD}_{2}=12.0 ; t[26]=2.502\right.$; $p=.019)$. 


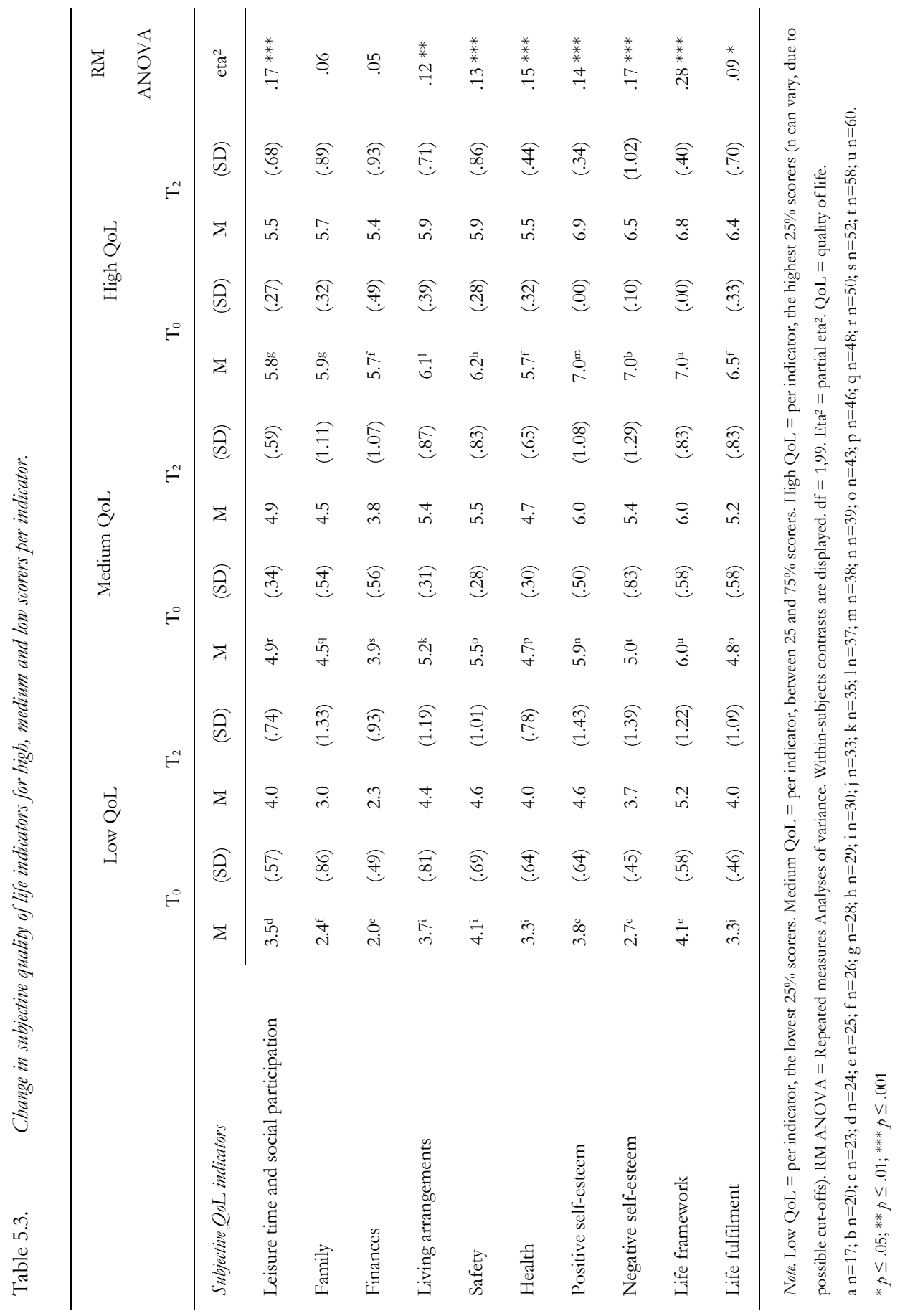


Between $T_{0}$ and $T_{2}$, the satisfaction scores on four of the six life domains changed differentially for patients who were in the low, medium and high QoL category at $\mathrm{T}_{0}$ (Table 5.3). There were no significant changes on the Family and Finances domains $(p=.055$ and $p=$ .082 , respectively). Generally, patients in the low category improved significantly $(p \leq .048)^{4}$ on QoL (except on Finances); patients in the medium category remained stable and patients in the high category reported a significantly lower QoL on three domains (i.e. Leisure time and social participation, Living arrangements and Health; $p \leq .048)$ at $\mathrm{T}_{2}$. Also, on the internal indicators of QoL (i.e. Positive and Negative Self-esteem, Life Fulfilment and Life Framework), patients who initially scored lower improved more than patients in the medium category. Patients in the high category reported significantly lower levels at $T_{2}$ compared to $T_{0}$ on Positive and Negative self-esteem $(p \leq .037)$. The significant effect sizes ranged from medium (eta $\left.{ }^{2}=.09\right)$ for Life Fulfilment to large (eta $\left.{ }^{2}=.28\right)$ for Life Framework. NA had no influence on changes in the indicators of subjective QoL or on change in global QoL which showed significant withinsubject contrasts initially.

Figure 5.1. Change in Cantril's ladder for high, medium and low scorers at $\mathrm{T}_{0}$

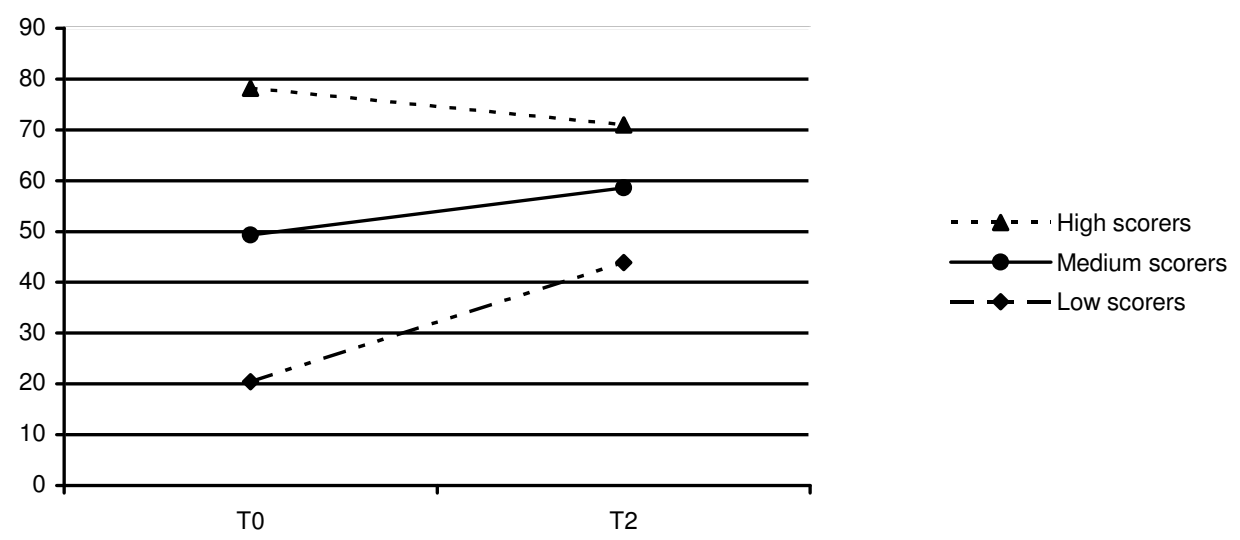

\section{Personality disorder and change in quality of life}

Patients with one or more PDs and those who only had PD traits differed on one objective indicator of QoL: at $\mathrm{T}_{2}$ more patients with PD traits had a job compared to patients with a PD

4 Data on changes in indicators per category (low, medium and high) are not presented here, only (largest) significance levels. Data are available from the first author. 


\section{CHAPTER 5}

$\left(\mathrm{PD}=32.4 \% ; \mathrm{PD}\right.$ traits $\left.=58.1 \% ; \chi^{2}[1]=5.92 ; p=.015\right)$ This was not the case at $\mathrm{T}_{0}$. We found no influence of PD on changes in objective indicators.

The presence of PD or PD traits had no significant relationship to change in indicators of subjective QoL or global QoL.

\section{Treatment intensity and change in quality of life}

Treatment intensity was related to change in one objective indicator of QoL, that is having a helping friend. Patients who received treatment with a higher intensity more often stated to have gained a helping friend between $\mathrm{T}_{0}$ and $\mathrm{T}_{2}$ than to have lost such a friend (McNemar: $p=$ .013). This was not the case for patients with low treatment intensity. Treatment intensity showed a significant relationship with change in Negative self-esteem $(\mathrm{F}[2,97]=6.30 ; p=.014$; eta $\left.^{2}=.06\right)$. Treatment intensity was not significantly related to changes in other domains nor in global QoL.

\section{DISCUSSION}

The idea to utilise quality of life as an outcome measure in forensic psychiatric outpatient treatment is relatively new (van Nieuwenhuizen et al., 2002; Ward, 2002). Although QoL is seldom an explicit treatment target, many objective indicators of QoL are addressed during community-based treatment, such as employment or social relationships. Regarding these objective indicators, we found that most of them did not change during the six month treatment period. The only exception was that more patients stated to have a helping friend at the second time point. Objective indicators of QoL tend to be highly stable as has been shown in previous studies with even much longer time intervals (Oliver et al., 1996; Ruggeri et al., 2005). In contrast to other studies that have demonstrated changes in domain-specific subjective indicators of QoL (Hansson \& Björkman, 2007; Oliver et al., 1996; Ruggeri et al., 2005), on average our forensic outpatients' ratings of their satisfaction on the life domains did not change between $\mathrm{T}_{0}$ and $\mathrm{T}_{2}$. However, patients with an initially low QoL improved significantly on satisfaction with four of the six life domains.

On most internal subjective indicators (e.g. Life fulfilment and Life framework), patients improved between $\mathrm{T}_{0}$ and $\mathrm{T}_{2}$. Furthermore, patients who initially scored low on each distinct indicator improved significantly, on all of these four indicators. 
Patients with a high global QoL score at $\mathrm{T}_{0}$ reported a lower global QoL at $\mathrm{T}_{2}$. Possibly, this relatively high rating at $\mathrm{T}_{0}$ could have been tempered somewhat as a consequence of treatment. Forensic treatment aims to lead patients to take responsibility for past harmful behaviour, which may result in an increase in feelings of guilt and remorse and a concomitant less positive rating of subjective QoL. As such, the decrease in subjective QoL is not necessarily a negative finding for some forensic outpatients. It may be a reflection of a welcome ego-deflation in a person with an unrealistically positive self-image.

On the other hand, the changes in the low and high baseline QoL categories may also be a result of a mechanism referred to as regression towards the mean. However, patients in the medium category of global subjective QoL also improved significantly. So regression towards the mean is not the entire explanation. Another explanation can be derived from the notion that subjective QoL is influenced by expectations, prior experiences, and perceptions of current conditions (Lehman, 1983). It could be that our forensic outpatients lowered their expectations and interpreted their situation more positively after a period in treatment, resulting in higher ratings on subjective QoL. The same mechanism could have applied to patients with an initially high score, for whom treatment made them interpret their life situation more realistically albeit less favourably (Carr, Gibson, \& Robinson, 2001).

Treatment intensity had no effect on most of the changes in subjective indicators of QoL, except for a positive effect on change in negative self-esteem. Moreover, patients who had more intensive treatment gained a helping friend significantly more often. Treatment provided at the forensic outpatient facilities did not explicitly target improvement of (subjective) QoL, which might account for the lack of a relationship between treatment intensity and most indicators. Very few of the previous studies explored change in QoL while QoL was an explicit treatment target (Karterud et al., 2003; Oliver et al., 1996). Furthermore, Karterud et al. (2003) also did not find a relationship between treatment dosage and QoL. However, we did not study the effect of different types of treatment, such as medication or psychotherapy, on change in QoL. It is advisable to examine the effect of different types of treatment on QoL, in future studies.

Based on previous findings (Karterud et al., 2003), PD patients were expected to have a similar change in QoL as patients with PD traits. Only one difference in change in objective QoL was found: PD patients more often gained a helpful friend over the six-month treatment period, which was not the case for patients with PD traits. In line with Karterud et al. (2003), 


\section{CHAPTER 5}

we did not find any differences in terms of change in subjective indicators of QoL. The differences between patients with PD and PD traits on change in QoL seem rather small. Thus, the categorical model of PDs, which uses a specific number of criteria to classify persons as PD vs. PD traits, does not seem useful to identify groups which benefit from treatment concerning their QoL. A dimensional approach to PD (see e.g. Livesley, 2007; Leibing, Jamrozinski, Vormfelde, Stahl, \& Doering, 2008) might be more useful in identifying subgroups which benefit from treatment in terms of increased QoL. Groups could be identified on the basis of personality dimensions, for instance based on the five-factor model of personality (see e.g. Costa \& McCrae, 1992). Evidence has been found for a relation of four of the five personality dimensions with health-related QoL in patients with a mood or anxiety disorder (van Straten, Cuijpers, van Zuuren, Smits, \& Donker, 2007) and for three of the five dimensions in patients with breast cancer (Halim, Derksen, \& van der Staak, 2001).

One of the limitations of the present study lies in the number of follow-up measurements and the interval between the measurements. We used just one follow-up measurement, six months after $\mathrm{T}_{0}$. To establish whether enduring change has taken place, repeated measurements are necessary, because two measurements result in a straight line whereas multiple measurements might result in undulations. We used a six-month follow-up: Karterud and colleagues (2003) used a one-year follow-up and Ruggeri et al. (2005) held a follow-up after two and after six years, which makes comparisons between these studies difficult. To monitor changes in subjective QoL, a shorter follow-up period and higher frequency of measurements is warranted, due to the reported changes after only six months in our sample. However, for changes in objective indicators of QoL, longer follow-up periods are warranted.

The extended Dutch version of the LQoLP contains 151 variables and the interview takes approximately 30 minutes to complete. In order to increase efficiency, it is advisable to weigh the value added by including every item or subscale. Most objective indicators did not change between $T_{0}$ and $T_{2}$. Re-assessing these circumstances every six months does not seem necessary, and these variables could therefore be skipped in short-term re-assessment. However, major life events, which have been found to influence QoL (see Chapter 4; Chan, Ungvari, Shek, \& Leung, 2003; Chand, Mattoo, \& Sharan, 2004; Roy, 1996), should be monitored during treatment to be able to aim interventions at coping with the events and to diminish the likelihood of a negative effect of these events on global well-being. On the other 
hand, regularly monitoring (changes in) global and domain-specific subjective QoL seems advisable, based on the results of this study. After establishing the level of QoL at the start of treatment, and relating it to objective life circumstances, treatment targets with regard to specific indicators of QoL and overall QoL can be set. This can be done as part of a treatment plan based on a Good Lives Model (Ward, 2002; Ward, Mann, \& Gannon, 2007). This model aims at improving the achievement of human goods, which are valued aspects of human functioning and living (Ward \& Brown, 2004, p. 246). The Good Lives Model was developed as a treatment model of offender rehabilitation which is strength based. The central assumption underlying the Good Lives Model is that "an individual is hypothesized to commit criminal offences because he lacks the capabilities to realize valued outcomes in personally fulfilling and socially acceptable ways" (Ward, Mann, \& Gannon, 2007, p. 90). Integrating relevant and changeable indicators of QoL in treatment of forensic outpatients through a Good Lives Model may therefore reduce the risk of re-offending. 



\section{Chapter 6}

\section{Social ties and short-term self-reported delinquent behaviour}

This chapter has (online) been published in a slightly revised version as: Bouman, Y.H.A., Ruiter, C. de, \& Schene, A.H. (in press). Social ties and short-term self-reported delinquent behaviour of forensic personality disordered outpatients. Legal and Criminological Psychology, published online 16 May 2009, URL:http://bpsoc.publisher.ingentaconnect.com/content/bpsoc/lcp/preprints/lcp-269, doi: 10.1348/135532509X444528. Reproduced with permission from Legal and Criminological Psychology (C) The British Psychological Society (2009). 


\section{CHAPTER 6}

\section{ABstract}

In community-based forensic psychiatry, patients' social ties are considered as protective factor in a risk management strategy. However, it is unknown whether these ties actually assist patients to refrain from re-offending. We hypothesised a protective role for social ties in re-offending behaviour. In a sample of forensic outpatients with a DSM-IV personality disorder $(N=55)$, the relationship between social ties (social contacts and participation in social institutions) and shortterm self-reported re-offences was studied within a prospective study design with a 6-month follow-up period. Our results provide evidence for a protective function of club participation. For violent re-offences, social institutions were protective and this protective function remained, even when a patient had network members with a criminal background. Except for work-related contacts, social contacts did not provide protection. The protective effect of social ties, especially club participation, on desistance from re-offending in forensic psychiatric patients merits further attention from researchers and clinicians. 


\section{INTRODUCTION}

In Dutch forensic psychiatry, structured risk assessment tools are generally used as guidance in treatment and risk management of inpatients and outpatients (Hildebrand, Hesper, Spreen, \& Nijman, 2005; Philipse, 2006; de Ruiter \& Hildebrand, 2007). In the Structured Professional Judgment (SPJ; Webster, Douglas, Eaves, \& Hart, 1997) approach to risk assessment, two types of risk factors are distinguished: static and dynamic. Static factors are historical and fixed, such as age at first offence. Dynamic factors can presumably change during treatment. Most risk assessment tools contain a number of dynamic risk factors related to social ties, such as relationships, social network characteristics, work/education and leisure activities (see e.g. Level of Service Inventory-Revised; Andrews \& Bonta, 1995; Historic/Clinical/Risk-management-20; Webster et al., 1997).

Another set of factors, which should be considered in risk assessment and management, are protective factors related to criminal desistance (Miller, 2006; Rogers, 2000). Although some authors consider protective factors as one end on a risk-protection continuum (Costa, Jessor, \& Turbin, 1999; Hawkins, Catalano, \& Miller, 1992; Webster, Martin, Brink, Nicholls, \& Middleton, 2004), others ascribe a separate role to protective factors (Farrington \& Loeber, 2000; Fitzpatrick, 1997). Presumably, protective factors can buffer risk factors and diminish the chance of re-offending even in high risk persons. Nevertheless, these factors are rarely separately considered in risk assessment research in adults with three exceptions: the Inventory of Offender Risk, Needs, and Strengths (IORNS; Miller, 2006), the Short Term Assessment of Risk and Treatability (START; Webster et al., 2004) and the Structured Assessment of PROtective Factors for violence risk (SAPROF; de Vogel, de Ruiter, Bouman, \& de Vries Robbé, 2007, 2009). In the SAPROF, protective factors are defined as "any characteristic of a person, his/her environment or situation which reduces the risk of future violent behavior" (original italics; de Vogel, de Ruiter, Bouman, \& de Vries Robbé, 2009, p. 25).

Risk assessment tools do not offer insight into the mechanisms through which social ties might serve as a risk or protective factor for future offending by using theoretical models. We turn to criminological theories for hypothesized relationships between social ties and delinquent behaviour. Hirschi's (1969) Social control theory states that "control theories assume that delinquent acts result when an individual's bond to society is weak or broken" ( $\mathrm{p}$. 16). He distinguishes four types of bonds: attachment to parents, peers, or school; 


\section{CHAPTER 6}

commitment to conventional lines of action; involvement in conventional activities; and belief in a common value system. Sampson and Laub's Life-Course Theory of Crime $(1990,2005)$ also includes hypothetical links between social ties and criminal acts. Whilst Hirschi developed his theory to explain adolescent delinquent behaviour, Sampson and Laub explored the role of social bonds in desistance from crime in adults. Their basic thesis is "that while continuity in deviant behaviour exists, social ties in adulthood - to work, family, and community - explain changes in criminality over the life span" (Sampson \& Laub, 1990, p. 609). Furthermore, they "contend that social interaction with adult institutions of informal social control has important effects on crime and deviance" (p. 609). They studied the influence of job stability, commitment, and attachment to spouse on criminal and deviant behaviour in young adults, and concluded that all three sources of informal social control were negatively correlated with adult antisocial behaviour. In later work, they emphasized the interplay between three elements: social ties, routine activities and human agency, which was hypothesized to explain persistent offending and desistance from crime (Sampson \& Laub, 2005).

Previous research has provided evidence for a protective role for several social ties on criminal behaviour within a general criminal population and in criminal adolescents. Having an intimate relationship (Klassen \& O'Connor, 1989) and, more specifically being married, have been identified as protective factors for criminal recidivism, although the quality of the relationship seems of greater importance than merely being married (Oddone-Paolucci, Violato, \& Schofield, 2000; Sampson \& Laub, 2005; Wright \& Wright, 1992). Friends outside the intimate sphere can be sources of social control and prevent recidivism as well, if these network-members are pro-social and stable (Borowsky, Hogan, \& Ireland, 1997; Vance, Bowen, Fernandez, \& Thompson, 2002). Most studies on the role of friendships are limited to adolescents. In studies of adult samples, friends are replaced by the general term social network, and that seems to have a protective function (Goggin, Gendreau, \& Gray, 1998; Hilterman, 2000), although the relationship of the size of the social network with desistance from criminal behaviour has not been supported in every study (see e.g. Estroff \& Zimmer, 1994). However, friends or family have also been related to an increased recidivism risk, when these network members had a criminal background (e.g. Andrews \& Bonta, 1995; Hilterman, 2000; Hirschi, 1969). In the MacArthur Risk Assessment study, Estroff and Zimmer (1994) found that composition of the network was related to violence. The number of relatives in the 
network was positively related to violent behaviour, and the number of mental health professionals in the social network was negatively related to violence (see also: Estroff, Zimmer, Lachicotte, \& Benoit, 1994). The amount of contact with mental health professionals also predicted violent acts negatively in psychiatric patients in the MacArthur study on risk assessment (Monahan et al., 2001).

In most criminological theories, social ties are not limited to social relationships. Other social institutions can provide support, control and resources. Work, structured leisure activities and church are three important institutions in which a person can participate. Employment status has often been found to be a factor which influences the risk of delinquent behaviour (see e.g. Gendreau, Goggin, \& Gray, 2000; Sampson \& Laub, 1990), but also a more subjective employment rating, such as when a patient/offender is able to pinpoint work needs, has been related to reduced risk in a meta-analysis (Gendreau et al., 2000). As far as we know, the possible protective role of structured leisure activities for adult offenders has rarely been studied, although there are indications from research in juveniles that structured leisure activities with others can help prevent delinquency (DuRant, Knight, \& Goodman, 1997; Hoge, Andrews, \& Leschied, 1996; Reddon, Pope, Friel, \& Sinha, 1996). A third social institution which could play a role in risk prevention is the church. Belonging to a religion has been found to reduce criminal behaviour in adolescents (Rutenfrans \& Terlouw, 1994), as was engaging in religious activities, such as church attendance, in adults (Ellis \& Peterson, 1996; Pettersson, 1991).

Most studies into a possible protective role of social ties have been conducted in adolescent samples, general or delinquent, and among general adult offender groups. Studies into social ties among (forensic) psychiatric patients are still limited, except for the MacArthur study (Monahan et al., 2001). A large proportion of Dutch forensic psychiatric patients suffer from a personality disorder (PD), especially cluster B PDs (antisocial, borderline, narcissistic and histrionic; Hildebrand \& de Ruiter, 2004). Several of the diagnostic criteria for PDs (American Psychiatric Association [APA], 2000) are related to the inability to engage in or maintain social relationships or to participate responsibly in social institutions. Whether social ties could serve a protective role for forensic patients with PDs is an empirical question. The current study examined the relationship between social ties and delinquent behaviour in forensic patients with personality disorders. More specifically, the focus was on the short-term 


\section{CHAPTER 6}

effect of social ties on criminal behaviour. This choice was made because social ties are dynamic factors that tend to fluctuate over time.

In line with the above-mentioned theoretical models and previous findings in other samples, we hypothesized that social ties have a protective effect on short-term delinquent behaviour in personality disordered offenders. Secondly, we hypothesized that there would be a positive relationship between risk factors and short-term delinquent behaviour. And thirdly, we expected the negative relationship between social ties and delinquent behaviour to remain when we controlled for the influence of risk factors.

\section{METHOD}

\section{Participants}

A prospective multi-site study was performed, using patients attending four forensic psychiatric outpatient facilities in The Netherlands. The inclusion criteria were: male, 18 years and older, IQ $>70$, predominant PD or PD traits. Patients suffering from schizophrenia or related disorders, (severe) anxiety disorders, or mood disorders were excluded. Of all eligible patients, a random sample was taken. The sampling procedure was as follows. First, researchers computed a random number selection (using random number selection in SPSS) based on a targeted number of 300 patients to participate in the research. Next, clinicians of the four locations delivered a list of patients meeting inclusion criteria, not meeting exclusion criteria. These lists were numbered consecutively and patients with numbers in the random number selection were included in the sample.

Because of a time limit for the first round of data collection (October 2003 until May 2005), a total of 214 patients were contacted by their therapist or the first author and handed a leaflet containing basic information about the study. Seventy-nine patients (36.9\%) did not want to participate: 135 patients (63.1\%) participated at baseline $\left(\mathrm{T}_{0}\right)$. Of these 135 patients, 55 $(40.7 \%)$ returned the questionnaire of Self-reported Delinquent Behaviours (SRDB; van Dam, Janssens, de Bruyn, van Koolen, \& Spee, 1999) at both $3\left(T_{1}\right)$ and 6 months $\left(T_{2}\right)$ after baseline. Comparing these 55 patients with the $80(135-55=)$ dropouts on psychiatric and criminal background variables, mental disorder (including PD), demographic characteristics and selfreported delinquent behaviours did not show significant differences, except that none of the three patients with Dependent PD dropped out $(\chi 2[1]=4.46 ; p=.035)$. 
Of the 55 patients, $39(70.9 \%)$ fulfilled diagnostic criteria for one or more PDs while $29.1 \%$ met criteria for one or more PD traits. Most patients were classified as PD Not Otherwise Specified (34.5\%), and 21.8\% suffered from a antisocial, borderline and/or narcissistic PD. Five patients (9.1\%) suffered from a cluster C PD (dependent and/or avoidant).

\section{Measures}

Self-reported offences

Offences of forensic patients were measured three and six months after baseline using the SelfReported Delinquent Behaviours list (SRDB; van Dam et al., 1999). The SRDB asks the respondent to indicate which of 21 types of delinquent behaviours he displayed during the previous three months. There is one open item for offences not listed. No official recidivism data were used, such as re-arrests or reconvictions, only self-reported offending behaviour was used. Selfreported delinquent behaviour was divided into property offences, violent offences and sexual offences (see Table 6.2). Furthermore, the sum of all 21 types of delinquent behaviours and the open question was calculated and used as total of offences. Each item was only counted once, even though a person could indicate that he displayed the specific delinquent behaviour multiple times during the 3-month period. A dichotomized score of offences was used in the analyses, with 0 indicating no offence and 1 indicating one or more types of offences within one of the four categories.

A one-week test-retest reliability study of the SRDB was conducted among 27 adult male forensic psychiatric outpatients. The reliability was $r_{s}=.72$ for property offences, $r_{s}=.74$ for violent offences and $r_{s}=.82$ for total number of offences. No information on the reliability of the SRDB for sexual offences could be determined due to the absence of such offences.

\section{Social ties}

In this study, social ties were operationalised as (1) social contacts and (2) participation in social institutions. Eight indicators of social contacts were used: (1) relationships with a partner, (2) family, and (3) friends; (4) marital status, (5) the presence of children, (6) living with others, and (7) social contact with a boss and (8) with co-workers at the workplace. Furthermore, four social institutions in which informal social control can be exerted were used: 


\section{CHAPTER 6}

(1) work, (2) structured daily activity, (3) structured leisure activities and (4) church attendance. Data were taken from the Lancashire Quality of Life Profile (LQoLP; van Nieuwenhuizen, Schene, \& Koeter, 1998), an interview assessing objective and subjective indicators of quality of life, and from the Level of Service Inventory Revised (LSI-R; Andrews \& Bonta, 1995), a need assessment instrument filled in by a trained interviewer using file information and a patientinterview. The 12 social ties variables were dichotomized as present (score 1) or not present (score 0 ). The summed score of social contacts, with a maximum of eight, and the summed score of social institutions, with a maximum of three (work was omitted from the summation, due to high overlap with daily activities), were also used in the analyses.

\section{Risk. factors}

The relationship between social ties and recidivism can be influenced by other characteristics of the patient. Based on the risk assessment literature (e.g. Andrews \& Bonta, 1995; Hilterman, 2000; Hirschi, 1969; Monahan, 1981; Monahan et al., 2001), three risk factors for recidivism were used: criminal friends, criminal family or partner, and prior criminal convictions. The first two are risk factors directly related to social ties. Regarding the third risk factor, Monahan (1981) stated that "if there is one finding that overshadows all others in the area of prediction, it is that the probability of future crime increases with each prior criminal act." (p. 104). These variables were taken from the LSI-R, and they were dichotomized into a score of 0 if the risk factor was absent and a score of 1 if it was present.

As a fourth general risk factor, the LSI-R (Andrews \& Bonta, 1995) was used to assess the level of risk a patient posed. Scores could range from 0 to 54, which were transformed into valid percentages. Following Austin, Coleman, Peyton and Johnson (2003), a score between $0 \%$ and $28 \%$ was considered low risk; a score between $28 \%$ and $41 \%$ was labelled moderate risk; and a score of $41 \%$ or more was considered high risk of recidivism. Fifteen patients $(27.3 \%)$ were assessed as low risk, 17 patients (30.9\%) were categorized as posing a medium risk, and 23 patients $(41.8 \%)$ were deemed to pose a high risk of recidivism.

\section{Treatment intensity}

Contact with mental health professionals as expressed through treatment intensity was used as protective control variable. Information on treatment was gathered over the period between $\mathrm{T}_{0}$ 
and $\mathrm{T}_{2}$. The number of contacts per type of treatment was registered. Not every treatment facility offered the same types of treatment. However, the professional background of clinicians was comparable. We distinguished between high and low treatment intensity, based on dichotomising the number of treatment contacts between $T_{0}$ and $T_{2}$ using a median split, which was 22 contacts for patients participating at $T_{1}$ and $T_{2}$. Twenty-seven patients had fewer than 22 treatment sessions during the six months ( $=$ low treatment intensity) and 28 patients had 22 or more sessions (= high treatment intensity).

\section{Procedure}

Three measurements were performed: baseline $\left(T_{0}\right)$, three months later $\left(T_{1}\right)$, and after six months $\left(\mathrm{T}_{2}\right)$. The sample of patients were contacted by their therapist or the first author and handed a leaflet containing basic information about the study. At $\mathrm{T}_{0}$, social ties were assessed for all participating patients by means of the extended Dutch version of the LQoLP (van Nieuwenhuizen, Schene, \& Koeter, 1998) and the LSI-R (Andrews \& Bonta, 1995). At $T_{1}$, all patients who were interviewed at $\mathrm{T}_{0}$ were sent or given an envelope containing the SRDB (van Dam et al., 1999). If a patient was no longer in treatment or the frequency of contact was low, the questionnaire was sent to his last known address, otherwise it was given to him during a treatment session. At $\mathrm{T}_{2}$, this list was administered for the second time to the participating patients. An appointment was made with the patient by contacting him during a treatment session or by calling him at his last known telephone-number. In order to guarantee anonymity of the patients, the data collection procedure was designed in such a way that the researchers were unable to determine which questionnaire was filled out by which patient. Before the first interview, every patient gave written informed consent and permission to obtain medical and judicial information.

\section{Data-analysis}

The bivariate relationships between the twelve social ties (including Work) and three risk factors, risk level and offences were examined using Chi Square tests. T-tests were used to study the relationship between delinquent behaviour and the sum of social institutions (excluding Work) and the sum of social relationships. Next, these analyses were repeated, controlling for criminal friends, for criminal family or partner, for prior convictions, for 


\section{CHAPTER 6}

general risk level and for treatment intensity, using partial correlations. If applicable, Spearman correlations were computed. Backward (likelihood ratio; LR) Hierarchic Logistic Regression analyses were performed for each type of self-reported offence, in which the three risk factors, the general risk level and treatment intensity were entered in Block 1 and the sum of social relationships and the sum of social institutions were entered in Block 2. This was repeated in reversed order. Significance levels were set at $\alpha \leq .05$.

\section{RESULTS}

\section{Patient characteristics}

Patients who participated in this study $(\mathrm{N}=55)$ were all male with an average age of 38.5 years. Almost a third of the patients had not finished secondary school (32.7\%). Patients often had financial debts (excluding mortgages). More than half of the patients $(58.2 \%)$ lived on social welfare.

\section{Criminal history}

Although the majority of the patients $(78.2 \%)$ were in treatment because of criminal behaviour, only one third $(34.5 \%)$ of them had been sentenced to mandatory treatment by court. About half of the patients (52.7\%) had displayed violent behaviour, and one third $(32.7 \%)$ had previously committed sexual offences. A smaller proportion had committed arson $(9.1 \%)$ or a property offence $(14.5 \%)$. Sixty-seven percent of the patients had ever been convicted of a crime (average number of convictions $=2.4$; $\mathrm{SD}=3.5$ ), which had led to incarceration for $36.4 \%$ of the patients. About a third (34\%) of the patients had criminal friends, and even more $(42.3 \%)$ had criminal family members.

\section{Social ties}

Most patients had frequent social contacts, as indicated by their contact with family members, living with others or their intimate partner relationship (Table 6.1). The possibility of social support was present for most patients, since most stated they had a friend who would help when they needed it. Furthermore, almost half of the patients had children. One patient reported having no social relationships. Contact with a boss or with co-workers can of course only be present if a patient has employment. Most patients who held a job reported good 
contact with both their bosses and co-workers. On average, patients mentioned 4.1 of the eight possible relationships used in this study $(\mathrm{SD}=1.8)$.

Patients engaged in structured activities with others, either in a work setting, other daily activities, in organized leisure activities or in church-visits. Except for church-visits, about a third of the patients engaged in each of the activities. Almost two-thirds $(63.6 \%)$ of the patients were involved in one or more of the three structured social institutions (work excluded; $\mathrm{M}=0.9 ; \mathrm{SD}=0.8)$.

\section{Self-reported offences}

More than half of the patients reported one or more types of offences between $T_{0}$ and $T_{2}$ (Table 6.2). Offences mentioned most frequently were possession of a weapon, dealing in stolen goods and threat with violence in public. Almost a third of the patients had committed a violent offence, and $27 \%$ had committed a property offence; there was no significant relationship between the two types of offences $\left(r_{s}=.24 ; p>.05\right)$. About one eighth of the patients displayed both types of offences. In analyzing the relationship between self-reported offences and social ties, sexual offences were not included, due to low base rate.

\section{Social ties and self-reported offences}

Two of the social contacts were significantly related to two types of offences (Table 6.1). Good contact with co-workers and with their boss corresponded to a lower rate of violent offences. Club participation was related to a lower level of property offences, violent offences and general offences. None of the patients who visited church reported violent offences, as opposed to a third of the patients who did not go to church. The number of social institutions a patient was engaged in correlated negatively and significantly with violent offences $\left(\mathrm{M}_{\mathrm{NO}}\right.$ VIOLENCE $\left.=1.10 ; \mathrm{SD}=0.82 ; \mathrm{M}_{\text {VIOLENCE }}=0.44 ; \mathrm{SD}=0.73 ; \mathrm{F}[1]=7.93 ; p=.007\right)$. This relationship was not found for property offences or for general offences. No significant relationships emerged between the number of social contacts and either type of offence. 


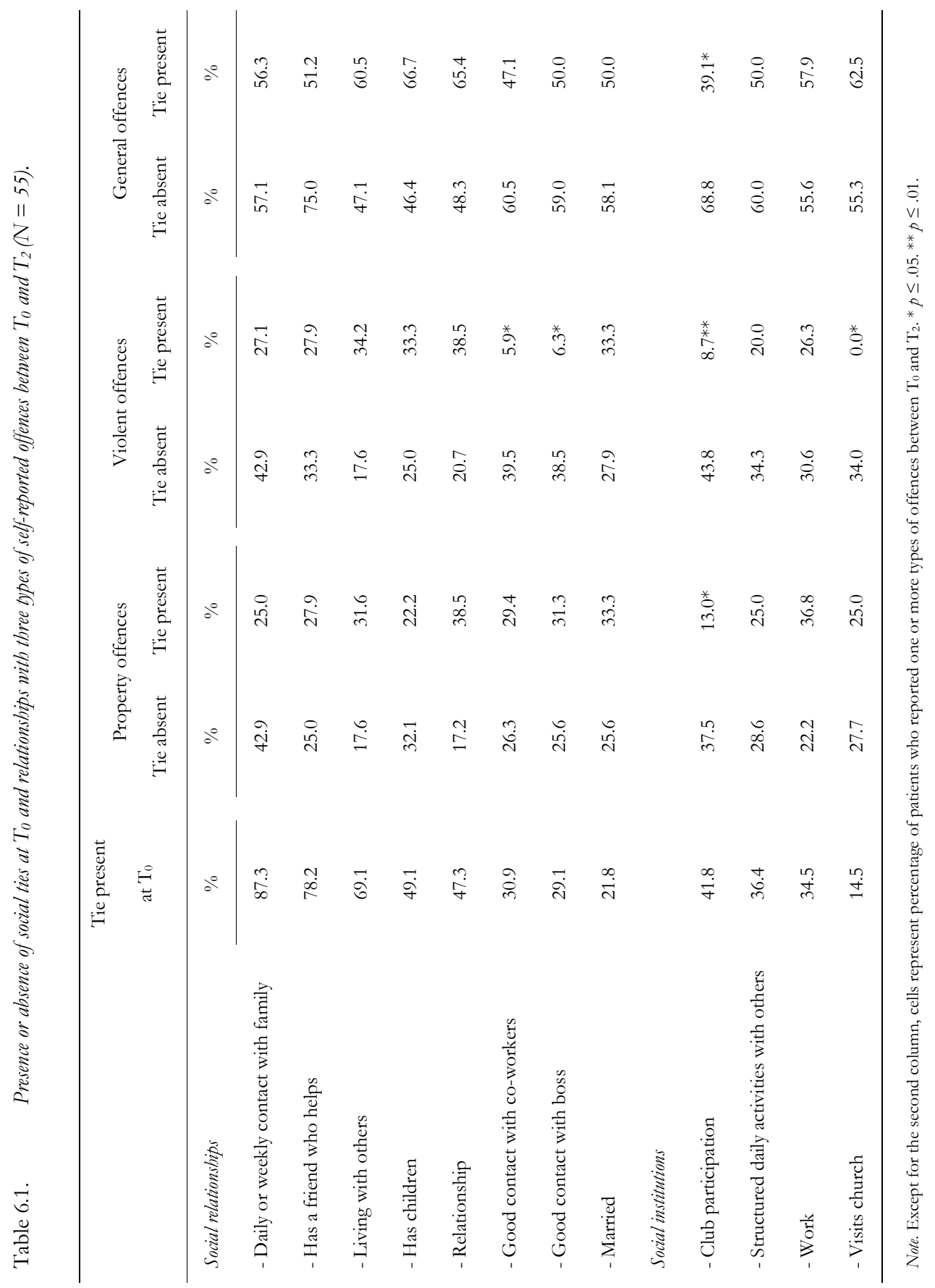


We explored the relationships of the five covariates - criminal family members, criminal friends, prior convictions, LSI-R risk level and treatment intensity - with self-reported offences. Two significant relationships emerged; if patients had criminal friends, they had committed property offences three times more often (yes $=44.4 \% ;$ no $=14.3 \% ; \chi^{2}[1]=5.84 ; p$ $<.05)$, and LSI-R risk level correlated with violent offences $\left(r_{\mathrm{s}}=.28 ; p<.05\right)$, but not significantly with property offences or general offences.

After controlling for criminal friends, three significant correlations between offences and social ties remained. If patients had criminal friends, club participation correlated negatively with property offences (no club participation $=70.0 \%$ recidivists; club participation $=12.5 \%$ recidivists; $\left.\chi^{2}[1]=5.95 ; p=.015\right)$; with violent offences (no $=70.0 \%$ recidivists; yes $=0 \%$; $\left.\chi^{2}[1]=9.16 ; p=.002\right)$; and with general self-reported offences (no $=90.0 \%$; yes $=25.0 \% ; \chi^{2}[1]$ $=7.90 ; p=.005)$. If patients reported not to have criminal friends, none of the previously found relationships of social ties with delinquent behaviour remained significant.

Controlling for criminal background of family members or one's partner, two correlations remained for patients with criminal family-members or partner: club participation correlated with violent offences (no club participation $=58.3 \%$ recidivists; club participation $=$ $0 \%$ recidivists; $\left.\chi^{2}[1]=8.56 ; p=.003\right)$. The number of social institutions also correlated negatively with violent offences for these patients $(0$ ties $=66.7 \%$ recidivists; 1 tie $=9.1 \% ; 2$ ties $\left.=0 \% ; \chi^{2}[2]=8.59 ; p=.014\right)$. If patients did not have family-members with a criminal background, church visits was related to a lower level of self-reported violent offences (no visit $=39.1 \%$ recidivists; visits $\left.=0 \% ; \chi^{2}[1]=3.91 ; p=.048\right)$.

The relationships of social ties with self-reported delinquent behaviours were next controlled for prior convictions and for LSI-R risk level. Five relationships remained when controlling for prior convictions. If patients had had prior convictions: club participation correlated negatively with violent offences (no club participation $=44.0 \%$ recidivists; club participation $=8.3 \%$ recidivists; $\chi^{2}[1]=4.71 ; p=.030$ ); and with property offences (no = $40.0 \%$ recidivists; yes $\left.=8.3 \% ; \chi^{2}[1]=3.89 ; p=.049\right)$; good contact with colleagues correlated negatively with violent offences $\left(\right.$ good contact $=0 \%$ recidivists; bad contact $=42.9 \% ; \chi^{2}[1]=$ $5.71 ; p=.017)$, as did good contact with a boss (good contact $=0 \%$ recidivists; bad contact $=$ $\left.41.4 \% ; \chi^{2}[1]=4.90 ; p=.027\right)$; the number of social institutions correlated negatively with 


\section{CHAPTER 6}

Table 6.2. $\quad$ Self-reported offences during six months $\left(T_{0}\right.$ to $\left.T_{2} ; N=55\right)$

\begin{tabular}{|c|c|c|}
\hline & $\%$ & $\mathrm{n}$ \\
\hline Property offences & 27.3 & 15 \\
\hline - Dealing in stolen goods & 14.5 & 8 \\
\hline - Using public transportation without paying & 10.9 & 6 \\
\hline - Selling of drugs & 7.3 & 4 \\
\hline - Vandalising public property (incl. graffiti) & 3.6 & 2 \\
\hline - Shoplifting & 1.8 & 1 \\
\hline - Abuse of animals & 1.8 & 1 \\
\hline - Burglary or theft & 0 & 0 \\
\hline Violent offences & 29.1 & 16 \\
\hline - Threat with public violence & 18.2 & 10 \\
\hline - Involvement in a fight & 14.5 & 8 \\
\hline - (Threat of) violence against family members & 10.9 & 6 \\
\hline - Assault & 5.5 & 3 \\
\hline - Wounding with a weapon & 0 & 0 \\
\hline - Armed burglary & 0 & 0 \\
\hline Sexual offences & 1.8 & 1 \\
\hline - Paedophilic offence & 1.8 & 1 \\
\hline - Sexual assault or rape & 0 & 0 \\
\hline \multicolumn{3}{|l|}{ Other offences } \\
\hline - Possession of an illegal weapon & 23.6 & 13 \\
\hline - Driving under the influence & 14.5 & 8 \\
\hline - Offences not listed & 3.6 & 2 \\
\hline - Arson & 0 & 0 \\
\hline Total general offences & 56.4 & 31 \\
\hline
\end{tabular}


violent offences $\left(0\right.$ ties $=58.8 \%$ recidivists; 1 tie $=6.7 \% ; 2$ ties $=25.0 \% ; 3$ ties $=.0 \% ; \chi^{2}[3]=$ $10.53 ; p=.015)$.

Two significant relationships remained when controlling for general risk level. For high risk patients club participation correlated negatively with violent offences (no club participation $=58.8 \%$ recidivists; club participation $=0 \%$ recidivists; $\chi^{2}[1]=6.24 ; p=.012$ ). And participation in social institutions correlated with violent offences for these patients $(0$ ties $=$ $64.3 \%$ recidivists; 1 tie $=12.5 \% ; 2$ ties $\left.=0 \% ; \chi^{2}[2]=6.36 ; p=.042\right)$. No significant correlations were found for patients in the low and in the medium risk category.

Three relationships remained while controlling for treatment intensity. For patients who received treatment at low intensity, violent offences were related to quality of contact with coworkers $\left(\right.$ good contact $=0 \%$ recidivists; bad contact $=38.9 \%$ recidivists; $\chi^{2}[1]=4.73 ; p=$ $.030)$, and similarly to the quality of contact with bosses (good contact $=0 \%$ recidivists; bad contact $\left.=38.9 \% ; \chi^{2}[1]=4.73 ; p=.030\right)$. For the group of low intensity treatment patients, club membership was related to a lower level of violent self-reported offences (no club participation $=43.8 \%$ recidivists; club participation $=0 \% ; \chi^{2}[1]=6.50 ; p=.011$ ).

Furthermore, we studied the effect of protective factors in high-risk patients $(\mathrm{N}=23)$, separately. Patients with a high risk level who had an intimate relationship reported property offences more often than patients without a relationship (no relationship $=9.1 \%$ recidivists; relationship $\left.=58.3 \% ; \chi^{2}[1]=6.14 ; p=.013\right)$. They also reported more violent offences if they lived with others than when they lived alone (living alone $=20.0 \%$ recidivists; living with others $\left.=61.5 \% ; \chi^{2}[1]=4.00 ; p=.046\right)$. Two other statistical relationships for high risk patients are mentioned earlier.

To explore the influence of social ties on criminal behaviour after controlling for the three risk factors, general risk level and treatment intensity, a hierarchic logistic regression analysis was performed (Table 6.3). Criminal friends and treatment intensity explained 29\% of the variance in self-reported property offences; none of the entries in Block 2 increased the degree of explained variance. Prior convictions and participation in social institutions together explained $24 \%$ of the variance in violent offences. In the third equation for self-reported general offences, prior convictions explained $12 \%$ of the variance. If the Blocks were entered in reversed order (not included in the Table), only the results for violent offences changed slightly: social institutions entered in the equation in Block $1(\mathrm{~B}=-1.18 ; \mathrm{SE}=0.49$; $(\mathrm{Exp}) \mathrm{B}=$ 


\section{CHAPTER 6}

$0.31 ; \chi^{2}[1]=7.47 ; p \leq .01 ;$ Nagelkerke $\left.\mathrm{r}^{2}=.19\right)$, and no entries in Block 2 added significantly to the equation.

Table 6.3. Prediction of self-reported offences using three risk. factors, general risk level and social relationships and social institutions $(\mathrm{N}=50)$.

\begin{tabular}{|c|c|c|c|c|c|c|c|c|c|}
\hline \multirow[b]{2}{*}{ Block 1 Risk factors } & \multicolumn{3}{|c|}{ Property offences } & \multicolumn{3}{|c|}{ Violent offences } & \multicolumn{3}{|c|}{ General offences } \\
\hline & $\mathrm{B}$ & se & $(\mathrm{Exp}) \mathrm{B}$ & B & se & (Exp)B & B & se & (Exp)B \\
\hline Prior convictions & & & & 0.22 & 0.10 & 1.25 & 0.23 & 0.13 & 1.26 \\
\hline Criminal friends & 1.79 & 0.75 & 5.98 & & & & & & \\
\hline Treatment intensity & -1.68 & 0.80 & 0.19 & & & & & & \\
\hline \multicolumn{10}{|l|}{ Block 2 Social ties } \\
\hline Social institutions & & & & -0.91 & 0.52 & 0.40 & & & \\
\hline Chi Square Model & 10.79 & & & 9.55 & & & 4.75 & & \\
\hline Df & 2 & & & 2 & & & 1 & & \\
\hline$P$ & .005 & & & .008 & & & .03 & & \\
\hline Nagelkerke $\mathrm{R}^{2}$ & .29 & & & .24 & & & .12 & & \\
\hline
\end{tabular}

Note. A Backward (LR) Hierarchic Logistic Regression was performed for each of the three types of offences. Five variables were entered in Block 1: Prior convictions, Criminal family member, Criminal friends, Treatment intensity and LSI-R risk level. In Block 2, two variables were entered: Social relationships and Social institutions. Only variables which entered any of the three end-models are displayed in the table. $\mathrm{B}=$ regression coefficient. $\mathrm{SE} \mathrm{B}=$ Standard error of $\mathrm{B}$.

Finally, we conducted post-hoc analyses using the number of PDs, the number of cluster B PDs and the presence of cluster B traits as separate covariates. The computation of the bivariate correlations resulted in one significant relationship: the number of cluster B PDs correlated with general offences $\left(\mathrm{r}_{\mathrm{s}}=.29 ; p=.032\right)$. In the logistic regressions, the number of PDs added $8 \%$ to the explained variance of violent offences $(\mathrm{B}=1.38$; $\mathrm{SE}=0.79$; $(\mathrm{Exp}) \mathrm{B}=$ 3.97; Model: $\chi^{2}[3]=13.10 ; p \leq .005$; Nagelkerke $\mathrm{r}^{2}=.32$ ). The number of cluster B PDs added $9 \%$ to the explained variance for self-reported general offences $(B=1.41 ; \mathrm{SE}=0.84$; $(\mathrm{Exp}) \mathrm{B}$ $=4.09$; Model: $\chi^{2}[2]=8.35 ; p \leq .05$; Nagelkerke $\mathrm{r}^{2}=.21$ ); no influence was found in the other cases. 


\section{Discussion}

This study aimed to identify the possible protective role of social ties for desistance from reoffending in forensic outpatients with personality disorders. We found that several social ties, or rather: ties to social institutions, were related to lower levels of self-reported offences. Patients who engaged in structured leisure activities, who had good contacts at work or who went to church displayed lower levels of subsequent offences than patients who did not participate in these social institutions. These relationships were found for self-reported violent offences, which included threat with violence in public, violence against family members and involvement in fights. Furthermore, club participation correlated with fewer property offences and less delinquent behaviour in general. Most of these protective relationships remained when we controlled for risk factors, but mainly for patients with risk factors than for patients without those factors. When patients followed treatment with a low intensity, several social ties were related to lower levels of violent behaviour, which was not the case if patients had higher intensity treatment during the same period. High risk patients who participated in social institutions in general and in clubs in particular reported significantly fewer violent offences. After entering four risk factors and treatment intensity, participating in social institutions still added to the explained variance in violent offences.

In this study, we did not find evidence for a protective role of intimate social network members. On the contrary, high risk patients reported more property offences if they had an intimate relationship; and high risk patients who lived with other people reported more violent offences. Whether the partner or other persons in the high risk patient's household had a criminal background was not examined, although this could have influenced the results. For instance, Hilterman (2000) found that the protective influence of non-deviant network members on recidivism during leave was nullified by deviant network members. Estroff and Zimmer (1994) found that intimate network members (partner, children and family) were more often victim of violence by psychiatric patients than people outside of the primary social network, and they also discovered that the more relatives a patient had in his social network the more likely he was to threaten with violence or display violent behaviour. Their sample, however, consisted of acute psychiatric patients. Based on the results of our study, it can be concluded that attachment to social institutions, but not intimate social ties, might have a protective function with regard to violent behaviour. 


\section{CHAPTER 6}

Personality disorders, especially cluster B PDs, are characterized by an inability to engage in and maintain pro-social relationships, which will be expressed in the absence of work, a social network, and of participation in other pro-social structured activities such as church or leisure organizations (APA, 2000). As a consequence, persons with a cluster B PD might, by definition, score low on participation in social relationships and social institutions, which might obscure a possible protective function of these ties for patients with other PDs. To explore this possible bias, we conducted post-hoc analyses using the number PDs, the number of cluster B PDs and the presence of cluster B traits as covariates. Although the number of PDs was related to violent offences and the number of cluster B PDs to general offences, none of the models changed to such an extent that that we would need to conclude that the absence or presence of a relationship between social ties and self-reported delinquent behaviour was a result of the composition of our sample with regard to type of personality disorders.

Work and work-related activities such as education have often been related to a reduction in criminal behaviour and criminal recidivism (see Gendreau et al., 2000). However, forensic PD outpatients did not seem to benefit from structured daily activities as such, among which work and education. A more qualitative aspect of work, namely having a good relationship with co-workers or a boss, was more important in this respect. In our study, as in others (Ellis \& Peterson, 1996; Pettersson, 1991), if a patient visited church, this was related to a lower level of self-reported violent behaviour. The third social institution taken into account here, structured leisure activities through club-membership, is a subject hardly ever studied in adult criminal samples. For youths, there are strong indications that involvement in such structured activities helps youngsters to stay out of trouble (DuRant et al., 1997; Hoge et al., 1996; Reddon et al., 1996). The same seems to hold true for this adult sample of male forensic outpatients with PDs.

More than half of the patients stated that they had engaged in delinquent behaviour at one or more occasions during the six months follow-up. In a study among juvenile delinquents (van Dam, Janssens, \& de Bruyn, 2003), 75\% of the boys reported such behaviour up until one year after finishing treatment. Besides the fact that Van Dam et al. studied juvenile delinquents, these boys were no longer in treatment during follow-up, whereas most participants in our sample of forensic outpatients still followed treatment and thus had some form of external control with regard to their (delinquent) behaviour. This might explain the larger proportion of 
delinquent boys who reported offending behaviour compared to our PD outpatients. In the MacArthur study, Monahan and colleagues (2001) found that $22.4 \%$ of their sample of psychiatric patients reported having engaged in violent behaviour during a one year follow-up. In our sample, $29.1 \%$ reported violent behaviour, which seems comparable. The number of patients who displayed delinquent behaviour is rather large. The types of behaviour included in the SRDB are criminal offences which will not always be reported to the police and which some patients do not interpret as criminal offences (e.g. using public transportation without paying; threat with public violence). However, minor infringements have been shown to be a precursor to subsequent criminal behaviour and reconvictions in forensic psychiatric patients (Philipse, 2005). Clinicians were unaware of these transgressions, otherwise treatment would have possibly been terminated.

No causal expectation could be formulated, due to the design of our study. We did not conduct analyses including causal modelling, because assumptions for such analyses were not met (experimental design or the number of respondents needed for Structural Equation Modelling). However, we did use a prospective design, which at least allows the conclusion that one type of behaviour follows another.

A second limitation of our study is the high number of drop-outs. One hundred thirtyfive patients participated in the first round of this study. Less than half $(40.7 \%)$ of them returned the self-report questionnaire on delinquent behaviour at the two subsequent assessments. This high non-response rate could lead to non-response bias, which should be taken into account when interpreting the results. We compared the responders with the dropouts on several characteristics, such as self-reported delinquent behaviour before $\mathrm{T}_{0}$, and we did not find any significant difference between the two groups. However, it is advisable to try to increase response rates in these types of clinical studies, but methods to enhance response rate, such as postal or telephone reminders or face-to-face contacts, could not be used here due to anonymity issues. The data collection procedure required that the primary researcher was unable to determine whether or not an individual patient had returned the questionnaire, and a group wise reminder was impossible due to the fact that $\mathrm{T}_{0}$ data were collected over a period of one-and-a-half years.

A third limitation stems from the use of self-report data to measure delinquent behaviour. Self-reported offences could lead to underestimation in some cases or 


\section{CHAPTER 6}

overestimation in other cases (Pauwels \& Pleysier, 2005; Zhang, Benson, \& Deng, 2000). The doubts about the reliability of self-reported offences made us decide to perform a test-retest reliability study on types of delinquent behaviour within our sample. The test-retest reliability was adequate, increasing our confidence in the quality of these self-report data. It is of course advisable to try and increase both the response rate and/or to test the validity of self-report data, for instance, through the use of official judicial files and third party information. However, the possible information gain (see Monahan et al., 2001) should be weighed against the possible loss in response rate. This study focused on short-term delinquent behaviour and did not use other sources, because firstly, we were interested in the relation between dynamic factors and more frequent infringements or delinquent behaviour; secondly, because the effect of the included factors on criminal (re)convictions has been subject of study more often; and thirdly, because we estimated a loss in response if proxies would have been approached, after approval of the patients, for additional information on recent delinquent behaviour.

The pivotal goal of forensic psychiatric treatment is the reduction of criminal recidivism. Most current risk assessment tools advocate the stimulation of social ties as a means to this end (see e.g. LSI-R, Andrews \& Bonta, 1995; HCR-20; Webster et al., 1997; START; Webster et al., 2004). In their Life-Course theory of Crime, Sampson and Laub (1990) seem to allot equal roles to close and more distal institution which provide social control, both formal and informal. Our patients with PD seem to rely more and sometimes even only on more distal sources of control such as co-workers or people with whom they spent their structured leisure time or whom they meet within their religious community than on closer sources such as a partner, family or friends. Our findings show that connection to social institutions, such as leisure clubs and churches may indeed serve the purpose of protection against re-offending, but that social ties to criminal friends are equally or even more powerful as risk factors for criminal recidivism. Thus, effective forensic treatment should focus on both the reduction of risk factors and the increase of protective factors within the realm of social bonds. 


\section{Chapter 7}

\section{Subjective well-being and recidivism}

Submitted as: Bouman, Y.H.A., Schene, A.H., \& Ruiter, C. de (2008). Subjective well-being and recidivism in forensic psychiatric outpatients: Preliminary evidence for a good lives model. 


\section{CHAPTER 7}

\section{ABSTRACT}

In community-based forensic psychiatry, subjective well-being (SWB) is rarely considered as an explicit treatment target. According to the Good Lives Model of Ward and colleagues (Ward, 2002; Ward \& Brown, 2004; Ward, Mann, \& Gannon, 2007), a negative relationship between SWB and re-offending in personality disordered patients can be hypothesised. In a multi-centre, prospective study, the short-term effect of SWB on self-reported criminal offending behaviour was explored over a three-month period. SWB was also related to official recidivism data over a follow-up period of three years. Overall SWB and satisfaction with health and finances predicted recidivism to a moderate degree. Furthermore, creating a meaningful life was negatively related to recidivism. For patients with a high risk level, SWB with health buffered self-reported reoffending; this effect was not found in relation to official reconvictions. The protective effect of positive SWB in reducing both short-term and long-term criminal behaviour in forensic psychiatric outpatients merits further attention in community-based forensic psychiatric treatment. 


\section{INTRODUCTION}

In treatment of forensic psychiatric (out)patients, risk assessment and risk management instruments are increasingly used to identify dynamic risk factors as the main treatment targets. Until the late nineties, none of the major risk assessment instruments incorporated protective factors. More recently, several instruments have been developed which incorporate these factors, such as the Structured Assessment of Violence Risk in Youth (SAVRY; Bartel, Borum, \& Forth, 2000); the Short Term Assessment of Risk and Treatability (START; Webster, Martin, Brink, Nicholls, \& Middleton, 2004); the Inventory of Offender Risk, Need and Strength (IORNS; Miller, 2006); and the Structured Assessment of Protective Factors for violence risk (SAPROF; de Vogel, de Ruiter, Bouman, \& de Vries Robbé, 2007). Only one risk management instrument, the Structured Outcome Assessment and Community Risk Monitoring (SORM; Grann et al., 2001), contains a self-report assessment of subjective well-being.

The idea that the risk of maladaptive behaviour, such as criminal offending, diminishes when persons have a fulfilling or 'good life' is central to the so-called 'Good Lives Model' (Ward, 2002). Several criminological theories also relate subjective well-being to desistance from crime. For instance, General Strain Theory (Agnew, 1992) states that strain results in negative affect, which in turn influences delinquent behaviour. Although the theoretical notion of subjective well-being has entered the field of risk assessment, the empirical evidence for it is very limited, as Ogloff and Davis (2004) stated: "despite the attention paid to concepts of psychological well-being (...), relatively little is actually known about these matters among offenders." (p. 238).

According to Lehman, quality of life (QoL) refers to a sense of well-being and satisfaction experienced by individuals under their current life conditions (Lehman, 1983). The distinction of QoL into two categories of indicators - social and subjective - is generally accepted (Farquhar, 1995; Glatzer \& Mohr, 1987; Goodinson \& Singleton, 1989; McCall, 1975). The relationship between social indicators or objective life circumstances, such as work, leisure activities, financial status, and recidivism has been demonstrated in several studies (see, e.g. Gendreau, Goggin, \& Gray, 2000; Goggin, Gendreau, \& Gray, 1998; Monahan et al., 2001; Oddone-Paolucci, Violato, \& Schofield, 2000). Paid employment, engagement in structured leisure activities, and sound financial management, all reduce the risk of re-offending. So far, the relationship between subjective QoL and criminal recidivism has rarely been explored. One 


\section{CHAPTER 7}

study used return to jail, due to violation of probation or parole conditions as an outcome measure in a sample of predominantly male offenders with schizophrenia $(N=65$; Draine \& Solomon, 1994). Just over a quarter of the sample had to return to jail within six months, and they were less satisfied with their living circumstances and with their lives in general, than those who did not violate the parole conditions.

Subjective well-being of forensic psychiatric outpatients has been explored in several studies (Chung, Cumella, Wensley, \& Easthope, 1998; Draine \& Solomon, 1992, 2000; Gerber et al., 2003; Swanson, Swartz, Elbogen, Wagner, \& Burns, 2003; Williams, 2003). Generally, forensic outpatients tend to be less satisfied with their lives overall than the general population, but they are more satisfied compared to general psychiatric outpatients. On the other hand, the subgroup of patients with Personality Disorders (PDs), which constitutes the largest part of the forensic outpatient population in The Netherlands (Hildebrand \& de Ruiter, 2004; Plemper, 2001), tended to be less satisfied than patients with schizophrenia (Lehman, 1999; Swinton, Oliver, \& Carlisle, 1999) and the general population (Narud, Mykletun, \& Dahl, 2005). Co-morbidity of a PD with a major mental disorder seems also to be associated with a lower subjective QoL (Draine \& Solomon, 2000; Masthoff, Trompenaars, van Heck, Hodiamont, \& de Vries, 2006). Furthermore, men reported higher levels of subjective wellbeing than women (Slade et al., 2004; van Nieuwenhuizen, 1998).

Taking the Good Lives Model (GLM; Ward, 2002; Ward \& Brown, 2004; Ward, Mann, \& Gannon, 2007) as a framework, the current research aimed at studying the relationship between subjective well-being and re-offending behaviour in a sample of male forensic psychiatric outpatients with PD or PD traits. Subjective well-being was defined as the patient's self-rating of general satisfaction with life, but it was also measured in relation to specific life domains. According to Lehman (1983), global well-being depends on personal characteristics, objective circumstances in various domains and on subjective satisfaction with these life domains. Within subjective well-being, two dimensions were discerned (van Nieuwenhuizen, 1998). The internal dimension measures domains related to personal autonomy (see Boevink, Wolf, van Nieuwenhuizen, \& Schene, 1995), comprising positive and negative self-esteem, life fulfilment and framework. The latter two assess whether an individual envisions his life as having some meaningful perspective and whether he has derived a set of life-goals from it. The external dimension consists of subjective life domain-specific ratings, for instance the domains finances and family relationships. 


\section{RESEARCH QUESTIONS AND HYPOTHESES}

We examined the following research questions: (1) What is the relationship between overall and domain-specific subjective well-being and short-term self-reported delinquent behaviour at a three months follow-up? (2) What is the relationship between overall and domain-specific subjective well-being and officially documented offending behaviour at a 3-year follow-up? (3) Are indicators of personal autonomy related to recidivism? (4) Is subjective well-being related to recidivism, after controlling for treatment intensity, prior convictions and risk level?

Based on the GLM, we hypothesized that patients with higher subjective well-being would report less delinquent behaviour than patients with low subjective well-being, in the short-term and also in the longer term. The GLM uses a general notion of well-being, which suggests a relationship of global and domain-specific subjective well-being with criminal behaviour, corresponding with the external factor described by Van Nieuwenhuizen (1998).

It is well established that certain risk factors influence criminal recidivism: treatment intensity, number of prior convictions and general risk level. Patients with a higher treatment intensity commit fewer offences than patients with a low treatment intensity (Monahan et al., 2001). Patients with prior convictions commit offences more often than patients without criminal convictions (Bonta, Law, \& Hanson, 1998; Coid, Hickey, Kahtan, Zhang, \& Yang, 2007; Monahan, 1981; Monahan et al, 2001). And, patients with a higher risk level for future criminal recidivism re-offend more than patients with a low risk level (Andrews \& Bonta, 2000; Bonta et al., 1998).

Thus, we hypothesized that subjective well-being will buffer these risk factors, particularly in high risk patients. High risk patients with a high level of subjective well-being will re-offend less compared to high risk patients with a low level of SWB. In a buffering model, "risk factors have an impact on behavior only under certain conditions such as the lack of protective mechanisms" (Fitzpatrick, 1997, p. 136).

\section{METHOD}

\section{Design}

A prospective multi-centre study was conducted using a random sample of adult male personality disordered forensic outpatients. The inclusion criteria were: male gender; 18 years or older; IQ higher than 70; and a primary diagnosis of PD or PD traits (the Diagnostic and 


\section{CHAPTER 7}

Statistical Manual of Mental Disorders [DSM-IV-TR]; American Psychiatric Association [APA], 2000). Exclusion criteria were: a co-morbid Axis I disorder of mood, anxiety or psychosis. The patients had to be in contact with the forensic treatment centre at least once a month at the time of the first interview $\left(\mathrm{T}_{0}\right)$.

\section{Procedure}

One hundred and thirty-five patients participated. Overall and domain-specific subjective wellbeing was assessed by means of the extended Dutch version of the Lancashire Quality of Life Profile (LQoLP; van Nieuwenhuizen, Schene, \& Koeter, 1998). Next, the Level of Service Inventory - Revised (LSI-R; Andrews \& Bonta, 1995) was completed by trained interviewers. Three months later $\left(\mathrm{T}_{1}\right)$, all patients who were interviewed at $\mathrm{T}_{0}$ were sent or given an envelope containing the Self-reported Delinquent Behaviour inventory (SRDB; van Dam, Janssens, de Bruyn, van Koolen, \& Spee, 1999). If a patient was no longer in treatment or the frequency of contact was low, the questionnaire was sent by mail, otherwise it was given to him during a treatment session. Due to privacy constraints, it was not possible to send a reminder to patients who did not respond. Again three months later $\left(\mathrm{T}_{2}\right)$, patients were approached for another assessment, at which time the LQoLP and the LSI-R were re-administered. Two years after the last interview, official reconviction data as documented in the Judicial registration system were gathered. Before $\mathrm{T}_{0}$, every patient gave written informed consent and permission to obtain medical and judicial follow-up information.

\section{Participants}

Of the 135 patients, 64 patients (47.4\%) returned the SRDB at $\mathrm{T}_{1}$. At $\mathrm{T}_{2}, 102$ patients $(75.6 \%)$ were re-interviewed.

The average age of the 135 patients was 37.5 years $(S D=10.4)$. About one third had not finished any type of formal education or only primary school. Almost half of the patients had an intimate relationship and about a third held a job. For a third of the patients, the treatment in the forensic outpatient facility was their first contact with mental health services. Seventy percent of the patients were diagnosed with a PD, of whom the majority with PD Not Otherwise Specified (37.8\%). cluster B disorders (antisocial, borderline and narcissistic PD) were present in $23 \%$ of the patients. The other patients did not reach the threshold for a full PD, but had a sub-clinical PD. Most patients had been previously convicted of a crime 
(74.6\%). The crimes were mainly violent offences (57.8\%), sexual offences $(28.1 \%)$ or property offences $(13.3 \%)$. For almost half of these patients, the LSI-R resulted in a high risk of recidivism, and $21.5 \%$ were judged low risk (for a more detailed description of the sample see chapter 2).

Patients who had not returned the questionnaire at $\mathrm{T}_{1}$ were compared to patients who had, on demographic, criminal and treatment characteristics. Responders did not differ from drop-outs on any of these characteristics.

The 102 patients who participated at $T_{2}$ were compared to the 33 patients who did not take part in the follow-up interview on these same characteristics. Patients who participated at $\mathrm{T}_{2}$ had fewer prior convictions (2.6 vs. 4.9; $\left.\mathrm{F}[1]=4.81 ; p=.030\right)$. Patients who did not participate at the second interview round had fewer co-morbid Axis I disorders, such as mild depression, post traumatic stress disorder, and dysthymic disorder $\left(10.3 \%\right.$ vs. $28.3 \%$; $\chi^{2}[1]=$ $3.98 ; p=.046)$. No other differences were found between responders and non-responders with regard to type of disorder; age; years of education; IQ; global subjective QoL at $\mathrm{T}_{0}$; framework of treatment (mandatory or not); having a relationship; having work; living of a social benefit; having debts or children; being previously admitted to a psychiatric hospital; LSI-R risk level; and being previously convicted or incarcerated.

\section{Independent variables}

\section{Subjective well-being}

Subjective well-being was assessed by means of Dutch version of the LQoLP (van Nieuwenhuizen, Schene, \& Koeter, 1998). Within subjective well-being, two dimensions were discerned (van Nieuwenhuizen, 1998): an internal dimension with four subscales and an external dimension with six domain-specific subjective ratings. The internal dimension consisted of four (sub)scales. It included the subscales positive and negative self-esteem of the Self-Esteem Scale (Rosenberg, 1965, in van Nieuwenhuizen, 1998; and in Oliver, Huxley, Bridges, \& Mohamad, 1996). Five positively labelled items were used to indicate positive selfesteem, for instance "You feel you have a number of good qualities" and five negatively phrased items were used to indicate negative self-esteem, for instance "You feel you do not have much to be proud of" (see Oliver et al., 1996, p. 255). For the analyses, the scores on the negative self-esteem subscale were reversed: a high score was therefore positive and a low score was negative. The two subscales of the Life Regard Index (Dutch adaptation by Debats, 


\section{CHAPTER 7}

van der Lubbe, \& Wezeman, 1993; see also Debats, 1996b) were also part of the internal dimension: the Framework scale, which assesses "the degree to which individuals can envision their lives within some meaningful perspective or have derived a set of life-goals or philosophy of life from these" (Debats, 1996a, p. 14) and the Fulfilment scale, which "measures the degree to which people see themselves as having fulfilled or as being in the process of fulfilling their framework of life-goals" (Debats, 1996a, p. 14). The external dimension consisted of six domain-specific subjective ratings concerning: leisure and social participation, finances, family, living circumstances, health and safety. The Life Satisfaction Scale (LSS) was used to measure satisfaction on these domains. All ten subjective indicators were transformed into a 7-point scale, with 1 = very dissatisfied / dissatisfactory; and 7 = very satisfied / satisfactory. A global measure of subjective well-being was also included, namely Cantril's Ladder (Cantril, 1965, in: van Nieuwenhuizen, Schene, Boevink, \& Wolf, 1998). On Cantril's Ladder, a patient is asked to rate his life on a continuum ranging from life at its worst (0) to life at its best (100) by indicating it on a $100 \mathrm{~mm}$ long ladder. The six domain-specific indicators of SWB and the four internal indicators of SWB, as well as Cantril's Ladder at $\mathrm{T}_{0}$ were related to self-reported offences at $\mathrm{T}_{1}$ and scores at $\mathrm{T}_{2}$ were related to official recidivism data at 3-year follow-up.

\section{Dependent variables}

Self-reported offences

Delinquent behaviour of forensic patients was measured using the Self-reported Delinquent Behaviour inventory (SRDB; van Dam et al., 1999). The SRDB asks the respondent to indicate which of the 21 listed types of offences he committed during the three months prior to assessment at $T_{1}$ and there is one open item for offences not listed. Self-reported offences were categorized into property offences, violent offences, sexual offences and general offences. A dichotomized score of each type of offence, with a score of zero indicating no such behaviour and a score of one indicating one or more incidences of the type of offence, was used in the analyses.

A one-week test-retest reliability study of the SRDB among 27 adult male forensic psychiatric outpatients was conducted. The reliability was $r_{s}=.72$ for property offences, $r_{s}=$ .74 for violent offences and $r_{s}=.82$ for total number of offences. No information on the reliability of the SRDB for sexual offences was obtained due to the absence of such behaviour. 


\section{Official recidivism}

Official recidivism data were obtained from the Central Judicial Documentation register of the Dutch Ministry of Justice in February 2008. This covered a period of at least 28 months and at most 46 months after $\mathrm{T}_{2}\left(\mathrm{M}_{\text {FOLLow-up time }}=37\right.$ months; $\mathrm{SD}=4.5$ months $)$. Data were obtained for 133 of the patients who entered the study at $\mathrm{T}_{0}$. Data on two patients were not or no longer present in the register. One-hundred and two patients participated at $\mathrm{T}_{2}$; data for these patients were used here.

We distinguished between patients who were convicted for an offence committed after $\mathrm{T}_{2}$ and patients who were not convicted. Minor offences, such as traffic violations, were not included. The type of offence committed was coded as a sexual, violent or property offence, or arson. These five indicators for recidivism were dichotomised into 0 (= not present) and 1 (= present).

\section{Control variables}

In the MacArthur risk assessment study (Monahan et al., 2001), patients who remained in regular contact with the treatment centre were less often violent after release from hospital than patients with a lower frequency of contact. We therefore distinguished high and low treatment intensity, by dichotomising the number of treatment contacts during the six months between $\mathrm{T}_{0}$ and $\mathrm{T}_{2}$, using a median split.

The LSI-R (Andrews \& Bonta, 1995) was used to assess the level of risk a patient posed. LSI-R total scores range from 0 to 54 and were transformed into valid percentages. Following Austin, Coleman, Peyton and Johnson (2003), a score between $0 \%$ and 28\% was considered low risk; a score between $28 \%$ and $41 \%$ was labelled moderate risk; and a score of $41 \%$ or more was considered high risk of recidivism. The scores at $\mathrm{T}_{0}$ were used in analysing the influence on self-reported offences, and the scores at $\mathrm{T}_{2}$ were used when examining the relationship with official recidivism data.

Previous offending behaviour has been established as one of the strongest predictors of future criminal behaviour (Bonta et al., 1998; Coid et al., 2007; Monahan, 1981; Monahan et al, 2001). We used previous conviction(s) $(0=$ no prior conviction; $1=$ one or more prior convictions) as indicator of previous offending behaviour. Here also, the score at $\mathrm{T}_{0}$ was used in studying the relationship to self-reported offences, and the score at $\mathrm{T}_{2}$ was related to official recidivism data. 


\section{CHAPTER 7}

\section{Data analysis}

The relationship between each indicator of subjective well-being and self-reported delinquent behaviour and official recidivism was studied using bivariate analyses. Zero-order correlations were reported and the predictive validity was studied. Next, the bivariate correlations were reassessed, controlling for treatment intensity, for prior convictions and for general risk level, using partial correlations. The predictive power of subjective well-being for recidivism was explored using Receiver Operating Characteristics (ROC) curves. In a ROC curve, the sensitivity is mapped against 1 minus the specificity (Fawcett, 2004; Mossman, 1994). A score of 0.5 represents random guessing, and a score of 1.0 represents perfect classification (Hanley \& McNeil, 1982). The threshold of the Areas Under the ROC curve (AUC) which can be considered adequate or good has not been agreed upon. For instance, Sjöstedt and Grann (2002) proposed an AUC $\geq .60$ as marginally accurate; $\geq .70$ as modest accuracy; $\geq .80$ as moderate accuracy; and $\geq .90$ as high accuracy, whereas De Vogel, De Ruiter, Van Beek and Mead (2004) considered AUCs $\geq .70$ as moderate and $\geq .75$ as good. We reported significance levels of the AUCs, and paid attention to the relevance of the outcome in the Discussion section.

\section{RESUlts}

\section{Subjective well-being at $T_{0}$}

At $\mathrm{T}_{0}$, most patients $(\mathrm{N}=64)$ were satisfied with their Living arrangements $(\mathrm{M}=5.3$; $\mathrm{SD}=$ 1.0) and their Safety $(M=5.4 ; S D=0.9)$. On the Life Satisfaction Scale (LSS) with Leisure time and social participation $(\mathrm{M}=4.9 ; \mathrm{SD}=0.8)$, with Family $(\mathrm{M}=4.7$; $\mathrm{SD}=1.2)$ and with Health $(M=4.6$; $S D=1.0)$, patients reported a positive score. Patients assessed the LSS with their Finances as neutral $(\mathrm{M}=4.0 ; \mathrm{SD}=1.4)$. On average, patients scored satisfactory $(\geq 5)$ on Positive Self-Esteem $(M=5.9$; $S D=1.2)$ and on their Life Framework $(M=5.8 ; S D=1.1)$. They assessed their Negative Self-Esteem as low $(M=4.9$; $S D=1.5)$ and Life Fulfilment $(M=$ 4.8; $\mathrm{SD}=1.2$ ) as almost satisfactory. Considering their lives in general, using Cantril's Ladder, patients viewed their lives as just below average quality $(\mathrm{M}=45.8 ; \mathrm{SD}=22.1)$. 


\section{Self-reported delinquent behaviour between $T_{0}$ and $T_{1}$}

More than $40 \%$ of the patients $(\mathrm{N}=64)$ reported any type of delinquent behaviour during the three months between $\mathrm{T}_{0}$ and $\mathrm{T}_{1}$. This was mostly violent offending behaviour $(21.7 \%)$, such as threat with violence in public or involvement in a fight. Equally, a relatively large proportion $(18.8 \%)$ reported property offences, such as dealing in stolen goods or using public transportation without payment. In the analysis of the relationship between self-reported offences and SWB, arson $(0 \%)$ and sexual offences $(1.6 \%)$ could not be examined separately, due to low base rate.

\section{Prediction of self-reported offences by subjective well-being indicators}

For each of the six domains, the four internal subscales and Cantril's Ladder, zero-order correlations were studied, in order to be able to compared these with the controlled correlations. Four significant zero-order correlations between subjective well-being indicators and self-reported delinquent behaviours were found: Satisfaction with Finances correlated with self-reported general offences $(\mathrm{r}=-.26 ; p<.05)$; Satisfaction with Health also correlated with self-reported general offences $(\mathrm{r}=-.38 ; p<.005)$; Life Fulfilment correlated with self-reported violent offences $(\mathrm{r}=-.32 ; p<.01)$ and with self-reported general offences $(\mathrm{r}=-.44 ; p<.001)$.

To explore the predictive validity of the indicators, the AUC of the ROC was calculated with the three types of self-reported offences as outcome variable (Table 7.1). The range of the AUCs for self-reported property offences was .43 to .72. Only the AUC between Framework and self-reported property offences, was significant (AUC $=.72)$. The range of the AUCs for self-reported violent offences was .45 to .73 . LSS with Health resulted in a significant AUC of .73 with violent offences. LSS with Health also resulted in a significant AUC of .71 with selfreported general offences, as did LSS with Finances (AUC $=.68$ ). Life Fulfilment also resulted in a significant AUC of .69 for self-reported general offences. The range of the other, nonsignificant, AUCs for general offences was .50 to .60. 


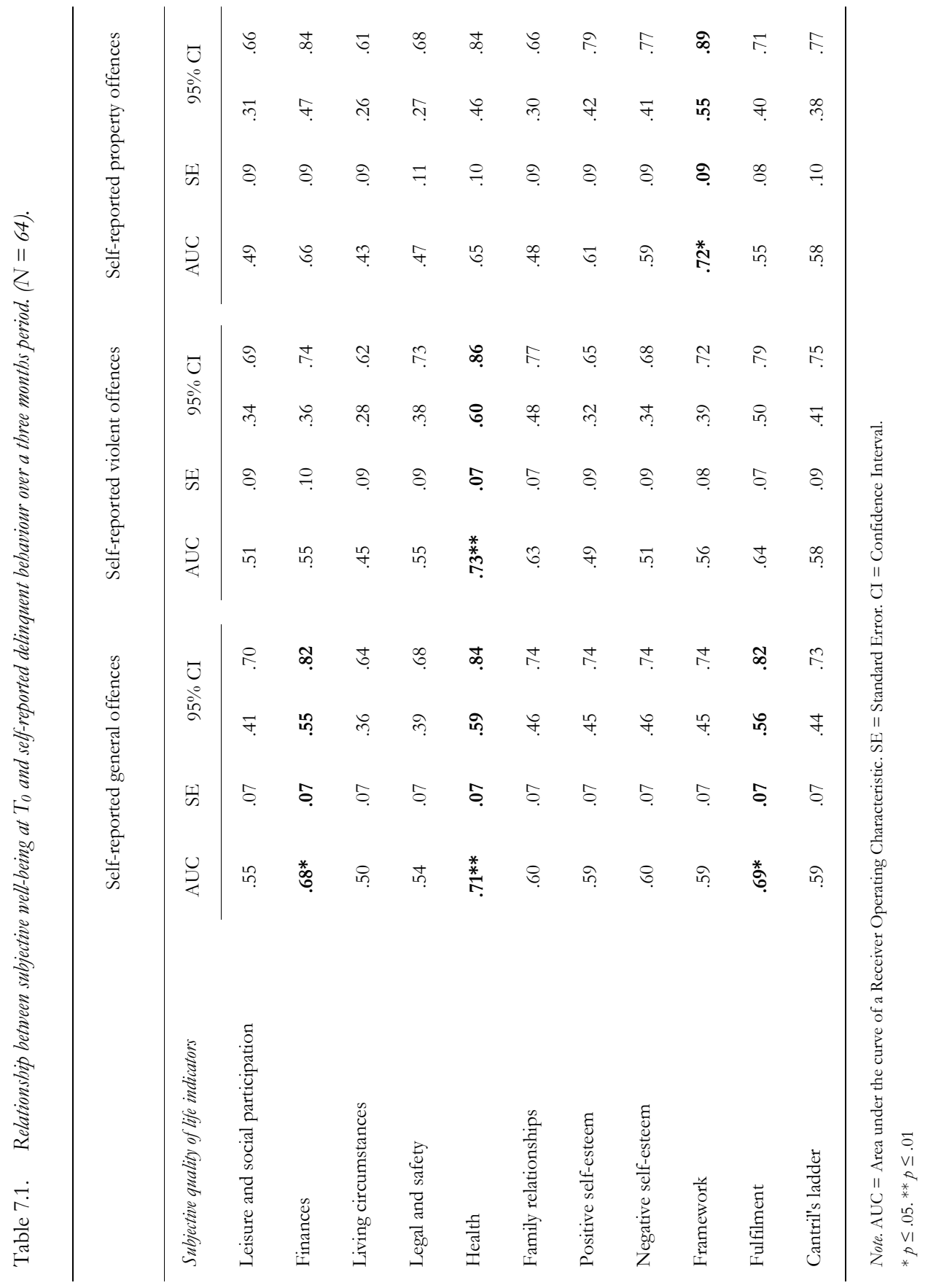




\section{Relationship between subjective well-being and self-reported offences controlling for risk variables}

Of the three variables - treatment intensity, previous convictions and risk level -, only risk level correlated significantly, though modestly, with self-reported property offences $\left(r_{\mathrm{s}}=.32\right)$ and self-reported general offences $\left(r_{\mathrm{s}}=.28\right.$; Table 7.2). In both cases, the higher the risk, the higher the rate of offences was.

The relationship between Satisfaction with Finances and self-reported general offences did not remain significant when controlling for risk level $(\mathrm{r}=-.22 ; p>.05)$. Satisfaction with Health still correlated with self-reported general offences when controlling for risk level ( $\mathrm{r}=$ $-.32 ; p<.05)$. The relationship between Life Fulfilment and self-reported violent offences remained significant controlling for risk level $(\mathrm{r}=-.26 ; p<.05)$. The same results were found for the relationship between Life Fulfilment and self-reported general offences: controlling for risk level: $\mathrm{r}=-.39(\phi<.005)$.

Table 7.2. Relationship of risk factors with self-reported delinquent behaviour over a three month period $\left(T_{0}-T_{1}\right.$;

$$
N=64)
$$

\begin{tabular}{|c|c|c|c|c|}
\hline & $P$ & General offences & Violent offences & Property offences \\
\hline Incidence & & 42.2 & 21.9 & 18.7 \\
\hline LSI-R low risk $(<28 \%)$ & 25.0 & 25.0 & 12.5 & .0 \\
\hline LSI-R medium risk $(28 \%-41 \%)$ & 31.3 & 42.1 & 15.8 & 21.1 \\
\hline LSI-R high risk ( $\geq 41 \%)$ & 43.8 & $59.1 *$ & 36.4 & $31.8 *$ \\
\hline Offence history: ever convicted & 67.2 & 46.5 & 25.6 & 20.9 \\
\hline Never convicted before & 32.8 & 33.3 & 14.3 & 14.3 \\
\hline Intensive treatment ( $\geq 17 \mathrm{x} / 6$ months $)$ & 53.1 & 44.1 & 26.5 & 11.8 \\
\hline Low treatment intensity & 46.9 & 40.0 & 16.7 & 26.7 \\
\hline
\end{tabular}

Note. Cells represent proportions of the group, who scored positive on the outcome-measure (i.e. self reported offences). $P=$ percentage.

$* p \leq .05$. 


\section{CHAPTER 7}

To test the hypothesis that SWB will buffer delinquent behaviour in high risk patients as defined by Austin and colleagues (2003; $\mathrm{N}=28$ ), we compared high risk patients who were less satisfied on the indicators of SWB with high risk patients who were satisfied on the three types of self-reported criminal behaviour. This comparison resulted in one significant relationship: high risk patients who were less satisfied with health reported three times more general offences than high risk patients who were more satisfied with their health (LSS $\geq \mathrm{M}$ : $20.0 \%$ offences vs. LSS $<$ M: $66.7 \%$ offences; $\left.\chi^{2}[1]=5.60 ; p=.018\right)$.

\section{Subjective well-being at $T_{2}$}

At $\mathrm{T}_{2}$, most patients $(\mathrm{N}=102)$ were satisfied with their Living arrangements $(\mathrm{M}=5.3 ; \mathrm{SD}=$ 1.1) and their Safety $(M=5.4 ; S D=1.0)$. On LSS with Leisure time and social participation $(M$ = 4.9; $\mathrm{SD}=0.8)$, with Family $(\mathrm{M}=4.5 ; \mathrm{SD}=1.5)$ and with Health $(\mathrm{M}=4.8 ; \mathrm{SD}=0.9)$, patients reported a positive score. Patients assessed the LSS with their Finances as just below neutral $(\mathrm{M}=3.8$; $\mathrm{SD}=1.5)$. There were no significant differences on domain-specific life satisfaction between $T_{0}$ and $T_{2}$.

On average, patients scored satisfactory $(\geq 5)$ on Positive Self-Esteem $(\mathrm{M}=6.0$; SD $=$ 1.3), Life Fulfilment $(M=5.1 ; S D=1.3)$, on Life Framework $(M=6.0 ; S D=1.0)$ and low on Negative Self-Esteem $(M=5.3$; $\mathrm{SD}=1.6)$. Except for Positive Self-Esteem, patients scored significantly higher at $\mathrm{T}_{2}$ on all aspects of their internal subjective well-being compared to $\mathrm{T}_{0}$. Considering their lives in general, using Cantril's Ladder, patients viewed it as satisfactory $(\mathrm{M}=$ 58.0; $\mathrm{SD}=19.4)$. This score was also significantly higher than their score at $\mathrm{T}_{0}$.

\section{Official recidivism data}

Almost a quarter of the patients $(24.5 \%)$ had been convicted of a new offence committed after $\mathrm{T}_{2}$. For $13.7 \%$ of the patients, a trial procedure was still in progress. Most patients were (re)convicted of a violent offence (19.6\%), whereas $9.8 \%$ had committed a property offence. No patients had been reconvicted of arson after $\mathrm{T}_{2}$, and two patients were reconvicted of sexual offences. The latter two outcomes were not used in studying the relationship between SWB and recidivism, due to low base rates. Eleven percent of the patients were sentenced to a prison sentence, and seven patients got fines. Almost six percent of the patients were convicted to community service. 


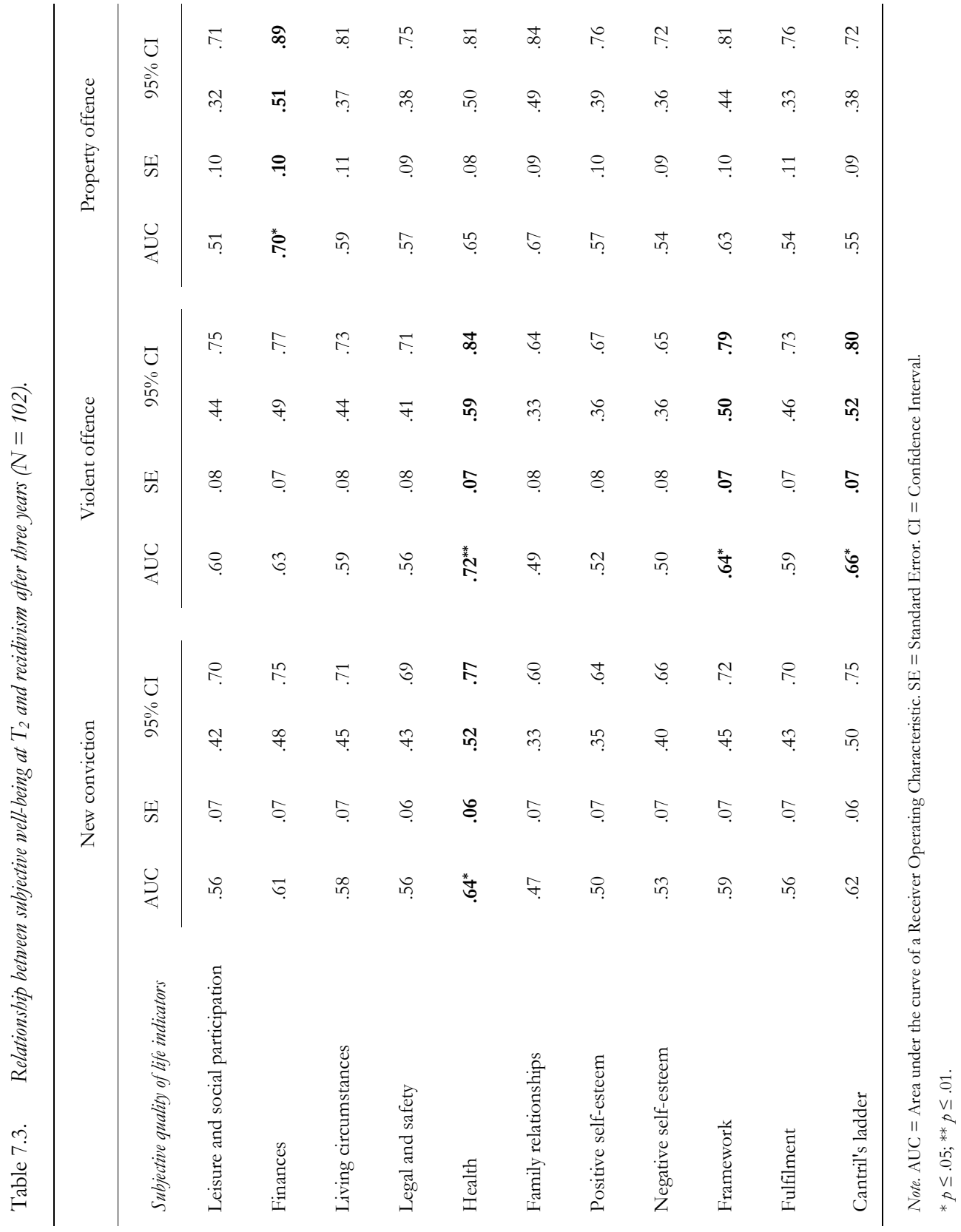




\section{CHAPTER 7}

\section{Subjective well-being and official recidivism}

Three relationships surfaced as significant zero-order correlations, when studying the relationships between subjective well-being indicators and official recidivism: Satisfaction with Health $(\mathrm{r}=-.25 ; p<.05)$; Life Framework $(\mathrm{r}=-.20 ; p<.05)$; and Cantril's ladder $(\mathrm{r}=-.20$; $p$ $<.05)$, all correlated with violent reconvictions.

We found one significant AUC-value for SWB at $\mathrm{T}_{2}$ for new convictions in general (for LSS with Health: AUC = .64) and one for new convictions for property offences (for LSS with Finances: $\mathrm{AUC}=.70$; Table 7.3). Three significant AUCs for violent offences emerged, one for Satisfaction with Health (AUC $=.72)$, one for Life Framework (AUC = .64), and one for Cantril's ladder (AUC $=.66)$.

\section{Controlling for risk variables in the relationship between subjective well-being and official recidivism}

Similar to the results for self-reported offences, treatment intensity and previous convictions did not correlate significantly with official recidivism (Table 7.4), so these variables were excluded from further analyses. Risk level, as measured with the LSI-R, correlated significantly with new convictions $\left(r_{\mathrm{s}}=.31\right)$, with violent offences $\left(\mathrm{r}_{\mathrm{s}}=.22\right)$ and with property offences $\left(\mathrm{r}_{\mathrm{s}}\right.$ $=.29)$.

None of the previously found zero-order relationships remained significant when controlling for risk level. The relationship between Satisfaction with Health and violent reconvictions became $\mathrm{r}=-.18(\phi>.05)$; the relationship between Life Framework and violent reconvictions went from $r=-.20(p<.05)$ to $r=-.13(p>.05)$ when controlling for risk level. The same result was found for the relationship between Cantril's Ladder and violent reconvictions: controlling for risk level: $r=-.17(p>.05)$.

Patients with a high risk level $(\mathrm{N}=55)$, as measured by the LSI-R, committed fewer violent offences if they were more satisfied with their health than when they were less satisfied with it (LSS Health $\geq$ M: $5.9 \%$ offences vs. LSS Health $<$ M: $36.8 \%$ offences; $\chi^{2}[1]=5.68 ; p=$ .017). The general level of SWB also seemed to act as a buffer: high risk patients who were less satisfied in general as measured with Cantril's Ladder (CL) committed three times more violent offences than high risk patients who were more satisfied with their lives (CL $\geq \mathrm{M}: 13.0 \%$ offences vs. CL $<\mathrm{M}: 37.5 \%$ offences; $\left.\chi^{2}[1]=4.04 ; p=.045\right)$. 
Table 7.4. $\quad$ Relationship of risk factors with official recidivism after $T_{2}(N=102)$

\begin{tabular}{|c|c|c|c|c|}
\hline & $P$ & $\begin{array}{l}\text { Any new } \\
\text { conviction }\end{array}$ & $\begin{array}{l}\text { Conviction for } \\
\text { violent offence }\end{array}$ & $\begin{array}{l}\text { Conviction for } \\
\text { property offence }\end{array}$ \\
\hline Incidence & & 24.5 & 19.6 & 9.8 \\
\hline LSI-R low risk $(<28 \%)$ & 18.6 & 5.3 & 5.3 & .0 \\
\hline LSI-R medium risk $(28 \%-41 \%)$ & 27.5 & 14.3 & 14.3 & .0 \\
\hline LSI-R high risk $(\geq 41 \%)$ & 53.9 & $36.4 * * *$ & $27.3 *$ & $18.2 * * *$ \\
\hline Offence history: ever convicted & 15.7 & 27.9 & 22.1 & 11.6 \\
\hline Never convicted before & 84.3 & 6.3 & 6.3 & .0 \\
\hline Intensive treatment $(\geq 17 \mathrm{x} / 6$ months $)$ & 55.9 & 24.6 & 17.5 & 14.0 \\
\hline Low treatment intensity & 44.1 & 24.4 & 22.2 & 4.4 \\
\hline
\end{tabular}

Note. Cells represent proportions of the group, who scored positive on the outcome-measure (i.e. recidivism).

$* p \leq .05 .{ }^{* *} p \leq .01 . * * * p \leq .005$.

\section{DIscussion}

Subjective well-being is believed to serve as a buffer to prevent criminal behaviour (Ward, 2002). In our study of forensic psychiatric outpatients, general subjective well-being did not show a negative relationship with self-reported criminal behaviour in the short-term. However, two specific SWB indicators - satisfaction with health and life fulfilment - did predict significantly decreased self-reported violent and general offences. The risk level of the patients correlated significantly with self-reported general and property offences, with a medium effect size $(\mathrm{r}=.28 ; \mathrm{r}=.31$; according to Cohen, 1988). The way patients perceived their health and their lives and, more specifically, when they envisioned themselves to achieve their own life goals correlated with general self-reported offences, even after controlling for risk level. SWB with health buffered a high risk level for self-reported general offences: high risk patients who were more satisfied with their general and mental health reported three times fewer general offences than high risk patients who were less satisfied.

General subjective well-being was only modestly negatively related to official violent reconvictions in the longer term. Satisfaction with health was also significantly related to fewer reconvictions for violent offences. After controlling for risk level, which again correlated with 


\section{CHAPTER 7}

reconvictions with a medium effect size, none of the previously mentioned significant relationships between subjective well-being indicators and official re-offending remained significant. However, satisfaction with health and general life satisfaction did buffer a high risk level for violent reconvictions after a three year follow-up. Patients' judgements about their health, as well as their satisfaction with mental health care, was associated with a significant difference in number of reconvictions for violent offences: more satisfied patients committed six times fewer violent re-offences than dissatisfied patients; general life satisfaction resulted in a three times lower level of reconvictions for violent crimes compared to patients who were not that satisfied with their lives.

As a theoretical framework, we used the Good Lives Model (Ward, 2002) to explore the relationship between subjective well-being and criminal behaviour. In the GLM, patients are hypothesized to be less inclined to commit offences if their lives are good and fulfilling. We operationalised 'a good life' as satisfaction with oneself and one's life as perceived by the patient. The fulfilling life was studied by means of two subscales of the Life Regard Index: life framework and life fulfilment. The results, especially for satisfaction with health and satisfaction with their lives in general, support the good lives notion. The strength of the correlations indicated that subjective well-being seems to have a stronger effect on short-term delinquent behaviour than on longer-term reconvictions, although for high risk patients, there was also an effect on the longer term.

The main limitation of this study was the sample size, especially in the study of the relationship between SWB and self-reported offences. The response-rate for self-reported delinquent behaviour after three months was less than 50\%. We were unable to (re-)approach non-responders to improve the response-rate, due to restrictions concerning the anonymity of participants. However, we did not find any significant differences between responders and non-responders at $\mathrm{T}_{1}$ on important risk factors.

In our sample, the domain-specific indicators of SWB did not change within the sixmonth period, but general SWB and three of the four internal indicators of SWB did change significantly. Whether these changes result in a lasting higher level of SWB is unknown, and could be a subject for future studies. With the present design, we were unable to determine whether indicators of SWB should be considered stable or acute dynamic factors (see Hanson \& Harris, 1998; Webster, Douglas, Belfrage, \& Link, 2000). The lack of a relationship of SWB with long-term criminal reconvictions may indicate either an absence of a relationship between 
SWB and longer term criminal behaviour or point at the acutely dynamic nature of SWB, which might fluctuate with degree of mental health support.

In our study, five significant AUCs reached a level of $\geq .70$ : between Satisfaction with Health and self-reported violent and general offences; between Life Framework and selfreported property offences; between Satisfaction with Finances and property reconvictions; and between Satisfaction with Health and violent reconvictions, but none reached the threshold of $\geq .75$. In our opinion, these values are of modest accuracy. The other significant AUCs did not reach this threshold. The lower bound of the $95 \%$ confidence intervals did not reach the .70 threshold in any case. The highest was found for the curve of satisfaction with health and self-reported violent offences: lower bound $\mathrm{AUC}=.60$. Although these values are modest, "[instruments] of modest accuracy yield relevant information that is better suited to legal decision-making than simply betting the base rate" (Mossman, 2008: p. 280), because "even modest accuracy (i.e., AUC $\cong 0.7$ ) can identify some offenders as statistically "likely" to recidivate" (p. 288).

The primary aim of this study was to identify possible protective factors for criminal (re)offending. Although the results are modest, they are promising enough to merit further exploration in future studies. Our study had a cross-sectional, prospective design. To more fundamentally explore the possible buffering effect of subjective well-being on criminal desistance, an experimental design is warranted. The Good Lives Model offers means to improve subjective well-being of offenders. Thus, a design in which forensic psychiatric outpatients are randomly assigned to a control group and to an experimental group which undergoes (additional) treatment with a good lives plan to enhance subjective well-being, which employs outcome measures such as short-term self-reported and official long-term reoffending could provide more insight into the possible causal relationship between subjective well-being and desistance from criminal offending. 



\section{Chapter 8}

General conclusions and discussion 
CHAPTER 8 
During the past decades, we have witnessed an increasing focus on risk assessment in forensic psychiatry. Subsequently, a number of scholars have called for a more balanced approach which also incorporates protective factors (Andrews, Bonta, \& Wormith, 2004; Douglas, Webster, Hart, Eaves, \& Ogloff, 2001; Farrington \& Loeber, 2000; Miller, 2006; Rogers, 2000). The research described in this thesis is an answer to that call. In this final chapter, we will discuss the main findings and their implications for our theoretical model, for forensic practice and for future research. More specifically, we will address the issue whether our findings provide support for the opinion that (objective and subjective indicators of) quality of life (QoL) should be incorporated into the community-based and clinical practice of forensic psychiatry.

\section{MAIN EMPIRICAL FINDINGS}

\section{Quality of life of forensic psychiatric outpatients}

The first aim of this study was to explore QoL of forensic psychiatric outpatients and to compare it with psychiatric outpatients without a personality disorder (PD). Next, we aimed to explore the QoL of two subgroups of forensic psychiatric outpatients: violent offenders and sexual offenders. So far, these specific subgroups had not been investigated in QoL research.

We found that, despite better objective life circumstances, forensic outpatients with a PD or PD traits gave their overall quality of life a lower score than outpatients with a major mental disorder, such as schizophrenia. Both groups displayed similar ratings for domain-specific subjective QoL (see Chapter 2). In a similar vein, violent offenders valued their overall QoL lower than sexual offenders despite similar objective circumstances (see Chapter 3).

To explain these discrepancies between objective and subjective ratings, we consider three arguments: (1) the judicial involvement in our forensic sample may have had a dominating negative impact on the patients' subjective ratings; (2) Personality Disorder Not Otherwise Specified was the most common diagnosis in the forensic sample and $61.1 \%$ of these patients had cluster B PD traits, closely followed by cluster B PDs (23\%). Previous studies have reported that outpatients with cluster B PD rated their overall QoL lower than patients with other PDs (Chen et al., 2006; Sareen, Stein, Cox, \& Hassard, 2004); (3) patients with schizophrenia may have adapted better to their disorder, accepted it as it is, or might have changed their frame of reference (see Schwartz \& Sprangers, 2000). 


\section{CHAPTER 8}

\section{Quality of life and recidivism}

In line with the aim of this thesis, we next examined the relationship of indicators of quality of life, known from the literature (Oliver et al., 1996; Ruggeri, Warner, Bisoffi, \& Fontecedro, 2001; Ruggeri et al., 2005; van Nieuwenhuizen, Schene, Boevink, \& Wolf, 1998), with selfreported offences in the short-term and with criminal recidivism as measured through official reconvictions over a longer time span. The association between objective QoL indicators and self-reported recidivism over six months yielded several interesting findings (see Chapter 6). Participation in organised leisure activities (e.g. sports clubs) seemed to have a protective effect on delinquent behaviour, as has previously been reported in adolescent offender samples (DuRant, Knight, \& Goodman, 1997; Hoge, Andrews, \& Leschied, 1996; Reddon, Pope, Friel, \& Sinha, 1996). In our forensic outpatients, however, closer social contacts, that is ties to a partner, family and friends, were unrelated to desistance from delinquent behaviour (see Chapter 6). This finding does not concur with previous research findings (Klassen \& O’Connor, 1989; Oddone-Paolucci, Violato, \& Schofield, 2000; Sampson \& Laub, 2005; Wright \& Wright, 1992). Likewise, having paid employment has previously been found to be negatively related to re-offending (Gendreau, Goggin, \& Gray, 2000; Sampson \& Laub, 1990). We also did not find support for that relationship. However, we did find a relationship between qualitative (social) aspects of work (i.e. good relationships at work with a boss or coworkers) and a lower level of violent recidivism in the short-term.

For forensic outpatients who were rated as high-risk, based on a structured instrument for the assessment of the risk of criminal recidivism, club membership and the number of social institutions in which they participated had a negative relationship with violent reoffending. Moreover, for high-risk patients, being in an intimate relationship was related to higher levels of criminal behaviour. Participation in more distant social institutions, such as leisure organisations and church, can therefore buffer a high risk level in forensic outpatients with PD, which is not the case for more intimate relationships.

Several subjective indicators of QoL were related to criminal behaviour during a follow up of three years (see Chapter 7). Higher satisfaction with finances and with health, as well as fulfilment of life goals correlated significantly with fewer self-reported offences within three months. Furthermore, higher satisfaction with health, higher overall subjective QoL and a more meaningful life perspective or set of life goals predicted fewer violent reconvictions over a period of three years for the total sample. For high-risk patients, satisfaction with health was 
negatively related with general self-reported offences. Satisfaction with health contained subjective indicators of mental and general health, as well as service satisfaction. Again, in high-risk patients, satisfaction with health and overall subjective QoL showed a negative relation with violent reconvictions.

In an earlier study (Draine \& Solomon, 1994), patients who violated parole conditions and had to return to jail were less satisfied with their living circumstances and with their lives in general before re-incarceration than patients who did not have to return to jail. These findings combined with our results point at the relevance of a positive subjective evaluation of QoL for desistance from criminal offending. The predictive accuracy of subjective indicators of QoL for violent recidivism or property offences was modest (AUC around .70). However, even predictors with modest accuracy can assist clinicians in risk prevention (Mossman, 2008) and these dynamic predictors therefore deserve attention as treatment targets.

\section{Change in quality of life}

If improving QoL would become a treatment target in forensic treatment, the dynamic nature of this outcome measure should be investigated, as well as key factors which influence QoL. One of the aims of this thesis was therefore to explore change in objective as well as subjective QoL over a six-month treatment period. We found that indicators of objective life circumstances tended to be stable (see Chapter 5). This was also found in previous studies on change in QoL among general psychiatric outpatients using even longer follow up periods, up to six years (Oliver, Huxley, Bridges, \& Mohamad, 1996; Ruggeri et al., 2005).

In risk assessment research, these objective indicators have been typified as stable dynamic (risk) factors (Hanson \& Harris, 2000). Objective circumstances can change, for instance if they are a particular focus in treatment, but mostly these changes take a long time and are difficult to attain. A number of these objective indicators are included in the DSM-IVTR criteria for PD (APA, 2000) as areas in which PD patients experience problems, for instance work and social relationships. Because of the stable nature of these indicators and because of the characteristics of our forensic PD sample, a positive change in objective life circumstances seems difficult to attain.

Overall subjective QoL changed positively during the six months period (Chapter 5). This is in line with other studies on QoL in psychiatric outpatients with PDs (Karterud et al., 2003) as well as outpatients with other disorders, mainly psychotic disorders (Hansson \& 


\section{CHAPTER 8}

Björkman, 2007; Oliver et al., 1996; Ruggeri et al., 2005; Swanson, Swartz, Elbogen, Wagner, \& Burns, 2003). Especially patients with an initially low level of subjective well-being improved; patients who already rated their lives rather positive scored significantly lower on their overall QoL after six months. Although domain-specific subjective QoL did not change during the six months for the entire sample, patients with an initially low score did improve.

In earlier studies, domains in which outpatients with psychiatric disorders improved significantly during and after treatment varied per study: Oliver et al. (1996) described positive changes in the leisure domain in outpatients with schizophrenia; Judd, Thomas, Schwartz, Outcalt and Hough (2003) found a positive change in the financial domain for dually diagnosed outpatients; on the other hand, Hansson and Björkman (2007) discovered positive changes in the domains work, living situation, family and health in psychiatric patients receiving case management. Our forensic outpatients seem to have a relatively high QoL score at baseline compared to, for instance, the Oliver et al. and the Hansson and Björkman samples, which might indicate a ceiling effect (Stucki, Daltroy, Katz, Johannesson, \& Liang, 1996). The baseline scores of our forensic outpatients on the life domains, which changed in the previous studies, resemble the level of the follow up scores in these previous samples.

When studying the relationship between change in QoL and several key factors identified as influential to change in QoL (see e.g. Fakhoury \& Priebe, 2002) or to risk of recidivism (Monahan et al., 2001), a few significant correlations emerged. Positive life events (LE) and positive controllable events, which occurred during a six month period, were related to a larger increase in overall QoL; uncontrollable events were related to a smaller increase (see Chapter 4). Although negative controllable LE correlated negatively with global QoL, these events did not result in a decrease in QoL. Forensic outpatients seem to be exposed to a relatively constant level of negative life events, and they may have gotten used to this situation. This confirms the central hypothesis of the Dynamic Equilibrium Model (DEM; Headey \& Wearing, 1989), which states that only a change in the stream of life events may lead to a change in subjective well-being.

Although only a few indicators had changed, treatment intensity was unrelated to change in almost all indicators of QoL during a six-month follow up in our forensic sample (see Chapter 5) with one exception; patients who had followed treatment with a high intensity more often gained a helping friend. Furthermore, a higher treatment intensity gave more reduction of negative self-esteem. It is important to stress that the forensic treatment which patients had 
received in our study was not explicitly directed towards improvement of (subjective) QoL. The main focus was on relapse prevention which might at least partly explain the lack of an effect on most subjective and objective indicators of QoL, but holds promise for the future when QoL will be explicitly targeted during treatment.

\section{IMPLICATIONS FOR THE THEORETICAL MODEL}

Our exploration of the role of QoL in forensic outpatients was focussed through the use of theoretical models derived from forensic psychology: the Good Lives Model (GLM; Ward, 2002), and from criminology: the General Strain Theory (GST; Agnew, 1992) and the Social Control Theory (SCT; Sampson \& Laub, 1990, 2005). The GLM hypothesises that if individuals have a good or fulfilling life, the need and urge for criminal behaviour diminishes. GST hypothesises that negative life events cause strain, which increases negative affect, which in turn results in a propensity for delinquent behaviour. SCT hypothesises that social ties can exert social control which diminishes the risk of criminal behaviour. We will now review our findings in light of these theories (see Figure 8.1).

\section{The Good Lives Model and criminal recidivism}

In the Good Lives Model (Ward, 2002), a good or fulfilling life is supposed to contribute to a reduction in recidivism (Ward \& Brown, 2004). A good life becomes possible when "an individual possesses the necessary conditions for achieving primary goods, has access to primary goods, lives a life characterized by the instantiation of these goods and when this is achieved in balance with the social obligations of community membership" (Ward \& Brown, 2004, p. 249). Primary (human) goods are "defined as actions, states of affairs, characteristics, experiences, and states of mind that are intrinsically beneficial to human beings" (p. 246). Examples are good health, freedom from stress and spirituality.

Several subjective indicators of QoL and overall QoL were found to be inversely related to both short-term and long-term criminal recidivism. This supports the general assumption of the GLM. More specifically, three primary human goods mentioned in the GLM were protective of re-offending: a good life (expressed through good health and sound finances), agency and spirituality (both expressed through life framework and life fulfilment). Both our study and studies by Purvis (2005; mentioned in Ward, Mann, \& Gannon, 2007) and Lindsay, 


\section{CHAPTER 8}

Ward, Morgan and Wilson (2007) underscore the importance of including notions of the good life or QoL in a theoretical model to understand criminal (re)offending.

\section{General Strain Theory and recidivism in forensic outpatients}

Since negative life events were not related to a decrease in subjective quality of life over time and forensic outpatients reported a fairly constant level of negative life events, we could not confirm nor falsify GST in this sample. This outcome might be related to two factors. Firstly, GST relates negative affect to criminal behaviour: we used subjective quality of life as an outcome measure and not negative affect. Although negative affect is strongly inversely related to subjective quality of life (Fakhoury \& Priebe, 2002; Ruggeri et al., 2005), this relationship is not so strong that they could seamlessly replace each other. Furthermore, Hanson and Harris (2000) found that, among sexual offenders, recidivists and non-recidivists had equivalent levels of negative affect and life stress, which does not support the GST either.

Secondly, all patients in this study had PD characteristics, and many had cluster B PD traits. These characteristics render them more prone to negative life events (Heikkinen et al., 1997; Leaf, Alington, Mass, DiGiuseppe, \& Ellis, 1991; Pagano et al., 2004; Samuels, Nestadt, Romanoski, Folstein, \& McHugh, 1994). One could argue that PD patients are under continuous strain, and therefore pose a constant high risk of delinquent behaviour. Or, alternatively, one could presume that, because PD patients are used to high levels of negative life events, they may have gotten used to the practical and emotional consequences of these constant mishaps in their lives, so that life events do not influence (a negative change in) QoL. Hence, the GST may not be as applicable to PD patients, due to high levels of external and internal stress these patients are continuously exposed to. This hypothesis could of course be tested in an intervention study that targets problem solving and stress coping skills in forensic outpatients with PD.

\section{Social Control Theory in forensic outpatients}

Social Control Theory of Sampson and Laub (1990, 2005) hypothesises a protective role for social ties in relation to criminal behaviour. According to Sampson and Laub, social ties in adulthood can be found in three types of institutions: family, work, and community. We found a protective role for work-related social contacts, club participation and church visits, and for participation in social institutions in general. 


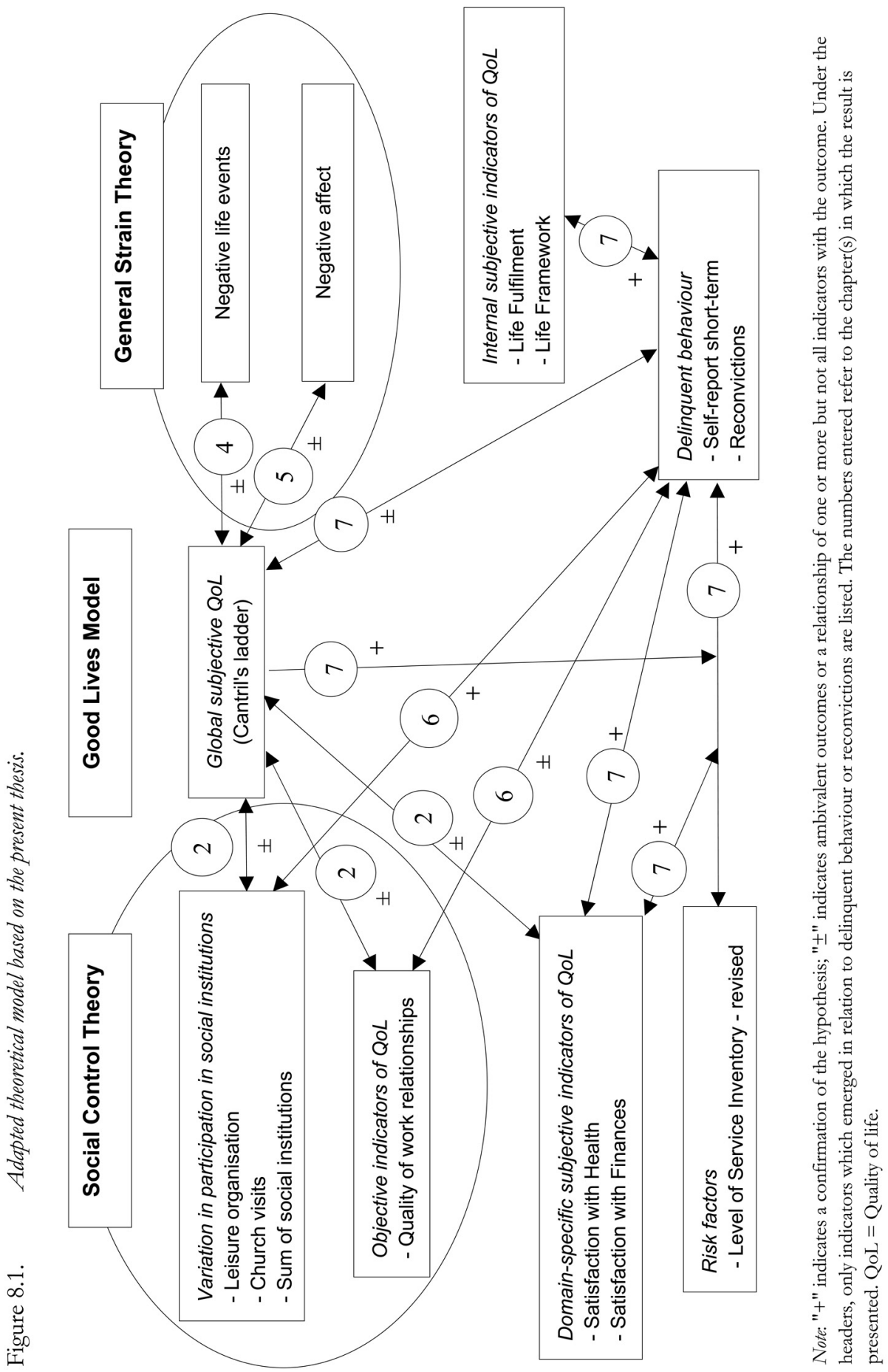




\section{CHAPTER 8}

However, we did not find confirmation for the protective function of social relationships within the intimate or close sphere of the patient (i.e. partner, family or friends). For high-risk patients, having an intimate relationship was even positively related to short-term self-reported property offences and living with others was positively related to violent behaviour. A good marriage has often been demonstrated to be negatively related to criminal behaviour (OddonePaolucci et al., 2000; Wright \& Wright, 1992). It seems fair to conclude that the sources of social control for forensic outpatients with PD are situated in institutions outside the intimate or the effective zone (i.e. consisting of people with whom the patient has both personal connections and a certain degree of confidentiality; and with whom the patient solely has personal connections, respectively; Franssen \& Knipscheer, 1990) of the social network. Patients who are capable of keeping good relationships at work, that is in the extended social network zone, which is characterised by relatively superficial relationships, and patients who are capable of participating in social institutions seem less likely to commit a re-offence. This confirms a part of Social Control Theory.

\section{The protective function of quality of life}

In the model used in this thesis (see Introduction, p. 17 and Figure 8.1), quality of life is propounded to mediate or buffer risk factors in relation to criminal recidivism or delinquent behaviour (cf. Fitzpatrick, 1997). Quality of life can have a direct or an indirect effect on criminal recidivism. Based on the prospective, cross-sectional results of the studies presented in Chapters 6 and 7, we can not determine whether the factors associated with delinquent behaviour are mediating or buffering factors. However, in patients who were assessed as posing a high risk of recidivism, their overall satisfaction with life and satisfaction with their health seemed to buffer violent behaviour, as did participation in structured leisure activities and in social institutions in general.

\section{STRENGTHS AND LIMITATIONS OF THIS THESIS}

This thesis describes a series of studies among adult male forensic psychiatric outpatients with a personality disorder or PD traits. To put the findings in perspective, the strengths and limitations of this research project need to be taken into account. 


\section{Strengths}

Until recently, quality of life was a topic only rarely addressed in forensic psychiatry (see van Nieuwenhuizen, Schene, \& Koeter, 2002). Besides several reports describing QoL in forensic in- or outpatient samples, only one previous study related subjective quality of life to recidivism in terms of return to jail (Draine \& Solomon, 1994). The outcome of that study was not criminal recidivism but violations of probation or parole conditions. To our knowledge, the current study was the first to relate subjective quality of life to criminal recidivism.

Besides using a multidimensional concept of QoL, this study was theory-based with regard to the hypothesised relationships between indicators of QoL and criminal behaviour. Many studies in forensic psychiatry aim at the reduction of risk without basing their hypotheses on theoretical assumptions (Bonta, 1997). Although psychological theories are sometimes included in risk assessment research (see e.g. Andrews \& Bonta, 1995; Dernevik, 2004), the majority of studies in forensic psychiatric populations are not theory-driven (see e.g. Silver, 2000, 2006).

In this study, QoL was measured using the extended Dutch version of the Lancashire Quality of Life Profile (LQoLP; van Nieuwenhuizen, Schene \& Koeter, 1998). This instrument is a well studied and validated structured interview. The LQOLP was specifically developed to measure QoL in (chronic) psychiatry. Several other studies into QoL in (forensic) psychiatry have used self-report measures of QoL (such as the World Health Organisation Quality of Life [WHOQOL] used by Sallopé \& Pham, 2007; Masthoff, Trompenaars, van Heck, Hodiamont, \& de Vries, 2006; Trompenaars, Masthoff, van Heck, Hodiamont, \& de Vries, 2006). However, most used the LQoLP or comparable interviews (Swinton, Oliver, \& Carlisle, 1999; Swinton, Carlisle, \& Oliver, 2001; Walker \& Gudjonsson, 2000; Draine \& Solomon, 1992, 1994, 2001; Gerber et al., 2003; Long, McLean, Boothby, \& Hollin, 2008; Swanson et al., 1998; Lindstedt, Söderlund, Stålenheim, \& Sjödén, 2005).

\section{Limitations}

Because of our cross-sectional design, patients varied greatly in length of treatment (between just started and nine years in treatment). In general, the QoL of patients is supposed to improve during treatment (Hansson \& Björkman, 2007; Judd et al., 2003; Oliver et al., 1996; Ruggeri et al., 2005; Skevington \& Wright, 2001; Swanson et al., 2003). However, improvement of QoL could also be subject to the law of diminishing returns. We did not find a relationship 


\section{CHAPTER 8}

between length of treatment and (change in) QoL, neither linear nor curvilinear. Despite this variety in treatment duration and absence of QoL as treatment target, global QoL improved on average, which might indicate a real improvement following treatment or indicate a response shift phenomenon (Schwartz \& Sprangers, 2000).

Psychiatric diagnoses were gathered from case files for this study. Not every forensic outpatient facility used standardised interviews to classify the disorders of patients. Although every clinician had been trained in clinical assessment, the accuracy of the diagnoses is unknown.

Patient attrition was a serious problem in our research. We started with a sample of 241 outpatients of whom 56 participated in every interview and returned every self-report questionnaire. Although there were hardly any significant differences on essential characteristics between participants and drop-outs, the high non-response rate could have led to selection bias. For instance, patients who were incarcerated after baseline, either because of previous or new offences, were not included in the study on criminal reconvictions, because only patients who participated at the second interview round were included 5 . And drop-outs seem to have a more severe criminal background, and patients with a more extensive criminal background more often reported lower levels of (global) QoL. Whether this had an influence on the results with regard to the relationship between subjective QoL and criminal recidivism is unclear, since no differences between responders and dropouts were found on subjective QoL at $\mathrm{T}_{0}$.

A second shortcoming of the limited sample size was the impossibility to form sufficiently large subgroups to perform robust statistical analyses. Two characteristics of these outpatients merit the formation of subgroups: the types of previous criminal behaviour (violent crimes, sexual assaults, sexual offences against children, arson and property offences) and type of personality disorder. In the risk assessment literature, the type of index offence is related to different base rates of re-offending (see e.g. van Horn, Mulder, \& Scholing, 2006; Philipse, 2005; Wartna, 2009). In recent studies on QoL in patients with PD (Chen et al., 2006; Saloppé \& Pham, 2007; Sareen et al., 2004), the type of PD resulted in differences in (subjective) QoL. Especially patients with antisocial and other cluster B PDs scored lower on several indicators

5 The results of post-hoc analyses between participation at $\mathrm{T}_{2}$ and official reconvictions showed that drop-outs more often had been reconvicted of a property offence than responders (dropouts $=35.5 \%$ reconvicted; responders $\left.=9.8 \% ; \chi^{2}[1]=11.791 ; p=.001\right)$. No significant differences were found for violent reconvictions and reconvictions in general. 
than patients with cluster A and C PDs. A third reason to seek larger samples is the fact that it would create the possibility of applying more sophisticated statistical analysis methods, such as structural equation modelling, which are designed to make causal inferences. In the regression analyses in Chapters 6 and 7, not every possible predictor was entered because of the maximum number of predictors based on sample size. Larger samples would allow testing of more comprehensive models of both quality of life and recidivism.

The follow-up time for criminal recidivism in this study was three or six months for selfreported delinquent behaviour and three years for criminal reconvictions (range $=2.3-3.8$ years). The follow-up period does not equate with time at risk, but with the time between the assessments and the retrieval of self-reported criminal behaviour and official judicial data, respectively. We focused on the influence of stable dynamic factors; factors which can change over time, and whose impact on re-offending over time may be clouded because the situation of the initial assessment may have changed. The length of follow-up also influences reconviction rates (see also Leuw, 1999). In recent risk assessment research in The Netherlands (Hildebrand, 2004; Philipse, Koeter, van der Staak, \& van den Brink, 2006; de Vogel, de Ruiter, Hildebrand, Bos, \& van de Ven, 2004), the follow-up times ranged from 7 to 20 years. The number of patients who were reconvicted will probably be an underestimation of the number of patients who will eventually re-offend.

\section{IMPLICATIONS FOR CLINICAL PRACTICE}

\section{Quality of life in risk assessment and risk management}

Several (treatment and risk assessment) models in forensic psychiatry incorporate (aspects of) quality of life. In a comprehensive Risk-Need-Responsivity model of forensic treatment encompassed in the Level of Service/Case Management Inventory (LS/CMI; Andrews, Bonta \& Wormith, 2004, p. 152), client well-being is included and related to responsivity, that is how treatment should be delivered to have the largest chance of a positive effect. The Structured Outcome Assessment and Community Risk Monitoring (SORM; Grann et al., 2001) includes a single measure of subjective quality of life in its assessment of treatment outcome and risk monitoring. The Structured Assessment of PROtective Factors for violence risk (SAPROF; de Vogel, de Ruiter, Bouman, \& de Vries Robbé, 2007, 2009) and the Short Term Assessment of Risk and Treatability (START; Webster, Martin, Brink, Nicholls, \& Middleton, 2004) include several 


\section{CHAPTER 8}

indicators of quality of life as possible protective factors, such as life goals and leisure activities. These recently developed measures which aim at including protective factors in risk assessment should be subjected to thorough evaluation, especially the predictive validity, before these instruments can be administered in connection with release decision-making which could result in either the prolongation of restrictive measures or release of patients into the community.

Quality of life can be used in risk management, by monitoring it and targeting it in treatment. The term quality in QoL refers to a property of the noun that follows, in this case: life. Life can be of a good or poor quality, and anything in between. Quality of life is not by definition protective of criminal behaviour, but a good quality can be. In treatment of forensic psychiatric outpatients with PD characteristics, targeting improvement of the quality of life in general and of the quality of the perception of health and of the financial situation may result in lower levels of criminal behaviour. Furthermore, enhancing participation in social institutions in general and structured leisure activities and a religious community may positively influence criminal desistance, and could be a main treatment target. With regard to participation in paid employment, not just having a job but the quality of contacts at work seem important and should be monitored instead of simply finding and keeping work. Two other indicators of QoL - life framework and life fulfilment - merit attention in treatment, since both were related to desistance from short-term criminal behaviour and reconvictions.

Risk management consists of several components, among which treatment of risk factors and monitoring of risk level. Monitoring (indicators of) QoL in a forensic outpatient population can be supported by the use of the extended Dutch version of the LQoLP (van Nieuwenhuizen, Schene \& Koeter, 1998). The LQoLP uses both objective and subjective domain-specific indicators to measure QoL and the Life Regard Index which measures life framework and life fulfilment. The LQoLP is considered lengthy, with 151 variables, and it takes approximately 30 minutes to administer. To be able to use the instrument for continuous monitoring, the development of a brief version which includes the most relevant items for our population is advisable. The Manchester short assessment of quality of life (MANSA; Priebe, Huxley, Knight, \& Evenas, 1999) is a shorter version of the LQoLP, and includes 16 questions, but does not include every relevant aspect which surfaced in our studies.

The optimal frequency of follow-up assessment of QoL in a forensic psychiatric outpatient population can not be ascertained from the results of this study. It seems advisable to follow patients from the beginning of treatment until at least half a year after treatment has 
ended. Assessment of the subjective indicators should be performed every six months, whereas the frequency of measuring the objective indicators can be less, for instance annually.

\section{Implementing a Good Lives Model}

The Risk-Need-Responsivity model of treatment of forensic psychiatric (out)patients offers a general method covering treatment targets relevant to patients with PD who are at risk of criminal recidivism (Andrews \& Bonta, 1998). According to Ward and colleagues, the RiskNeed-Responsivity model "lacks the conceptual resources to adequately guide therapists and to engage offenders" (Ward \& Brown, 2004, p. 245) in treatment. They label the risk approach: a pincushion model of treatment, with a pin representing a risk factor and treatment aiming at removing each individual pin (Ward, Mann, \& Gannon, 2007), without considering the need this represents for the patient. Rehabilitation should focus on reducing/avoiding risk and on promoting human goods: the GLM aims at incorporating both treatment aims.

Ward and Brown (2004) propose that the GLM "conceptualizes dynamic risk factors as distortions in the internal and external conditions required for the acquisition of human goods" (p. 244). In the model, two levels of goods are distinguished: primary and secondary (or instrumental) goods. Primary human goods are described above (\$ 8.2.1.) and instrumental or secondary goods "provide concrete ways of securing these [primary, YB] goods" (p. 246). They list 10 classes of basic human goods: life (including healthy living and functioning), knowledge, excellence in play and work (including mastery experiences), excellence in agency (i.e. autonomy and self-directness), inner peace (i.e. freedom from emotional turmoil and stress), friendship (including intimate and family relationships), community, spirituality (in the broad sense of finding meaning and purpose in life), happiness, and creativity (Ward, Mann, \& Gannon, 2007). Ward, Mann and Gannon (2007, p. 97) distinguish six phases in the formulation of a treatment plan: (1) Identifying the problems a patient has and what criminogenic needs are evident, related to the offending behaviour; (2) Identifying the primary goods that are directly or indirectly linked to the offending behaviour; (3) Identifying the overarching good [original italics] and making this the primary focus of the treatment plan; (4) Selection of the secondary goods or values that specify how primary goods will be translated into ways of living and functioning; (5) Identification of the contexts or environments the person is likely to be living in; (6) Construction of a treatment plan based on the previous five phases. 


\section{CHAPTER 8}

The GLM can be improved by implementing premises from other theories on wellbeing. For instance, Ward and colleagues consider each human good equally important for every person, despite possible (insurmountable) barriers to achieve a specific good. A mechanism of substitution should be embedded in the model by which an impossibility to achieve a certain good can be compensated by the achievement of a different good (Ormel, Lindenberg, Severink, \& Verbrugge, 1999).

Employing the Good Lives Model in the treatment of forensic psychiatric (out)patients may affect the motivation and responsivity of the patient in a positive way as well as strengthen possible protective factors, which, in combination with a risk approach, might make treatment of this population more effective and efficient.

\section{SUGGESTIONS FOR FUTURE RESEARCH}

We suggest several pathways of research which can lead to more effective positioning of (indicators of) QoL in forensic assessment and treatment:

- In general, the predictive validity of protective factors should be more thoroughly investigated. A study on the subject is under way, and a first, retrospective analysis seems promising (de Vries Robbé, de Vogel, \& de Spa, submitted).

- $\quad$ Evaluation of the Good Lives Model (GLM) using a (quasi-) experimental design (treatment as usual versus treatment based on GLM) with the following treatment outcomes: short-term criminal behaviour, long-term criminal recidivism and subjective well-being is useful.

- Stronger empirical evidence for the relationships found in this study is needed. By replicating the current study, and by increasing both the number of participants and the number of patients participating in follow-up assessments, and by including patients at the start of treatment, more sophisticated statistical analysis methods can be used, which allows the testing of causal models.

- Only a limited number of objective indicators of QoL was examined in relation to criminal behaviour. The contribution of other objective indicators on criminal desistance warrants further examination in forensic outpatients with PD.

- $\quad$ Differentiation between types of index offence and type of PD seems useful based on the results reported in Chapters 2 and 3, and based on other studies in which 
differentiation by PDs (Chen et al., 2006; Saloppé \& Pham, 2007; Sareen et al., 2004) has proven useful. Furthermore, many patients in forensic community-based treatment suffer from several personality and psychiatric disorders. This co-morbidity of psychiatric disorders can influence the QoL of outpatients, based on studies in which co-morbidity was associated with a lower QoL compared to patients with fewer disorders (Draine \& Solomon, 2000; Masthoff et al., 2006). Studies focussing on the QoL of these subgroups, and on treatment-outcomes for the distinct subgroups seem useful.

\section{CONCLUDING REMARKS}

In this thesis, the population studied consisted of forensic psychiatric outpatients with personality disorders or traits of PD. The concept of QoL of these patients has been explored and change in QoL has been mapped. This population is very specific, both with regard to their psychopathology and to the treatment setting in which they were studied. Several authors have noted that a different concept of QoL is warranted in clinical forensic psychiatry (Coid, 1993; Swinton et al., 1999; van Nieuwenhuizen et a., 2002), mainly because of a lack of freedom and autonomy. In long-stay forensic psychiatry, the issues of spirituality and purpose in life become even more important in relation to QoL. In general however, the definition of QoL as adopted by Lehman (1983): a sense of well-being and satisfaction experienced by individuals under their current life conditions, is also applicable to patients with different mental disorders and in other (clinical) settings, and also to non-disordered offenders. The indicators which are most important may, however, differ with disorder or setting, as was shown in Chapter 2. A concept-map, using the more general definition as starting point, would be a useful method to explore which indicators make up the concept per setting and disorder. In the long-stay facility of the Pompestichting, a forensic psychiatric facility in The Netherlands, such an exploration has been conducted and resulted in a setting specific instrument for QoL (the Forensic inpatient Quality of Life Questionnaire; Vorstenbosch, Bulten, Bouman, \& Braun, 2008), which is currently tested on reliability and validity. Besides the usefulness of QoL in forensic psychiatric settings, QoL can also direct rehabilitation after incarceration, as has been adopted by several (private) institutions in The Netherlands. This led to very promising results with regard to recidivism-rates: ex-detainees who successfully 


\section{CHAPTER 8}

followed the program, which aimed at living circumstances, work, intimate and other social relationships and purpose in life (Pont, van de Woude, \& Moerings, 2005), recidivated less often than ex-detainees who did not successfully complete the program (18\% versus 59\% reconvictions; van Wingerden \& Moerings, 2007). Although our hope is preliminary, and much more research is needed, the inclusion of certain objective and subjective indicators of quality of life as targets in the treatment of forensic psychiatric outpatients and inpatients during the reintegration phase of treatment could enhance responsivity and assist in criminal desistance. 


\section{Summary}

\section{Background}

In (community-based) forensic psychiatry, treatment is provided for patients who have committed an offence or are at risk of committing an offence in relation to a mental disorder. The majority of patients in Dutch forensic psychiatry suffer from a personality disorder (PD), mainly of the dramatic, emotional or erratic type (i.e. cluster B). The offences these patients have committed or are at risk of committing are mostly aggressive or sexual in nature. In combination with the mental disorder, the (sexually) aggressive behaviour is the reason these individuals have been referred to forensic psychiatric services or have been sentenced to judicial measure mandating psychiatric treatment.

Over the last decade, risk assessment and risk management have become guiding principles in forensic psychiatry. The forensic treatment targets are (dynamic) factors which increase the risk of criminal recidivism. This exclusive focus on risk reduction bares the risk of neglecting the responsivity of the patient and of the possible protective factors in the patient himself or his environment. Only recently, protective factors have (re-)gained attention from researchers and clinicians, both in The Netherlands and abroad. Research into possible protective factors is virtually absent, especially for adult PD patients.

The aim of the current research is to enhance our knowledge on factors which might prevent criminal recidivism, either directly or indirectly. The factors which were studied were the living circumstances of the patients and the level of satisfaction with these circumstances (i.e. objective and subjective well-being) summarized by the concept of quality of life. Quality of life (QoL) can be defined as a sense of well-being and satisfaction experienced by individuals under their current life conditions. QoL is a multi-dimensional concept which uses both objective and subjective indicators to describe the level of quality of life. Subjective indicators reflect the individual's cognitive and affective judgement of his entire life-situation, as well as of specific life domains, such as employment, financial situation and social contacts. Considering the purpose of the study, that is to relate (indicators of) quality of life with criminal recidivism, and the fact that objective life circumstances of patients would change immediately and drastically after release from a secure setting, only patients in community- 
based forensic care have been studied, since they are at liberty to shape their own life circumstances.

\section{Three models}

Risk assessment research is rarely theory-based. For the current research project, hypotheses relating indicators of quality of life with criminal recidivism were derived from three different theoretical models: (1) Following Hirschi (1969), the Social Control Theory of Sampson and Laub $(1995,2005)$ hypothesizes that persons act delinquently when their interpersonal bonds as well as their bond to society in general are weak or broken; (2) General Strain Theory of Agnew (1992) assumes that the removal of positive stimuli or the presentation of negative stimuli lead to strain, which increases the level of negative affect, in the form of disappointment, depression, anger and the like, which, in turn, increases the likelihood of aggression and/or delinquent behaviour; (3) the Good Lives Model developed by Ward (2002) is based on the idea that "an individual is hypothesized to commit criminal offences because he lacks the capabilities to realize valued outcomes in personally fulfilling and socially acceptable ways" (Ward, Mann, \& Gannon, 2007, p. 90). The central assumption is that if a patient/offender lives a good and/or fulfilling life, the chance of re-offending diminishes. Thus, indicators of quality of life may serve a protective function, also for high-risk patients.

\section{Sample and measures}

The research took place at four community-based forensic psychiatric institutions in different regions of The Netherlands: Kairos, de Waag, de Tender and het Dok. Of a random sample of 241 adult male patients with a personality disorder (PD) or traits of PDs, 135 patients agreed to participate at the first assessment. Participants were on average 37.5 years old, and almost a third was employed. Two third of the patients had ever been convicted of a crime, and almost half of the responders had been incarcerated. During the first assessment, the extended Dutch version of the Lancashire Quality of Life Profile was administered, which consists of an interview on objective and subjective indicators of quality of life. Furthermore, the Level of Service Inventory-Revised, a professional judgment risk assessment instrument, and self-report questionnaires on life events and on delinquent behaviour were administered. The latter two questionnaires were re-administered three month after the baseline assessment. Again three months later, 102 patients participated in the six-months follow-up and were interviewed using 
the same assessment instruments. Just over two years after the last follow-up interviews, recidivism data were gathered from the Dutch Judicial Documentation Register. Patients' consent was obtained for all phases of the study.

\section{Results}

First, quality of life of the patients was explored. This was done in two ways: (1) by comparing our forensic outpatients to patients with major mental disorders in community-based general psychiatry and (2) by comparing patients within our forensic outpatient sample who had committed an aggressive offence to patients with a sexual offence. Compared to the patients with a major mental disorder, PD patients in community-based forensic psychiatry reported better objective life circumstances, such as having paid employment and an intimate relationship (see Chapter 2). Both groups did not differ on the domain-specific subjective assessment of their lives. However, global subjective QoL was lower in the PD than in the general psychiatric patient group. For PD outpatients, different indicators (e.g. satisfaction with health and with finances) contributed to their global assessment of QoL, whereas for general psychiatric outpatients, satisfaction with their everyday activities and their objective sense of safety seemed most important.

For the PD patient group, we subsequently compared patients who had committed a violent offence to patients with a sexual offence (see Chapter 3). Although sexual offenders and violent offenders hardly differed on objective indicators of quality of life, sexual offenders were more satisfied in general and in particular with their family relationships, safety and health. Furthermore, for both groups, different objective and subjective indicators correlated with global well-being. Besides satisfaction with leisure and social participation, with health and with finances, satisfaction with safety and having paid employment, and not having debts were most important for aggressive patients and, for sexual offenders, not adhering to a religion.

Following General Strain Theory, the relationship between life events and quality of life (QoL) was studied (see Chapter 4). Negative life events which could be controlled by the patient showed a negative relationship with overall subjective well-being. These controllable events do not happen at random to the person, but are related to his own behaviour. Positive events and positive controllable events were associated with a positive change in QoL. Events over which the patient had no control were negatively related to change in QoL. 
Besides the influence of life events on QoL, the change in objective and subjective indicators of QoL has been examined (see Chapter 5). It was concluded that objective life circumstances did not change over the six month period, with one exception. Patients reported that they more often had a helpful friend at follow-up than at baseline. Although domainspecific subjective QoL did not change for the total group of patients, patients with an initially low score reported a significantly higher score at follow-up on nine of the ten domains and on global subjective QoL. Patients with an initially high score reported significantly lower scores on five of the ten life domains at follow-up than at baseline. Treatment-intensity, mood and severity of PD had no impact on change in QoL.

To examine the central assumption of our research, which states that patients will be less likely to commit criminal offences when they live a good and fulfilling life, objective circumstances were related to self-reported delinquent behaviour six months after the assessment of the life circumstances (see Chapter 6). Patients who engaged in structured leisure activities less often reported general delinquent behaviour. Furthermore, patients who reported good relationships at work less often engaged in violent delinquent behaviour. Other social relationships, such as those with family or friends, were not associated with a reduction in short-term delinquent behaviour. In general, participation in social institutions was related to lower levels of violent behaviour.

Several subjective indicators of QoL, namely satisfaction with finances and with health, also had a negative relationship with self-reported short-term delinquent behaviour, and with longer term general and violent reconvictions and with property offences (see Chapter 7). Furthermore, having goals in life and the judgment that one could achieve these goals also proved to have a possible protective role in relation to criminal recidivism. Satisfaction with health buffered against both self-reported short-term delinquent behaviour and longer term reconvictions for high-risk patients. The same effect was found for global subjective wellbeing: high-risk patients with a higher level of well-being committed fewer offences than highrisk patients with a lower level of global well-being.

\section{General conclusions and recommendations}

The Good Lives Model (GLM) is based on the general assumption that if forensic patients have a good or fulfilling life the risk of (re-)offending diminishes. The findings of this thesis provide some support for this assumption. Aspects of a good life and life fulfilment were related to a 
decrease in delinquent behaviour, measured after the assessment of the indicators of a good life. The sample studied consisted of adult male patients in community-based forensic treatment who suffered from a PD or PD traits. Whether these results can be generalised to other populations needs to be examined.

Following Social Control Theory, social institutions may protect forensic patients against committing re-offence by exerting control. For the sample studied, this control function seems primarily related to more distant institutions, such as leisure organisations, church and work. As noted, we did not find evidence to confirm the first hypothesis of General Strain Theory, since we did not find a relationship between negative life events and change in QoL. The relationship between strain and delinquent behaviour was not examined in this study.

Within risk-assessment, dynamic and static factors are distinguished, and within the dynamic factors, acute and stable factors have been identified. We were unable to establish whether objective indicators of QoL might be considered acute or stable dynamic factors, because they hardly seem to change in the short term. Subjective indicators did change for a part of the sample. The possible influence of treatment on QoL indicators has also not been established. However, treatment interventions which specifically aim at these domains might be effective. In a randomised controlled trail, this effect can be studied by comparing a control group, who receive treatment as usual, with an experimental group who receive treatment according to the principles of the GLM. This might improve the knowledge on the (possible) protective function of objective and/or subjective life circumstances. Of course, the ultimate goal of such research efforts is to improve the efficacy and efficiency of forensic treatment. Recent experiences with a comparable approach in the re-integration of general criminal offenders after detention are promising. 


\section{Nederlandse samenvatting}

\section{Achtergrond}

In de (ambulante) forensische psychiatrie vindt behandeling plaats van patiënten die een delict hebben gepleegd of mogelijk gaan plegen. Een meerderheid van de patiënten in de forensische psychiatrie in Nederland lijdt aan een persoonlijkheidsstoornis, in het bijzonder stoornissen met een overdreven, emotioneel labiel of onconventioneel karakter (Cluster B). De meest voorkomende delicten of delictgedragingen betreffen agressieve en seksuele delicten. De delicten zijn de reden, naast de psychische stoornis, dat iemand naar de forensische psychiatrie wordt verwezen of door de rechter een maatregel opgelegd krijgt waarbij psychiatrische behandeling wordt geëist.

Binnen de forensisch psychiatrische behandeling zijn risicotaxatie en risicomanagement sinds ruim een decennium belangrijke begrippen. Bij risicotaxatie wordt onderzocht welke beïnvloedbare factoren het risico op het (opnieuw) plegen van een delict vergroten. Door weinig aandacht te besteden aan mogelijk beschermende factoren, loopt de risicotaxatie het gevaar niet optimaal aan te sluiten bij de mogelijkheden van de patiënt (responsiviteit) en eenzijdig gericht te worden op risicoverhogende aspecten bij de patiënt en zijn omgeving. Beschermende factoren staan pas de laatste jaren op het netvlies van onderzoekers en behandelaars in de forensische psychiatrie, zowel in Nederland als daarbuiten. Onderzoek naar de mogelijk protectieve werking van dergelijke factoren is uitermate schaars en ontbreekt vrijwel volledig bij patiënten die lijden aan een persoonlijkheidsstoornis.

Het doel van het huidige onderzoek is om een bijdrage te leveren aan de kennis over een groep factoren die mogelijk beschermen tegen delictgedrag, op directe dan wel indirecte wijze. De onderzochte factoren betreffen de levensomstandigheden van de patiënt en hoe tevreden hij daarover is (welzijn en welbevinden), samengevat in het begrip kwaliteit van leven. Het concept kwaliteit van leven wordt gedefinieerd als het gevoel van welzijn en tevredenheid dat een individu ervaart onder zijn/haar huidige levensomstandigheden. Het is een multidimensioneel concept, waarbij zowel objectieve als subjectieve indicatoren gebruikt worden om de kwaliteit van leven in kaart te brengen. Subjectieve indicatoren verwijzen naar de cognitieve en affectieve beoordeling van de eigen levensomstandigheden door een individu, tevens gericht op specifieke levensdomeinen, zoals wonen, werk, financiën, relaties en veiligheid. Gezien het 
doel van dit onderzoek, om (indicatoren van) kwaliteit van leven in relatie te brengen met criminele recidive, en het feit dat de objectieve levensomstandigheden van klinisch opgenomen patiënten na ontslag onmiddellijk veranderen, zijn louter ambulante forensische patiënten onderzocht. Deze laatsten kunnen (vaak) hun eigen levensomstandigheden vormgeven.

\section{Drie modellen}

Het meeste onderzoek naar risicofactoren voor delictgedrag bij forensisch psychiatrische patiënten is niet gebaseerd op een theoretisch model. Voor het huidige project is ter fundering van de hypotheses gebruik gemaakt van drie theoretische modellen. (1) De Social Control Theorie van Sampson en Laub (1995, 2005) hanteert, in navolging van Hirschi (1969), als uitgangspunt dat mensen overgaan tot delinquent gedrag indien hun interpersoonlijke bindingen ofwel hun bindingen met de maatschappij in het algemeen worden verzwakt dan wel verdwijnen. (2) De General Strain Theorie van Agnew (1992) veronderstelt dat het wegnemen van positieve stimuli of de presentatie van negatieve stimuli leidt tot 'strain' (te vertalen als: druk of stress), wat tot een toename van negatieve emoties, zoals teleurstelling, depressie en angst leidt, wat op haar beurt weer leidt tot een toename van agressief of delinquent gedrag. (3) Het Good Lives Model van Ward (2002) is gebaseerd op de hypothese dat een individu overgaat tot crimineel gedrag wanneer hij de vaardigheden ontbeert om gewenste uitkomsten te realiseren op een persoonlijk en sociaal geaccepteerde wijze. De centrale assumptie is dat wanneer een individu zijn leven goed vorm geeft en er tevreden over is, de kans op delictgedrag en delictherhaling kleiner wordt; en dat indicatoren van kwaliteit van leven protectief werken, ook bij patiënten met een hoog risicoprofiel.

\section{Onderzochte populatie en meetinstrumenten}

Het onderzoek heeft plaats gevonden bij vier ambulante forensisch psychiatrische instellingen: Kairos, de Waag, de Tender en het Dok. Van de 241 mannelijke patiënten die benaderd zijn en lijden aan een persoonlijkheidsstoornis of trekken daarvan, hebben 135 patiënten deelgenomen aan de eerste meting. De deelnemers waren gemiddeld 37,5 jaar oud, en ongeveer éénderde had betaald werk. Tweederde van de patiënten is ooit veroordeeld; iets minder dan de helft heeft ooit een gevangenisstraf opgelegd gekregen. Bij de eerste meting is de uitgebreide Nederlandse versie van het Lancashire Kwaliteit van Leven Profiel afgenomen. Dit is een interview dat objectieve en subjectieve indicatoren van kwaliteit van leven in kaart brengt. 
Daarnaast zijn de Level of Service Inventory-Revised (een risicotaxatie instrument), een zelfrapportagelijst voor delictgedrag in de afgelopen drie maanden en een life events lijst ingevuld of afgenomen. Na drie maanden hebben de patiënten nogmaals de life events en delictlijst ingevuld. Zes maanden na de eerste meting hebben 102 patiënten weer meegedaan en zijn wederom de vragenlijsten afgenomen. Ruim twee jaar na de laatste interviews zijn gegevens met betrekking tot recidive opgevraagd bij de Centrale Justitiële Documentatie. Alle fasen van het onderzoek zijn uitgevoerd met schriftelijke toestemming van de patiënten.

\section{Resultaten}

Als eerste is de kwaliteit van leven van de onderzoekspopulatie bestudeerd, zowel door deze patiënten te vergelijken met een andere groep ambulante psychiatrische patiënten als door binnen de groep ambulante forensische patiënten - patiënten met een agressief delict te vergelijken met patiënten met een seksueel delict. Ten opzichte van ambulante patiënten die lijden aan een psychotische, stemmings- of angststoornis, bevinden ambulante forensische patiënten met een persoonlijkheidsstoornis (PS) zich in objectief betere levensomstandigheden: zij hebben vaker werk en een intieme relatie (zie Hoofdstuk 2). Wat betreft hun subjectieve beoordeling van de verschillende levensdomeinen verschilden de groepen niet. In het algemeen beoordeelden de forensische patiënten met een PS hun leven als minder positief dan de ambulante patiënten met As I stoornissen. Daarnaast speelden andere indicatoren, zoals tevredenheid over gezondheid en over financiën, een rol in het voorspellen van het algemeen welbevinden bij PS patiënten in vergelijking met de andere groep, voor wie tevredenheid met dagelijkse activiteiten en veiligheid het meest doorslaggevend waren.

Binnen de groep PS patiënten is vervolgens de groep die in het verleden agressief gedrag had vertoond vergeleken met de groep patiënten met seksuele delicten (zie Hoofdstuk 3). Ondanks dat beide groepen in vergelijkbare objectieve levensomstandigheden bleken te verkeren, waren patiënten die seksuele delicten hadden gepleegd meer tevreden over hun leven in het algemeen en over hun relaties met familie, hun veiligheid en hun gezondheid in het bijzonder. Daarnaast bleek dat voor beide groepen andere indicatoren van belang zijn voor hun algemeen welbevinden. Naast tevredenheid over vrijetijdsbesteding en sociale contacten, over gezondheid en over financiën waren tevredenheid over veiligheid, het hebben van werk en afwezigheid van schulden voor patiënten met een agressief delict van belang en het niet aanhangen van een geloof voor seksuele delinquenten. 
In overeenstemming met de General Strain Theorie is vervolgens gekeken naar de relatie tussen life events en kwaliteit van leven (zie Hoofdstuk 4). Negatieve events die beïnvloedbaar zijn door het individu, die het individu met andere woorden niet at random treffen, maar iets met zijn eigen gedrag te maken hebben, lieten als enige een negatieve relatie met algemeen welbevinden zien. Positieve gebeurtenissen en positieve controleerbare gebeurtenissen waren gerelateerd aan een positieve verandering in algemene kwaliteit van leven. Gebeurtenissen waar de patiënt geen invloed op heeft, lieten een negatief verband met verandering in algemene kwaliteit van leven zien.

Naast de invloed van levensgebeurtenissen op verandering in kwaliteit van leven is door ons de verandering van indicatoren voor kwaliteit van leven onderzocht (zie Hoofdstuk 5). Hieruit bleek dat, op één uitzondering na, objectieve levensomstandigheden niet veranderden gedurende een periode van zes maanden. Patiënten gaven alleen aan zes maanden later meer behulpzame vrienden te hebben dan bij de eerste meting. Hoewel de subjectieve indicatoren voor de gehele groep niet veranderden, rapporteerden patiënten met een initieel lage score op de betreffende domeinen verbetering op negen van de tien levensdomeinen en op algemeen welbevinden. Patiënten met een initieel hoge score lieten tijdens de tweede meting op vijf van de tien domeinen een lagere score zien dan bij de eerste meting. Behandelintensiteit, (negatieve) stemming en ernst van de PS hadden geen invloed op verandering in kwaliteit van leven.

Onze assumptie luidt dat de kans op delictgedrag en delictherhaling vermindert wanneer een patiënt zijn leven adequaat vorm geeft en er tevreden over is. Ter toetsing hiervan zijn objectieve levensomstandigheden gerelateerd aan zelfgerapporteerd delictgedrag gedurende zes maanden na de meting van de levensomstandigheden (zie Hoofdstuk 6). Patiënten die deelnamen aan een georganiseerde vorm van vrijetijdsbesteding rapporteerden minder delictgedrag. Daarnaast bleek dat patiënten, die goede relaties hadden op het werk, minder gewelddadig gedrag rapporteerden. Andere sociale contacten, zoals die met familie of vrienden, boden geen bescherming tegen dergelijk gedrag. In het algemeen was participatie in sociale instituties gerelateerd aan een lager niveau van gewelddadig gedrag.

Van de subjectieve indicatoren lieten tevredenheid over financiën en over gezondheid een positief effect zien op zelfgerapporteerd delictgedrag op de korte termijn en op algemene, gewelddadige recidives en vermogensdelicten op de langere termijn (zie Hoofdstuk 7). Tenslotte bleek het hebben van doelen in het leven en de beoordeling dat men die doelen zou 
kunnen bereiken een protectieve werking te hebben. Voor patiënten met een hoog niveau van risico op delictherhaling bleek tevredenheid met gezondheid bufferend te werken voor zowel zelfgerapporteerde als officiële recidive. Ditzelfde effect werd gevonden voor algemeen welbevinden: hoog-risico patiënten met een hoger algemeen welbevinden pleegden minder vaak een delict, gedurende drie jaar na de tweede meting, dan hoog-risico patiënten met een lager niveau van welbevinden.

\section{Bespreking van de resultaten}

Het Good Lives Model van Ward hanteert als centrale assumptie dat wanneer patiënten een goed leven of een goede levensvervulling hebben de kans op het (opnieuw) plegen van een delict vermindert. De resultaten van de studies in deze these leveren aanwijzingen ter onderbouwing van deze assumptie. Aspecten van een goed leven en een goede levensvervulling waren gerelateerd aan delictgedrag dat na de meting van kwaliteit van leven heeft plaatsgevonden. Gezien de onderzochte steekproef geldt dit echter alleen voor mannelijke poliklinische forensische patiënten met een persoonlijkheidsstoornis of trekken daarvan, en zal verder onderzoek dienen uit te wijzen in hoeverre deze bevindingen generaliseerbaar zijn naar andere groepen.

Een deel van de protectieve werking van levensomstandigheden kan, analoog aan de Social Control Theorie, gevonden worden in de controlerende werking van sociale instituties. Voor de onderzochte groep patiënten lijkt dit echter vooral samen te hangen met de binding aan instituties die enigszins verder van de patiënt staan, zoals clubs of verenigingen, de kerk, en sociale contacten op het werk. Gezien het ontbreken van een relatie tussen negatieve levensgebeurtenissen en verandering in kwaliteit van leven, leverden de resultaten geen bevestiging op voor dit aspect van de General Strain Theorie. De directe relatie tussen strain en delinquent gedrag is niet bestudeerd in dit onderzoek.

Binnen risicotaxatie wordt onderscheid gemaakt tussen veranderbare en onveranderbare factoren, en binnen de groep veranderbare factoren, tussen acute en stabiele factoren. Tot welke groep de door ons onderzochte objectieve indicatoren voor kwaliteit van leven behoren en of deze samenhangen met korte of langere termijn effecten op criminele recidive was niet goed vast te stellen omdat zij op korte termijn nauwelijks bleken te veranderen. Subjectieve omstandigheden bleken voor een deel van de steekproef wel te veranderden, ook op korte termijn. Mogelijke beïnvloeding van deze subjectieve indicatoren door behandeling is echter 
(nog) niet vastgesteld, maar gerichte studies naar behandelinterventies zouden hierover uitsluitsel kunnen geven. Gekoppeld aan een experimentele onderzoeksopzet, met een controlegroep die een dergelijke behandeling niet ondergaat, kan het inzicht in de (mogelijk) beschermende werking van objectieve en/of subjectieve levensomstandigheden verder uitgebreid worden. Dit heeft uiteindelijk tot doel de behandeling van forensisch psychiatrische patiënten effectiever en efficiënter vorm te geven. Recente ervaringen met een dergelijke aanpak in de re-integratie van veroordeelde delinquenten na afloop van hun detentie zijn positief en hoopvol voor andere, vergelijkbare populaties. 


\section{REFERENCES}

\section{References}

Abrams, R.C., Alexopoulos, G.S., Spielman, L.A., Klausner, E., \& Kakuma, T. (2001). Personality disorder symptoms predict declines in global functioning and quality of life in elderly depressed patients. American Journal of Geriatric Psycbiatry, 9, 67-71.

Agnew, R. (1992). Foundation for a General Strain Theory of crime and delinquency. Criminology, 30, 4787.

Agnew, R. (1997). Stability and change in crime over the life course: A strain theory explanation. In T. P. Thornberry (Ed.), Developmental theories of crime and delinquency: Vol. 7. Advances in criminological theory (pp. 101-132). New Brunswick and London: Transaction Publishers.

American Psychiatric Association (2000). DSM-IV-TR, Diagnostic and statistical manual of mental disorders, 4th edition, text revision. Washington DC: Author.

Anderson, J. (2008). Disputing autonomy: Second-order desires and the dynamics of ascribing autonomy. Sats - Nordic Journal of Philosophy, 9, 7-26.

Andrews, D.A., \& Bonta, J.L. (1995). The Level of Service Inventory - Revised. Toronto, Canada: Multi-Health Systems.

Andrews, D.A., \& Bonta, J. (1998). The psychology of criminal conduct, Second edition. Cincinnati, OH: Anderson Publishing Co..

Andrews, D.A., \& Bonta, J.L. (2000). Level of Service Inventory-Revised, User's manual. New York, Toronto: Multi-Health Systems Inc.

Andrews, D.A., Bonta, J.L., \& Wormith, J.S. (2004). Level of Service/Case Management Inventory (LS/CMI): An offender assessment system. North Tonawanda, NY, Toronto: Multi-Health Systems Inc..

Andrews, D.A., Bonta, J., \& Wormith, J.S. (2006). The recent past and near future of risk and/or need assessment. Crime \& Delinquency, 52, 7-27.

Atkinson, M.J., \& Zibin, S. (1996). Quality of Life Measurement Among Persons with Chronic Mental Illness: A Critique of Measures and Methods. Health Canada:

Ottawa. Retrieved on 01 September 2006, from http://www.phac-aspc.gc.ca/mhsm/pubs/quality_of_life-qualite_de_vie/index-eng.php. 
Austin, J., Coleman, D., Peyton, J., \& Johnson, K.D. (2003). Reliability and validity study of the LSI-R risk assessment instrument (Final Report Submitted to The Pennsylvania Board of Probation and parole on January 9th 2003). Washington, DC: The George Washington University, The Institute on Crime, Justice and Corrections. Retrieved on 21 June 2005 http://www.pccd.state.pa.us/pccd/lib/pccd/stats/lsi_r_final_report.pdf.

Baker, F., \& Intagliata, J. (1982). Quality of life in the evaluation of community support systems. Evaluation and Program Planning, 5, 69-79.

Bandura, A. (1994). Self-efficacy. In V. S. Ramachaudran (Ed.), Encyclopedia of human behavior (Vol. 4, pp. 71-81). New York: Academic Press.

Bartel, P., Borum, R., \& Forth, A. (2000). Structured Assessment for Violence Risk in Youth (SAVRY). Consultation edition. Tampa, FL: University of South Florida.

Bech, P., Dunbar, G.C., \& Stoker, M.J. (1993). The challenge of measuring quality of life in psychiatric patients. In B. Jönsson \& J. Rosenbaum (Eds.), Health Economics of Depression (pp. 111-128). John Wiley \& Sons Ltd..

Bijleveld, C.C.J.H., \& Kamp, L.J.Th. van der (1998). Longitudinal Data Analysis: Design, models and methods. London, Thousand Oaks \& New Delhi: Sage Publications.

Blenkiron, P., \& Hammill, C.A. (2003). What determines patients' satisfaction with their mental health care and quality of life? Postgraduate Medical Journal, 79, 337-340.

Boevink, W.A., Wolf, J.R.L.M., Nieuwenhuizen, Ch. van, \& Schene, A.H. (1995). Kwaliteit van leven van langdurig van ambulante zorg afhankelijke psychiatrische patiënten; Een conceptuele verkenning [Quality of life in psychiatric patients depending on long-term outpatient care: A conceptual exploration]. Tijdschrift voor Psychiatrie, 37, 97-110.

Bonta, J. (1997). Do we need theory for offender risk assessment? CSC Forum, 9. Retrieved on 13 February 2001 from: http://www.csc-scc.gc.ca/text/pblct/forum/e091/091i_e.pdf.

Bonta, J.L., \& Andrews, D.A. (2007). Risk-Need-Responsivity Model for Offender Assessment and Rehabilitation. (User report 2007-06). Ottawa, Ontario: Public Safety Canada. Retrieved on 9 September 2008 from http://www.publicsafety.gc.ca/res/cor/rep/_fl/Risk_Need_2007-06_e.pdf

Bonta, J., Law, M., \& Hanson, K. (1998). The prediction of criminal and violent recidivism among mentally disordered offenders: A meta-analysis. Psychological Bulletin, 123, 123-142.

Borowsky, I.W., Hogan, M., \& Ireland, M. (1997). Adolescent sexual aggression: Risk and protective factors. Pediatrics, 100, E7. 


\section{REFERENCES}

Bowling, A. (1991). Measuring health: a review of quality of life measurement scales. Buckingham: Open University Press.

Bowling, A. (1995). Measuring disease, a review of disease-specific quality of life measurement scales, Open University Press, Buckingham, Philadelphia.

Bowling, A. (1997). Measuring health, a review of quality of life measurement scales, second edition, Open University Press, Buckingham, Philadelphia.

Burns, V.E., Carroll, D., Ring, C., Harrison, L.K., \& Drayson, M. (2002). Stress, coping, and hepatitis B antibody status. Psychosomatic Medicine, 64, 287-293.

Carr, A. J., Gibson, B., \& Robinson, P. G. (2001). Is quality of life determined by expectations or experience? BMJ, 322, 1240-1243. [On-line]. Retrieved on 2 May 2005 from http://www.bmj.com/cgi/content/full/322/7296/1240.

Centraal Bureau voor de Statistiek (n.d.). [Indices] Available from Centraal Bureau voor de Statistiek Web site. Retrieved on 5 December 2007 from http://www.cbs.nl/nl-NL.

Chan, G.W.L., Ungvari, G.S., Shek, D.T.L., \& Leung, J.J.P. (2003). Hospital and community-based care for patients with chronic schizophrenia in Hong Kong. Social Psychiatry and Psychiatric Epidemiology, 38, 196-203.

Chand, P.K., Mattoo, S.K., \& Sharan, P. (2004). Quality of life and its correlates in patients with bipolar disorder stabilized on lithium prophylaxis. Psychiatry and Clinical Neurosciences, 58, 311-318.

Chen, H., Cohen, P., Crawford, T.N., Kasen, S., Johnson, J.G., \& Berenson, K. (2006). Relative impact of young adult personality disorders on subsequent quality of life: findings of a community-based longitudinal study. Journal of Personality Disorders, 20, 510-523.

Chung, M.C., Cumella, S., Wensley, J., \& Easthope, Y. (1998). Quality of life and psychological well-being of mentally disordered offenders after court diversion: a 6-month follow-up. International Journal of Offender Therapy and Comparative Criminology, 42, 164-173.

Cohen, J. (1988). Statistical power analysis for the behavioral sciences. Hillsdale, NJ: Erlbaum.

Coid, J.W. (1993). Quality of life for patients detained in hospital. British Journal of Psychiatry, 162, 611-620.

Coid, J., Hickey, N., Kahtan, N., Zhang, T., \& Yang, M. (2007). Patients discharged from medium secure forensic psychiatric services: Reconvictions and risk factors. British Journal of Psychiatry, 190, 223

229. Retrieved September 9, 2008. doi: 10.1192/bjp.bp.105.018788.

Costa, F.M., Jessor, R., \& Turbin, M.S. (1999). Transition into adolescent problem drinking: The role of psychosocial risk and protective factors. Journal of Studies on Alcohol, 60, 480-490. 
Costa, P.T. Jr., \& McCrae, R.R. (1992). The five-factor model of personality and its relevance to personality disorders. Journal of Personality Disorders, 6, 343-359.

Craig, L.A., Brown, K.D., Beech, A., \& Stringer, I. (2006). Differences in personality and risk characteristics in sex, violent and general offenders. Criminal Behaviour and Mental Health, 16, 183194.

Cramer, V., Torgersen, S., \& Kringlen, E. (2006). Personality disorders and quality of life. A population study. Comprehensive Psychiatry, 47, 178-184.

Cramer, V., Torgersen, S., \& Kringlen, E. (2007). Socio-demographic conditions, subjective somatic health, Axis I disorders and personality disorders in the common population: The relationship to quality of life. Journal of Personality Disorders, 21, 552-567.

Cullen, F. T., \& Wright, J. P. (1997). Liberating the Anomie-Strain paradigm: Implications from socialsupport theory. In N. Passas \& R. Agnew (Eds.), The future of anomie theory (pp. 187-206). Boston: Northeastern University Press.

Dam, C. van, Janssens, J.M.A.M, Bruyn, E.E.J. de, Koolen, J.J.C.M. van, \& Spee, J.E.J. (1999). Self-report delictlijst. Bewerking van de self-report delictlijst zoals ontwikkeld door het WODC. [Self-report offence list. Adaptation of the self-report offence-list developed by WODC.] K.U.N./ R.I.J. Nijmegen, The Netherlands: De Hunnerberg.

Dam, C. van, Janssens, J.M.A.N., \& Bruyn, E.E.J. de (2003). Risico en beschermende factoren voor recidive in de leefsituatie na vertrek uit een justitiële jeugdinrichting [Risk and protective factors for recidivism in the living situation after release from a juvenile correctional treatment centre]. In J.R.M. Gerris (Ed.), Gezin, school en gemeente: integrale jeugdzorg en sociale integratie (pp. 23-41). Assen, The Netherlands: Koninklijke Van Gorcum BV..

Dawson-Saunders, B., \& Trapp, R.G. (1994). Basic \& clinical biostatistics. Second edition. London: Prentice Hall International Limited.

Debats, D.L. (1996a). Meaning in life: Psychometric, clinical and phenomenological aspects. PhD Thesis. University Groningen, The Netherlands.

Debats, D.L. (1996b). Meaning in life: Clinical relevance and predictive power. British Journal of Clinical Psychology, 35, 503-516.

Debats, D.L., Lubbe, P.M. van der, \& Wezeman, F.R.A. (1993). On the psychometric properties of the Life Regard Index (LRI): A measure of meaningful life. An evaluation in three independent samples based on the Dutch version. Personality and Individual Differences, 14, 337-345. 


\section{REFERENCES}

Derks, F., Hildebrand, M., \& Mulder, J. (1998). Forensische dagbehandeling. Resultaten in termen van psychosociaal welbevinden en recidive (Forensic day-treatment: results in terms of psycho-social well-being and recidivism). Tijdschrift voor criminologie, 3, 273-287.

Dernevik, M. (2004). Structured clinical assessment and management of risk of violent recidivism in mentally disordered offenders. Stockholm, Sweden: Karolinska University Press.

Diener, E., \& Suh, E. (1997). Measuring quality of life: Economic, social, and subjective indicators. Social Indicators Research, 40, 189-216.

Dixon, W.A., \& Reid, J.K. (2000). Positive life events as a moderator of stress-related depressive symptoms. Journal of Counseling and Development, 78, 343-347.

Douglas, K.S., Webster, C.D., Hart, S.D., Eaves, D. \& Ogloff, J.R.P. (2001). HCR-20; Violence risk management companion guide. Burnaby, Canada: Mental Health, Law, and Policy Institute, Simon Fraser University.

Draine, J., \& Solomon, P. (1992). Comparison of seriously mentally ill case management clients with and without arrest histories. The Journal of Psychiatry and the Law, 20, 335-349.

Draine, J., \& Solomon, P. (1994). Jail recidivism and the intensity of case management services among homeless persons with mental illness leaving jail. The Journal of Psychiatry \& Law, 22, 245-261.

Draine, J., \& Solomon, P. (2000). Anxiety and depression symptoms and quality of life among clients of a psychiatric probation and parole service. Psychiatric Rebabilitation Journal, 24, 38-45.

DuRant, R.H., Knight, J., \& Goodman, E. (1997). Factors associated with aggressive and delinquent behaviors among patients attending an adolescent medicine clinic. Journal of Adolescent Health, 21, 303-308.

Eitle, D., \& Turner, R.J. (2002). Exposure to community violence and young adult crime: The effects of witnessing violence, traumatic victimization, and other stressful life events. Journal of Research in Crime and Delinquency, 39, 214-237.

Ellis, L., \& Peterson, J. (1996). Crime and religion: an international comparison among thirteen industrial nations. Personality and Individual Differences, 20, 761-768.

Estroff, S.E., \& Zimmer, C. (1994). Social networks, social support, and violence among persons with severe, persistent mental illness, in J. Monahan and H.J. Steadman (ed), Violence and mental disorder, developments in risk assessment (pp. 249-295). the University of Chicago press, Chicago and London. 
Estroff, S.E., Zimmer, C., Lachicotte, W.S., \& Benoit, J. (1994). The influence of social networks and social support on violence by persons with serious mental illness. Hospital and Community Psychiatry, 45, 669-679.

Fakhoury, W.K.H., \& Priebe, S. (2002). Subjective quality of life: It's association with other constructs. International Review of Psychiatry, 14, 219-224.

Farquhar, M. (1995). Definitions of quality of life: a taxonomy. Journal of Advanced Nursing, 22, 502-508.

Farrington, D.P., \& Loeber, R. (2000). Epidemiology of juvenile violence. Child and Adolescent Psychiatric Clinics of North America, 9, 733-748.

Fawcett, T. (2004). ROC Graphs: Notes and Practical Considerations for Data Mining Researchers. Retrieved on August 11, 2006 from: http://home.comcast.net/ tom.fawcett /public_html/papers/ROC101.pdf.

Fitzpatrick, K.M. (1997). Fighting among America's youth: A risk and protective factors approach. Journal of Health and Social Behavior, 38, 131-148.

Franssen, M.-J.A.M.J., \& Knipscheer, K.C.P.M. (1990). Normative influences of the intimate social network on health behavior. in C.P.M. Knipscheer \& T.C. Antonucci (Eds.). Social Network Research, Substantive issues and methodological questions (pp. 17-29). Amsterdam / Lisse: Swets \& Zeitlinger b.v..

Gendreau, P., Goggin, C., \& Gray, G. (2000). Case need review: employment domain. Saint John, NB: Centre for Criminal Justice Studies, University of New Brunswick.

Gerber, G.J., Prince, P.N., Duffy, S., McDougall, L., Cooper, J., \& Dowler, S. (2003). Adjustment, integration, and quality of life among forensic patients receiving community outreach services. International Journal of Forensic Mental Health, 2, 129-136.

Glatzer, W., \& Mohr, H.M. (1987). Quality of life: concept and measurement. Social Indicators Research, 19, $15-38$.

Goggin, C., Gendreau, P., \& Gray, G. (1998). Case needs review: Associates / Social interaction Domain. Saint John, NB: Centre for Criminal Justice Studies, University of New Brunswick.

Goodinson, S.M., \& Singleton, J. (1989). Quality of life: a critical review of current concepts, measures and their clinical implications. International Journal of Nursing Studies, 26, 327-341. 


\section{REFERENCES}

Grann, M., Hiscoke, U.L., Haggard-Grann, U., Sturidsson, K., Dernevik, M., Hallqvist, J., Kullgren, G., Langstrom, N., Lotterberg, M., Lovstrom, L., Siversson, E., Stahle, B., \& Woodhouse, A. (2001). SORM-E, Structured Outcome Assessment and Community Risk Monitoring. Stockholm, Sweden: Karolinska Institute.

Halim, M.S., Derksen, J.J.L., Staak, C.P.F. van der (2001, November). Associations between five-factor model of personality and quality of life. Poster presented at the $8^{\text {th }}$ Annual conference of the International Society of Quality of Life Research, Amsterdam, The Netherlands.

Hanley, J.A., \& McNeil, B.J. (1982). The meaning and use of the area under a receiver operating characteristic (ROC) curve. Radiology, 143, 29-36.

Hanson, R.K., \& Bussière, M.T. (1998). Predicting relapse: A meta-analysis of sexual offender recidivism studies. Journal of Consulting and Clinical Psychology, 66, 348-362.

Hanson, R.K., \& Harris, A. (1998). Dynamic predictors of sexual recidivism (User report No. 1998-1). Ottawa: Department of the Solicitor General of Canada. Retrieved 16 March 2000 from: http://ww2.pssp.gc.ca/publications/Corrections/199801b_e.pdf.

Hanson, R.K., \& Harris, A.J.R. (2000). Where should we intervene? Dynamic predictors of sexual offense recidivism. Criminal Justice and Behavior, 27, 6-35.

Hanson, R.K., \& Morton-Bourgon, K. (2005). The characteristics of persistent sexual offenders: A metaanalysis of recidivism studies. Journal of Consulting and Clinical Psychology, 73, 1154-1163

Hanson, R.K., Scott, H., \& Steffy, R.A. (1995). A comparison of child molesters and nonsexual criminals: Risk predictors and long-term recidivism. Journal of Research in Crime and Delinquency, 32, 325-337.

Hansson, L., \& Björkman, T. (2007). Are factors associated with subjective quality of life in people with severe mental illness consistent over time? - A 6-year follow-up study. Quality of Life Research, 16, 916.

Hawkins, J.D., Catalano, R.F., \& Miller, J.Y. (1992). Risk and protective factors for alcohol and other drug problems in adolescence and early adulthood: Implications for substance abuse prevention. Psychological Bulletin, 112, 64-105.

Headey, B., \& Wearing, A. (1989). Personality, life events, and subjective well-being: Toward a dynamic equilibrium model. Journal of Personality and Social Psychology, 57, 731-739.

Heikkinen, M.E., Henriksson, M.M., Isometsa, E.T., Marttunen, M.J., Hillevi, M.A., \& Lonnqvist, J.K. (1997). Recent life events and suicide in personality disorders. The Journal of Nervous \& Mental Disease, 185, 373-381. 
Hildebrand, M. (2004). Psychopathy in the treatment of forensic psychiatric patients. Assessment, prevalence, predictive validity, and clinical implications. Amsterdam: Dutch University Press.

Hildebrand, M., Hesper, B.L., Spreen, M., \& Nijman, H.L.I. (2005). De waarde van gestructureerde risicotaxatie en van de diagnose psychopathie. Een onderzoek naar de betrouwbaarheid en predictieve validiteit van de HCR-20, HKT-30 en PCL-R. [The value of structured risk assessment and psychopathy. A research into the validity and reliability of the HCR-20, HKT-30 en PCL-R]. Utrecht, The Netherlands: Expertisecentrum Forensische Psychiatrie.

Hildebrand, M., \& Ruiter, C. de (2004). PCL-R psychopathy and its relation to DSM-IV Axis I and II disorders in a sample of male forensic psychiatric patients in the Netherlands. International Journal of Law and Psychiatry, 27, 233-248.

Hilterman, E.L.B. (2000). Tijdens de oefening terug naar af. Een onderzoek naar de predictie van ernstige recidive door tbs-gestelden tijdens verlof. [Back to square one during treatment. A research of the prediction of severe recidivism by forensic patients during leave.]. Tijdschrift voor Criminologie, 42, 232-252.

Hirschi, T. (1969). Causes of Delinquency. Berkeley: University of California Press.

Hoge, R.D., Andrews, D.A., \& Leschied, A. (1996). An investigation of risk and protective factors in a sample of youthful offenders. Journal of Child Psychology and Psychiatry and Allied Disciplines, 37, 419424.

Holloway, F. (1995). The quality of life of long-term psychiatric day patients: an exploratory study of the impact of clinical factors on quality of life. Social Work \& Social Sciences Review, 6, 110-116.

Horn, J. van, Mulder, J., \& Scholing, A. (2006). Recidive bij subgroepen van zedendelinquenten in de ambulante forensische psychiatrie. [Recidivism in subgroups of sex offenders in community-based forensic psychiatry]. Tijdschrift voor Seksuologie, 30, 187-194.

Jovev, M., \& Jackson, H.J. (2006). The relationship of borderline personality disorder, life events and functioning in an Australian psychiatric sample. Journal of Personality Disorders, 20, 205-217.

Judd, P.H., Thomas, N., Schwartz, T. Outcalt, A., \& Hough, R. (2003). A dual diagnosis demonstration project: Treatment outcomes and cost analysis. Journal of Psychoactive Drugs, 35 (Supplement), 181-192.

Karterud, S., Pedersen, G., Bjordal, E., Brabrand, J., Friis, S., Haaseth, Ø., Haavaldsen, G., Irion, T., Leirvåg, H., Tørum, E., \& Urnes, Ø. (2003). Day treatment of patients with personality disorders: Experiences from a Norwegian treatment research network. Journal of Personality Disorders, 17, 243 262. 


\section{REFERENCES}

King, L.A. (2001). The hard road to the Good Life: The happy, mature person. Journal of Humanistic Psychology, 41, 51-73.

Klassen, D., \& O'Connor, W.A. (1989). Assessing the risk of violence in released mental patients: a crossvalidation study. Psychological Assessment, 1, 75-81.

Klein, K., \& Boals, A. (2001). The relationship of life event stress and working memory capacity. Applied Cognitive Psychology, 15, 565-579.

Leaf, R.C., Alington, D.E., Mass, R., DiGiuseppe, R., \& Ellis, A. (1991). Personality disorders, life events, and clinical syndromes. Journal of Personality Disorders, 5, 264-280.

Lehman, A.F. (1983). The well-being of chronic mental patients. Archives of General Psychiatry, 40, 369-373.

Lehman, A.F. (1988). A quality of life interview for the chronically mentally ill. Evaluation and Program Planning, 11, 51-62. doi:10.1016/0149-7189(88)90033-X.

Lehman, A.F. (1999). A review of instruments for measuring quality-of-life outcomes in mental health. In N.E. Miller \& K.M. Magruder (Eds.). Cost-effectiveness of psychotherapy: A guide for practitioners, researchers, and policymakers (pp. 174-181). New York: Oxford University Press.

Leuw, E. (1999). Recidive na de TBS. Patronen, trends en processen en de inschatting van gevaar. [Recidivism after TBS. Patterns, trends and processes and the assessment of danger]. Den Haag: Ministerie van Justitie, WODC.

Leibing, E., Jamrozinski, K., Vromfelde, S.V., Stahl, J., \& Doering, S. (2008). Dimensions of personality Relationship between DSM-IV personality disorder symptoms, the five-factor model, and the biosocial model of personality. Journal of Personality Disorders, 22, 101-108.

Lievore, D. (2004). Recidivism of sexual assault offenders: Rates, risk factors and treatment efficacy. Canberra: Australian Institute of Criminology.

Lindsay, W.R., Ward, T., Morgan, T., \& Wilson, I. (2007). Self-regulation of sex offending, future pathways and the Good Lives Model: Applications and problems. Journal of Sexual Aggression, 13, $37-50$.

Lindstedt, H., Söderlund, A., Stålenheim, G., \& Sjödén, P.-O. (2005). Personality traits as predictors of occupational performance and life satisfaction among mentally disordered offenders. Nordic Journal of Psychiatry, 59, 357-364.

Link, B.G., Phelan, J.C., Bresnahan, M., Stueve, A., \& Pescosolido, B.A. (1999). Public conceptions of mental illness: labels, causes, dangerousness, and social distance. American Journal of Public Health, 89, 1328-1333. 
Livesley, W.J. (2007). A framework for integrating dimensional and categorical classifications of personality disorder. Journal of Personality Disorders, 21, 199-224.

Long, C.G., McLean, A., Boothby, A.J., \& Hollin, C.R. (2008). Factors associated with quality of life in a cohort of forensic psychiatric in-patients. The British Journal of Forensic Practice, 10, 4-11.

Lu, L. (1999). Personal or environmental causes of happiness: A longitudinal analysis. The Journal of Social Psychology, 139, 79-90.

Lucas, R.E., Clark, A.E., Georgellis, Y., \& Diener, E. (2004). Unemployment alters the set point for life satisfaction. Psychological Science, 15, 8-13.

Lucas, R.E., Georgellis, Y., Clark, A.E., \& Diener, E. (2003). Reexamining adaptation and the set point model of happiness: Reactions to changes in marital status. Journal of Personality and Social Psychology, $84,527-539$.

Mann, R.E., Webster, S.D., Schofield, C., \& Marshall, W.L. (2004). Approach Versus Avoidance Goals in Relapse Prevention with Sexual Offenders. Sexual Abuse: A Journal of Research and Treatment, 16, 6575 .

Mason, T. (1999). The psychiatric "Supermax"?: Long-term, high-security psychiatric services. International Journal of Law and Psychiatry, 22, 155-166.

Masthoff, E.D., Trompenaars, F.J., Heck, G.L. van, Hodiamont, P.P., \& Vries, J. de (2006). Quality of life and psychopathology: Investigations into their relationship. Australian and New Zealand Journal of Psychiatry, 40, 333-340.

Masthoff, E.D., Trompenaars, F.J., Heck, G.L. van, Michielsen, H.J., Hodiamont, P.P., \& Vries, J. de (2007). Predictors of quality of life: A model based study. Quality of Life Research, 16, 309-320.

Maxwell, S.E., \& Delaney, H.D. (1993). Bivariate median splits and spurious statistical significance. Psychological Bulletin, 113, 181-190.

McCall, S. (1975). Quality of life. Social Indicators Research, 2, 229-248.

Miller, H.A. (2006). A dynamic assessment of offender risk, needs, and strengths in a sample of prerelease general offenders. Behavioral Sciences and the Law, 24, 767-782.

Miller, M.A., \& Rahe, R.H. (1997). Life changes scaling for the 1990s. Journal of Psychosomatic Research, 43, 279-292.

Monahan, J. (1981). Predicting violent behavior: An assessment of clinical techniques. Beverly Hills CA: Sage. 


\section{REFERENCES}

Monahan, J., Steadman, H.J., Silver, E., Appelbaum, P.S., Robbins, P.C., Mulvey, E.P., Roth, L.H., Grisso, T., \& Banks, S. (2001). Rethinking risk assessment: the MacArthur study of mental disorder and violence. Oxford, New York: Oxford University Press.

Mossman, D. (1994). Assessing predictions of violence: Being accurate about accuracy. Journal of Consulting and Clinical Psychology, 62, 783-792.

Mossman, D. (2008). Analyzing the performance of risk assessment instruments: A response to Vrieze and Grove (2007). Law and Human Behavior, 32, 279-291.

Narud, K., Mykletun, A., \& Dahl, A.A. (2005). Quality of life in patients with personality disorders seen at an ordinary psychiatric outpatient clinic. BMC Psychiatry, 5, 10. doi:10.1186/1471-244X-5-10. Retrieved on 2 May 2005 from http://www.biomedcentral. com/1471-244x/5/10.

Nieuwenhuizen, Ch. van (1998). Quality of life of persons with severe mental illness: An instrument. Amsterdam: Thesis Publishers.

Nieuwenhuizen, Ch. van, Schene, A.H., Boevink, W.A., \& Wolf, J.R.L.M. (1997). Measuring the quality of life of clients with severe mental illness: A review of instruments. Psychiatric Rehabilitation Journal, 20 (4), 33-41.

Nieuwenhuizen, Ch. van, Schene, A., Boevink, W., \& Wolf, J. (1998). The Lancashire Quality of Life Profile: First experiences in the Netherlands. Community Mental Health Journal, 34, 513-524.

Nieuwenhuizen, Ch. van, Schene, A.H., \& Koeter, M.W.J. (1998). Lancashire Kwaliteit van Leven Profiel, Uitgebreide Nederlandse versie (Lancashire Quality of Life Profile, extended Dutch version). Eindhoven, The Netherlands: Youth Forensic Psychiatric Hospital 'De Catamaran'.

Nieuwenhuizen, Ch. van, Schene, A.H., \& Koeter, M.W.J. (2002). Quality of life in forensic psychiatry: an unreclaimed territory. International Review of Psychiatry, 14, 198-202.

Nieuwenhuizen, Ch. van, Schene, A.H., Koeter, M.W.J., \& Huxley, P.J. (2001). The Lancashire Quality of Life Profile: Modification and psychometric evaluation. Social-Psychiatry and Psychiatric Epidemiology, 36, 36-44.

Oddone-Paolucci, E., Violato, C., \& Schofield, M.A. (2000). A review of marital and family variables as they relate to adult criminal recidivism. Calgary: National Foundation for Family Research and Education.

Ogloff, J.R.P., \& Davis, M.R. (2004). Advances in offender assessment and rehabilitation: contributions of the risk-need-responsivity approach. Psychology, Crime \& Law, 10, 229-242.

Oliver, J., Huxley, P., Bridges, K., \& Mohamad, H. (1996). Quality of life and the mental health services. London \& New York: Routledge. 
Oosterhuis, H. (2004). Between institutional psychiatry and mental health care: social psychiatry in The Netherlands, 1916-2000. Medical History, 48, 413-428.

Orley, J., Saxena, S., \& Herrman, H. (1998). Quality of life and mental illness. Reflections from the perspective of the WHOQOL. British Journal of Psychiatry, 172, 291-293.

Ormel, J., Lindenberg, S., Severink, N., \& Verbrugge, L.M. (1999). Subjective well-being and social production functions. Social Indicators Research, 46, 61-90.

Ouimet, M., \& Le Blanc, M. (1996). The role of life experiences in the continuation of the adult criminal career. Criminal Behaviour and Mental Health, 6, 73-97.

Pagano, M.E., Skodol, A.E., Stout, R.L., Shea, M.T., Yen, S., Grilo, C.M., Sanislow, C.A., Bender, D.S., McGlashan, T.H., Zanarini, M.C., \& Gunderson, J.G. (2004). Stressful life events as predictors of functioning: Findings from the collaborative longitudinal personality disorders study. Acta Psychiatrica Scandinavica, 110, 421-429.

Pauwels, L., \& Pleysier, S. (2005). Effecten van antwoordstijlen in etiologisch self-report-onderzoek. Een 'causale modellenbenadering'. [Effects of response-styles in etiologic self-report research. A 'causal models approach'.] Tijdschrift voor Criminologie, 47, 42-61.

Perry, J.C., Lavori, P.W., Pagano, C.J., Hoke, L., \& O'Connell, M.E. (1992). Life events and recurrent depression in borderline and antisocial personality disorders. Journal of Personality Disorders, 6, 394 407.

Pettersson, T. (1991). Religion and criminality: structural relationships between church involvement and crime rates in contemporary Sweden. Journal for the Scientific Study of Religion, 30, 279-291.

Philipse, M.W.G. (2005). Predicting criminal recidivism. Empirical studies and clinical practice in forensic psychiatry. PhD Thesis, Nijmegen, The Netherlands: Radboud Universiteit Nijmegen.

Philipse, M. (2006). 'Evidence based practice' in de tbs. Maatschappelijke aspiraties versus empirische realiteit. ['Evidence based practice' in Dutch forensic psychiatry. Societal aspirations versus empirical reality]. Pedagogiek, 26, 274-290.

Philipse, M.W.G., Koeter, M.W.J., Staak, C.P.F. van der, \& Brink, W. van den (2006). Static and dynamic patient characteristics as predictors of criminal recidivism: A prospective study in a Dutch forensic psychiatric sample. Law and Human Behavior, 30, 309-327. doi: 10.1007/s10979-006-9013-4.

Plemper, E. (2001). Ambulante forensische psychiatrie: Onderzoek forensisch psychiatrische poli- en dagklinieken

[Community based forensic psychiatry: research forensic outpatient and day-treatment facilities]. Utrecht, The Netherlands: Verwey-Jonker Instituut. 


\section{REFERENCES}

Pont, M., Woude, M. van der, \& Moerings, M. (2005). Exodus: op de goede weg? Proces, 2005, 7-14.

Priebe, S., Huxley, P., Knight, S., \& Evenas, S. (1999). Application and results of the Manchester short quality of life (MANSA). International Journal of Social Psychiatry, 45, 7-12.

Rahe, R.H. (1975). Epidemiological studies of life change and illness. International Journal of Psychiatry in Medicine, 6, 133-146.

Reddon, J.R., Pope, G.A., Friel, J.P., \& Sinha, B.K. (1996). Leisure motivation in relation to psychosocial adjustment and personality in young offender and high school samples. Journal of Clinical Psychology, 52, 679-685.

Rogers, R. (2000). The uncritical acceptance of risk assessment in forensic practice. Law and Human Behavior, 24, 595-605.

Rooy, A. de (2004). Risicotaxatie in de forensische psychiatrie: Psychometrische evaluatie van de Level of Service Inventory-Revised [Risk assessment in forensic psychiatry: Psychometric evaluation of the Level of Service Inventory-Revised]. Master's thesis Mental Health Science, Maastricht University.

Rovers, B. (1998). Theoretische integratie van Hirschi en Merton [Theoretical integration of Hirschi and Merton]. Tijdschrift voor Criminologie, 40, 151-165.

Roy, A. (1996). Psychosocial factors and chronic depression. Journal of Nervous and Mental Disease, 184, 509-510.

Ruggeri, M., Nosè, M., Bonetto, C., Cristofalo, D., Lasalvia, A., Salvi, G., Stefani, B., Malchiodi, F., \& Tansella, M. (2005). Changes and predictors of change in objective and subjective quality of life. Multiwave follow-up study in community psychiatric practice. British Journal of Psychiatry, 187, 121130.

Ruggeri, M., Warner, R., Bisoffi, G., \& Fontecedro, L. (2001). Subjective and objective dimensions of quality of life in psychiatric patients: a factor analytical approach. The South Verona Outcome Project 4. British Journal of Psychiatry, 178, 268-275.

Ruiter, C. de, \& Hildebrand, M. (2007). Risk assessment and treatment in Dutch forensic psychiatry. Netherlands Journal of Psychology, 63, 166-175.

Ruiter, C. de, \& Trestman, R.L. (2007). Prevalence and treatment of personality disorders in Dutch forensic mental health services. The Journal of the American Academy of Psychiatry and the Law, 35, 92 97. 
Rutenfrans, C.J.C., \& Terlouw, G.J. (1994). Delinquentie, sociale controle en 'life events'; eerste resultaten van een longitudinaal onderzoek. [Delinquency, social control and life events; first results of a longitudinal research.] Den Haag: WODC, Onderzoek en beleid, nr. 131.

Saloppé, X, \& Pham, T.H. (2007). Impact des troubles mentaux sur la qualité de vie perçue par des patients issus d'un hospital psychiatrique sécuritaire. [Impact of psychiatric disorders on the quality of life of patients in a forensic psychiatric hospital]. L'Encéphale, 33, 892-901.

Sampson, R.J., \& Laub, J. H. (1990). Crime and deviance over the life course: the salience of adult social bonds. American Sociological Review, 55, 609-627.

Sampson, R.J., \& Laub, J. H. (2005). A life-course view of the development of crime. The ANNALS of the American Academy of Political and Social Sciences, 602, 12-45.

Samuels, J.F., Nestadt, G., Romanoski, A.J., Folstein, M.F., \& McHugh, P.R. (1994). DSM-III personality disorders in the community. American Journal of Psychiatry, 151, 1055-1062.

Sareen, J., Stein, M.B., Cox, B.J., \& Hassard, S.T. (2004). Understanding comorbidity of anxiety disorders with antisocial behavior. Findings from two large community surveys. The Journal of Nervous and Mental Disease, 192, 178-186.

Schwartz, C.E., \& Sprangers, M.A.G. (eds.) (2000). Adaptation to changing health: Response shift in quality-of-life research. Washington: American Psychological Association.

Silver, E. (2000). Extending social disorganization theory: A multilevel approach to the study of violence among persons with mental illnesses. Criminology, 38, 1043-1074.

Silver, E. (2006). Understanding the relationship between mental disorder and violence: The need for a criminological perspective. Law and Human Behavior, 30, 685-706.

Simmons, S. (1994). Quality of life in community mental health care - a review. International Journal of Nursing Studies, 31, 183-193.

Sjöstedt, G., \& Grann, M. (2002). Risk assessment: What is being predicted by actuarial prediction instruments? International Journal of Forensic Mental Health, 1, 179-183.

Skevington, S.M., \& Wright, A. (2001). Changes in the quality of life of patients receiving antidepressant medication in primary care: Validation of the WHOQOL-100. British Journal of Psychiatry, 178, 261 267.

Slade, M., Leese, M., Ruggeri, M., Kuipers, E., Tansella, M., \& Thornicroft, G. (2004). Does meeting needs improve quality of life? Psychotherapy and Psychosomatics, 73, 183-189. 


\section{REFERENCES}

Steadman, H.J., \& Ribner, S.A. (1982). Life stress and violence among ex-mental patients. Social Science \& Medicine, 16, 1641-1647.

Straten, A. van, Cuijpers, P., Zuuren, F.J. van, Smits, N., \& Donker, M. (2007). Personality traits and health-related quality of life in patients with mood and anxiety disorders. Quality of Life Research, 16, $1-8$.

Streiner, D.L., Norman, G.R., McFarlane, A.H., \& Roy, R.G. (1981). Quality of life events and their relationship to strain. Schizophrenia Bulletin, 7, 34-42.

Stucki, G., Daltroy, L., Katz, J.N., Johannesson, M., \& Liang, M.H. (1996). Interpretation of change scores in ordinal clinical scales and health status measures: The whole may not equal the sum of the parts. Journal of Clinical Epidemiology, 49, 711-717.

Suh, E., Diener, E., \& Fujita, F. (1996). Events and subjective well-being: Only recent events matter. Journal of Personality and Social Psychology, 70, 1091-1102.

Swanson, J.W., Swartz, M.S., Elbogen, E.B., Wagner, H.R., \& Burns, B.J. (2003). Effects of involuntary outpatient commitment on subjective quality of life in persons with severe mental illness. Behavioral Sciences and the Law, 21, 473-491.

Swanson, J., Swartz, M., Estroff, S., Borum, R., Wagner, R., \& Hiday, V. (1998). Psychiatric impairment, social contact, and violent behavior: evidence from a study of outpatient-committed persons with severe mental disorder. Social Psychiatry and Psychiatric Epidemiology, 33, S86-S94.

Swinton, M., Carlisle, J., \& Oliver, J. (2001). Quality of life for patients with a personality disorder comparison of patients in two settings: an English special hospital and a Dutch TBS clinic. Criminal Behaviour and Mental Health, 11, 131-143.

Swinton, M., Oliver, J., \& Carlisle, J. (1999). Measuring quality of life in secure care: comparison of mentally ill and personality disordered offenders. International Journal of Social Psychiatry, 45, 284-291.

Taylor, J. (2005). Substance use disorders and Cluster B personality disorders: Physiological, cognitive, and environmental correlates in a college sample. The American Journal of Drug and Alcohol Abuse, 31, 515-535.

Thornton, D. (2002). Constructing and testing a framework for dynamic risk assessment. Sexual Abuse: A Journal of Research and Treatment, 14, 139-153.

Trompenaars, F.J., Masthoff, E.D., Heck, G.L. van, Hodiamont, P.P., \& Vries, J. de (2005). Relationships between demographic variables and quality of life in a population of Dutch adult psychiatric outpatients. Social Psychiatry and Psychiatric Epidemiology, 40, 588-594, doi: 10.1007/s00127-005-09460 . 
Trompenaars, F.J., Masthoff, E.D., Heck, G.L. van, Hodiamont, P.P., \& Vries, J. de (2006). The WHO Quality of Life Assessment Instrument (WHOQOL-100): Investigating its discriminant ability for psychiatric outpatients. European Journal of Psychological Assessment, 22, 207-215.

Vance, J.E., Bowen, N.K., Fernandez, G., \& Thompson, S. (2002). Risk and protective factors as predictors of outcome in adolescents with psychiatric disorder and aggression. Journal of the American Academy of Child \& Adolescent Psychiatry, 41, 36-43.

Vaux, A., \& Ruggiero, M. (1983). Stressful life change and delinquent behavior. American Journal of Community Psychology, 11, 169-183.

Vatne, S., \& Bjørkly, S. (2008). Empirical evidence for using subjective quality of life as an outcome variable in clinical studies. A meta-analysis of correlates and predictors in persons with major mental disorder living in the community. Clinical Psychology Review, 28, 869-889.

Vogel, V. de, Ruiter, C. de, Beek, D. van, \& Mead, G. (2004). Predictive validity of the SVR-20 and Static99 in a Dutch sample of treated sex offenders. Law and Human Behavior, 28, 235-251.

Vogel, V. de, Ruiter, C. de, \& Bouman, Y. (2007). Meting van protectieve factoren en het belang ervan voor behandeling in de forensische setting: Introductie van de SAPROF. Tijdschrift voor Psychotherapie, 33, 102-119.

Vogel, V. de, Ruiter, C. de, Bouman, Y., \& Vries Robbé, M. de (2007). SAPROF; Richtlijnen voor beoordelen van beschermende factoren voor gewelddadig gedrag [SAPROF; Guidelines for the assessment of protective factors for violent behaviour]. Utrecht, The Netherlands: Forum Educatief.

Vogel, V. de, Ruiter, C. de, Bouman, Y.H.A., \& Vries Robbé, M. de (2009). SAPROF; Guidelines for the assessment of protective factors for violence risk. Utrecht, The Netherlands: Forum Educatief.

Vogel, V. de, Ruiter, C. de, Hildebrand, M., Bos, B., \& Ven, P. van de (2004). Type of discharge and risk of recidivism measured by the HCR-20. A retrospective study in a Dutch sample of treated forensic psychiatric patients. International Journal of Forensic Mental Health, 3, 149-165.

Vorstenbosch, E.C.W., Bulten, B.H., Bouman, Y.H.A., \& Braun, P.C. (2008). Forensic inpatient Quality of Life questionnaire. Nijmegen, The Netherlands: Pompestichting.

Vries Robbé, M. de, Vogel, V. de, \& Spa, E. de (2009). Protective factors for violence risk in forensic psychiatric patients: A retrospective validation study of the $S A P R O F$. Submitted.

Walker, J., \& Gudjonsson, G. (2000). The Lancashire Quality of Life Profile: Data and experiences with 58 detained mentally disordered offenders. Criminal Behaviour and Mental Health, 10, 123-135.

Ward, T. (2002). The management of risk and the design of good lives. Australian Psychologist, 37, $172-179$. 


\section{REFERENCES}

Ward, T., \& Brown, M. (2004). The good lives model and conceptual issues in offender rehabilitation. Psychology, Crime \& Law, 10, 243-257.

Ward, T., Hudson, S.M., \& Marshall, W.L. (1995). Cognitive distortions and affective deficits in sex offenders: a cognitive deconstructionist interpretation. Sexual Abuse: A Journal of Research and Treatment, 7, 67-83.

Ward, T., Mann, R.E., \& Gannon, T.A. (2007). The good lives model of offender rehabilitation: clinical implications. Aggression and Violent Behavior, 12, 87-107.

Ward, T., Melser, J., \& Yates, P.M. (2007). Reconstructing the risk-need-responsivity model: A theoretical elaboration and evaluation. Aggression and Violent Behavior, 12, 208-228.

Ward, T. \& Steward, C.A. (1993). The treatment of sex offenders: Risk management and good lives. Professional Psychology: Research and Practice, 34, 353-360.

Ware, J.E., \& Sherbourne, C.D. (1992). The MOS 36-Item Short-Form Health Survey (SF-36®): I. conceptual framework and item selection. Medical Care 30: 473-483.

Wartna, B.S.J. (2009). In de oude fout. Over het meten van recidive en het vaststellenvan het succes van strafrechtelijke interventies. [Making old mistakes. On measuring recidivism and establishing the success of judicial interventions]. Den Haag, The Netherlands: Wetenschappelijk Onderzoek en Documentatiecentrum.

Webster, C.D., Douglas, K.S., Belfrage, H., \& Link, B.G. (2000). Capturing change. An approach to managing violence and improving mental health. In S. Hodgins (Ed.) Violence among the mentally ill. Effective treatment and management strategies (pp. 119-144). Dordrecht, Boston, London: Kluwer Academic Publisher.

Webster, C.D., Douglas, K.S., Eaves, D., \& Hart, S.D. (1997). HCR-2: Assessing risk for violence, Version 2. Burnaby, British Columbia: Mental Health, Law, and Policy Institute, Simon Fraser University.

Webster, C.D., Martin, M., Brink, J., Nicholls, T.L., \& Middleton, C. (2004). Short Term Assessment of Risk and Treatability (START). Clinical guide for evaluation risk and recovery. Ontario, Canada: St. Joseph's Healthcare Hamilton.

WHOQOL Group (1995). The World Health Organization Quality of Life Assessment (WHOQOL): Position paper from the World Health Organization. Social Science \& Medicine, 41, 1403-1409.

WHOQOL Group (1998). Development of the World Health Organization WHOQOL-BREF quality of life assessment. Psychological Medicine, 28, 551-558. 
Wingerden, S. van, \& Moerings, M. (2007). Het succes van Exodus. Evaluatie-onderzoek naar resocialisatie en recidive van oud-bewoners. Proces, vol 2007, 2-8.

Williams, D.J. (2003). "Quality of life" as perceived by sex offenders on early release in a halfway house: Implications for treatment. Journal of Offender Rehabilitation, 38, 77-93.

Willige, G. van der, Schreurs, P., Tellegen, B., \& Zwart, F. (1985). Het meten van 'life events': de Vragenlijst Recent Meegemaakte Gebeurtenissen (VRMG) [Measuring 'life events': Questionnaire of Recently Experienced Events]. Nederlands Tijdschrift voor de Psychologie, 40, 1-19.

Wilson, D., Tien, G., \& Eaves, D. (1995). Increasing the community tenure of mentally disordered offenders: An assertive case management program. International Journal of Law and Psychiatry, 18, 61 69.

World Health Organization (1980). International classification of impairments, disabilities, and handicaps: A manual of classification relating to the consequences of disease, published in accordance with resolution WHA29.35 of the Twenty-ninth World Health Assembly, May 1976. Geneva, Switzerland: Author.

World Health Organization (2002). Towards a common language for functioning, disability and health: ICF. Geneva, Switzerland: Author. Retrieved on 5 February, 2009 from http://www.who.int/governance/eb/who_constitution_en.pdf.

World Health Organization (2005). Constitution of the World Health Organization. Retrieved on 5 February 2009 from http://www.who.int/governance/eb/who_constitution_en.pdf.

Wright, K.N., \& Wright, K.E. (1992). Does getting married reduce the likelihood of criminality? A review of the literature. Federal Probation, 56, 50-56.

Zalsman, G., Huang, Y-y., Oquendo, M.A., Burke, A.K., Hu, X-z., Brent, D.A., Ellis, S.P., Goldman, D., \& Mann, J.J. (2006). Association of a triallelic serotonin transporter gene promotor region (5HTTLPR) polymorphism with stressful life events and severity of depression. American Journal of Psycbiatry, 163, 1588-1593.

Zautra, A., \& Majo, J. (1981). Life events and life quality variability. Journal of Community Psychology, 9, 148152.

Zautra, A., \& Reich, J. (1980). Positive life events and reports of well-being: Some useful distinctions. American Journal of Community Psychology, 8, 657-670.

Zhang, S., Benson, T., \& Deng, X. (2000). A test-retest reliability assessment of the international selfreport delinquency instrument. Journal of Criminal Justice, 28, 283-295. 


\section{List of abbreviations}

General

APA

American Psychiatric Association

$\mathrm{C} / \mathrm{U}$

Controllable / Uncontrollable (life events)

DEM

Dynamic Equilibrium Model

DSM-IV-TR

Diagnostic and statistical manual of mental disorders, 4th edition, text revision

GLM Good Lives Model

GST

General Strain Theory

ICD-10

International classification of diseases, 10th edition

IQ

Intelligence quotient

LCU

Life Change Units

LE

Life Event(s)

LSS

Life Satisfaction Scale

MMD

Major mental disorder

PD

Personality Disorder

$\mathrm{P} / \mathrm{N}$

Positive / Negative (life events)

QoL

Quality of Life

RNR

Risk-Need-Responsivity

SCT

Social Control Theory

SES

Socio-economic status

SPJ

Structured Professional Judgement

SWB

Subjective Well-Being

$\mathrm{T}_{0}$

First measurement

$\mathrm{T}_{1}$

Second measurement

$\mathrm{T}_{2}$

Third measurement

Questionnaires / interviews / instruments

BPRS

HCR-20

IORNS

LQoLP

LS/CMI

LSI-R

MANSA

QOLI
Brief Psychiatric Rating Scale

Historical / Clinical / Risk-management

Inventory of Offender Risk, Needs, and Strengths

Lancashire Quality of Life Profile

Level of Service/Case Management Inventory

Level of Service Inventory Revised

Manchester Short Assessment of Quality of Life

Quality of life interview 
QREE

RLCQ

SAPROF

SAVRY

SF36

SORM

SRDB

START

VRMG

WHOQOL

ZRDG

\section{Statistical}

ANOVA

AUC

CI

df

ICC

$\mathrm{M}$

$p$

$\mathrm{P}$

r

$\mathrm{r}_{\mathrm{s}}$

ROC

$\mathrm{SD}$

se
Questionnaire of Recently Experienced Events

Recent Life Change Questionnaire

Structured Assessment of PROtective Factors for violence risk

Structured Assessment of Violence Risk in Youth

Short Form-36

Structured Outcome Assessment and Community Risk Monitoring

Self-reported Delinquent Behaviour

Short Term Assessment of Risk and Treatability

Vragenlijst Recent Meegemaakte Gebeurtenissen [Questionnaire of

Recently Experienced Events]

World Health Organisation Quality of Life

Zelf Rapportage Delict Gedrag [Self-reported Delinquent Behaviour]

Analysis of Variance

Area Under the ROC Curve

Confidence interval

degrees of freedom

Interclass correlation

Mean

Chance of type I error

Percentage

Pearson's correlation

Spearman's correlation

Receiver Operating Characteristic

Standard Deviation

Standard error 


\section{Dankwoord}

Gedurende de afgelopen zeven jaar hebben talrijke mensen mij ondersteund in het volbrengen van dit project. Maar eigenlijk begon dit project al ongeveer tien jaar geleden: mijn toenmalige leidinggevende, Thieu Verhagen, stond een meer wetenschappelijke onderzoeksafdeling voor ogen, waarmee ik het pad van beleidsgericht onderzoek en beleidsondersteunende activiteiten verliet en meer de diepte in kon gaan. Na diverse omzwervingen langs diverse hoogleraren, met een steeds specifiekere onderzoeksvraag voor ogen, vond ik uiteindelijk Corine de Ruiter bereid mij te begeleiden in dit proces. Zij heeft vervolgens aanvullende expertise in huis gehaald waarmee het begeleidingskoppel compleet was: Aart Schene. Ik wil hen beiden zeer hartelijk danken voor hun inbreng, kennis, en vooral hun geduld en doorzettingsvermogen. Het begeleiden van een buitenpromovendus is een vak apart, vooral als ze al iets langer van school is.

Naast promotoren kon dit project niet van start zijn gegaan, doorlopen en afgerond zonder de mogelijkheden die de Pompestichting mij bood. Dit onderzoek heb ik uitgevoerd als mijn werk, en mede omdat de toenmalige directeur en mijn leidinggevende, Michel van Weers, het uitgangspunt hanteerde dat iedere onderzoeker gepromoveerd diende te zijn, is dit mogelijk geweest. Dat een multi-site onderzoek waarbij de automatisering nog niet volledig is doorgevoerd stropiger is dan gewenst bleek diverse malen. En daarmee kom ik direct op de derde groep mensen en organisaties die ik veel dank verschuldigd ben: de poliklinieken waar het onderzoek is uitgevoerd. Dit was bij de Waag, met haar thuisbasis in Utrecht. Joan van Horn, onderzoeker bij de Waag, heeft dit project direct omarmd en met medewerking van haar directie en de behandelaars en patiënten zijn daar de eerste participanten vandaan gekomen. Ik heb erg veel aan haar ondersteuning gehad in die beginperiode. Ook de polikliniek Kairos, vooral in Nijmegen en Arnhem, heeft het onderzoek omarmd en vele patiënten aangeleverd die aan het onderzoek mee wilden doen. Dit vooral door de inzet van behandelaars, die nu niet meer hun kamer in hoeven te duiken als ik in de buurt ben. Door te kiezen voor een steekproef van patiënten zorgde ik voor extra werk, welke inspanningen vergde van iedere behandelaar. Desondanks heeft ook de directie van de Tender uit Deventer mij de gelegenheid gegeven patiënten via haar poli te betrekken. Naast de directie wil ik vooral Klaus Drieschner bedanken die geduldig de patiëntenlijsten heeft geanonimiseerd en mij goede tips gaf voor het 
onderzoek in het algemeen. En tenslotte heeft ook de toenmalige directeur van de polikliniek het Dok uit Rotterdam, Henriëtte Cuperus, haar fiat gegeven om patiënten van die polikliniek mee te mogen nemen in het onderzoek. Zoals duidelijk mag zijn hebben vele behandelaars van de vier poliklinieken een bijdrage geleverd aan het onderzoek, zowel door het leveren van geschikte patiënten als ook het invullen van lijsten. De belangrijkste groep zijn echter de patiënten: belangeloos hebben zij zich diverse malen laten interviewen en lijsten ingevuld. Zonder respondenten geen onderzoek.

Vooral gedurende de fase van dataverzameling, maar ook tijdens het opstarten van het onderzoek hebben diverse stagiaires een belangrijke rol gespeeld: achtereenvolgens hebben Yvette Nijhuis, Anton Scheltinga, Moniek te Thij, Saskia Mioch, Lieke Demarteau, Björn Suttka, Evelien van den Bosch, Githa van Es, Valérie Fabrie en Kim Leenders mij ondersteund in het denkproces in het begin, interviews afgenomen en geholpen bij de data-invoer en het denken over analyses. Naast stagiaires hebben diverse mensen, op diverse momenten, ondersteuning geboden. Hiervoor wil ik de onderzoekers van de afdeling DO\&O van de Pompestichting, meelezende en meedenkende vrienden, vriendinnen en familie en de anonieme reviewers hartelijk danken. Speciaal wil ik Marjon Spoorenburg vermelden, die mij continu, en snel, van nieuw leesvoer heeft voorzien; Erik Bulten die vanuit een pragmatisch oogpunt mij heeft geprobeerd pragmatisme te leren, om dit naast perfectionisme te laten functioneren; en vooral Martien Philipse die te veel om op te noemen heeft betekend voor mij gedurende het gehele project: dat we nog vaak met de hand omhoog geduldig tegenover elkaar mogen wachten.

Om optimaal te kunnen functioneren is een goede balans tussen werk en vrije tijd nodig. Wat goed is: misschien levert deze dissertatie daartoe aanknopingspunten. In mijn geval heb ik me daarbij vooral gericht op primaire levensbehoeften: uiteten met MIMY (dat er nog vele etentjes bij vele restaurants in Nijmegen mogen volgen) en op georganiseerde vrijetijdsbesteding (kan protectief werken, zeggen ze): altijd met rugby, maar verschillende teams. Maar bovenal een rustmoment, thuis: Ingrid bedankt! Op dat er nog vele (on)rustige tijden mogen volgen! Ma: bedankt voor het luisterend oor op de melkbus. Pa: school zit er op. 


\section{Curriculum Vitae}

Yvonne H.A. Bouman is born in Eindhoven on 15 February 1964. After finishing her Atheneum-B at the Eindhovens Protestants Lyceum in 1983, she took one year of Medicine at the University of Nijmegen, but changed to Medical Sociology in which she gathered her Doctoral degree in 1989. In 1996, she began to work as a scientific researcher for the Pompestichting in Nijmegen, after having conducted various researches for various employers, both in general psychiatry and in sports sciences. Together with other researchers from the Pompestichting and the van der Hoevenstichting, she translated the HCR-20 into Dutch, and with another researcher from the Rooijse Wissel, she also translated a Swedish risk assessment and management instrument, the Structured Outcome Assessment and Community Risk Monitoring, into Dutch. The Structured Assessment of PROtective Factors, which is an instrument to be used with a validated risk assessment instrument, has been developed by researchers from the van der Hoevenstichting, the Trimbos-institute and herself. It is currently used in several Dutch forensic psychiatric institutions, and has been translated into English and German. She conducted the current research as an employee of the Pompestichting and at four forensic outpatient facilities.

Besides her work as a scientific researcher, Yvonne has been a rugby-coach for the last 15 years. After finishing her active sports career, which took her to participating in the World Cup in 1991, she took up this hobby and has been coaching different teams at club level and has been assistant coach of the Dutch national women's side. In 2007, she was rewarded a special nomination by the Dutch National Rugby Union for all her work for the sport in general. 


\section{Previous publications}

Bouman, Y.H.A. (1993). Een vrouw....?: Onderzoek naar de positie van vrouven in de sport in Overijssel. [A women ...l?: Research into the position of women in sports in the province of Overijssel]. Almelo, The Netherlands: Emancipatiebureau Overijssel.

Bouman, Y. (1996). Vrounven in landelijke sportorganisaties 1995: Een stapje terug. [Women in national sports organisations 1995: A step back]. Arnhem, The Netherlands: NOC*NSF.

Bouman, Y.H.A. (2001). Verlof in een TBS-kliniek: De Pompekliniek. [Leave in a forensic psychiatric hospital: The Pompehospital]. Delikt en Delinkwent, 31, 118-134.

Bouman, Y., \& Bakkum, N. van (1994). Vrounen in landelijke sportorganisaties: Een inventarisatieonderzoek, in opdracht van NOC*NSF. [Women in national sports organisations: a descriptive research for NOC*NSF]. Arnhem, The Netherlands: NOC*NSF.

Bouman, Y., Daaleman, C., Mensink, C., \& Leusink, K. (1991). Verslaafden in beeld. Een inventariserend onderzoek naar aantal en kenmerken van heroïne-, cocaïne- en fruitautomaatverslaafden in de gemeente Enschede.

[Addicts in the picture. A descriptive study into the seize and characteristics of heroine and cocaine addicts and compulsive gamblers in the city of Enschede]. Zutphen, The Netherlands: Medisch Sociologisch Onderzoek.

Hilterman, E.L.B., \& Bouman, Y.H.A. (2004). SORM: Structured outcome assessment and community risk monitoring. (authorised Dutch translation and adaptation). Venray/Nijmegen, The Netherlands: FPI de Rooyse Wissel/Pompestichting.

Hout, A.C. van den, Bouman, Y.H.A., \& Hoefsloot Schmeink-Modderkolk, M.C.I. (1988). Samenhang in de gezondheidszorg in de regio Oost-Veluwe. [Coherence in health care in the region of Oost-Veluwe]. Apeldoorn, The Netherlands: Samenwerking GGZ Oost-Veluwe.

Knoppers, A., \& Bouman, Y. (1996). Trainers/coaches: een kewestie van kwaliteit?: De arbeidscultuur van trainers/coaches $(\mathrm{m} / \mathrm{v}$ ). [Trainers/coaches: A matter of quality? The labour culture of trainers/coaches $(\mathrm{m} / \mathrm{f})]$. publicatienummer 327, Arnhem, The Netherlands: NOC*NSF.

Knoppers, A., \& Bouman, Y. (1998). Altijd beter dan mijn sporters: Arbeidscultuur van trainers m/v. [Always superior to my athletes: The labour culture of trainers/coaches $(\mathrm{m} / \mathrm{f})] \mathrm{NOC} * \mathrm{NSF}$

Publicatienummer 386, Arnhem, The Netherlands: NOC*NSF. 


\section{EERDERE PUBLICATIES}

Philipse, M., Ruiter, C. de, Hildebrand, M., \& Bouman, Y. (2000). HCR-20. Beoordelen van het risico van gewelddadig gedrag. Versie 2. Nijmegen/ Utrecht, The Netherlands: Prof. mr. W.P.J. Pompestichting/Dr. Henri van der Hoeven Stichting.

Vogel, V. de, Ruiter, C. de, \& Bouman, Y. (2004). SAPROF: Structured assessment of protective factors for violence risk. Research versie. Utrecht/Nijmegen, The Netherlands: Van der Hoeven-kliniek/Trimbos instituut/Pompestichting.

Vogel, V. de, Ruiter, C. de, \& Bouman, Y. (2007). Meting van protectieve factoren en het belang ervan voor behandeling in de forensische setting: Introductie van de SAPROF. [Measuring protective factors and the importance thereof for treatment in a forensic setting: Introduction of the SAPROF]. Tijdschrift voor Psychotherapie, 33, 102-119.

Vogel, V. de, Ruiter, C. de, Bouman, Y., \& Vries Robbé, M. de (2007). SAPROF; Richtlijnen voor beoordelen van beschermende factoren voor gewelddadig gedrag [SAPROF; Guidelines for the assessment of protective factors for violent behaviour]. Utrecht, The Netherlands: Forum Educatief.

Vogel, V. de, Ruiter, C. de, Bouman, Y.H.A., \& Vries Robbé, M. de (2009). SAPROF; Guidelines for the assessment of protective factors for violence risk. Utrecht, The Netherlands: Forum Educatief.

Vorstenbosch, E.C.W., Bulten, B.H., Bouman, Y.H.A., \& Braun, P.C. (2008). Forensic inpatient Quality of Life questionnaire. Nijmegen, The Netherlands: Pompestichting. 